This work is licensed under a Creative Commons Attribution 3.0 License.

\author{
Monograph \\ urn:1sid:zoobank.org:pub:55A0F74D-FA80-4C6A-AD74-B49C9061A449
}

\title{
A revision of the spider genus Anemesia (Araneae, Cyrtaucheniidae)
}

\author{
Sergei ZONSTEIN \\ Steinhardt Museum of Natural History, Tel Aviv University, Tel Aviv 69978, Israel. \\ Email: znn@post.tau.ac.il \\ urn:1sid:zoobank.org:author:BD9F97A7-CADB-4DD2-9082-1689952DDF38
}

\section{Table of contents}

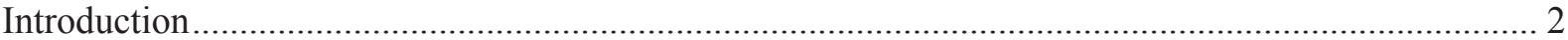

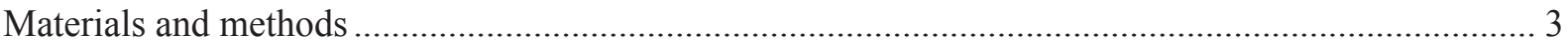

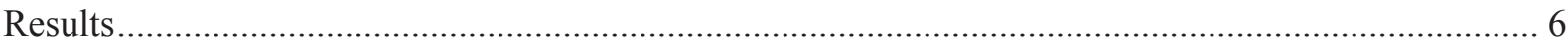

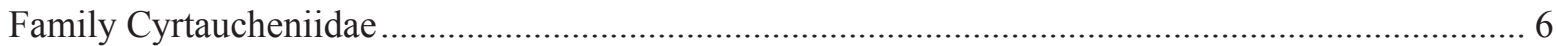

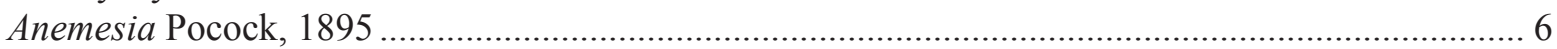

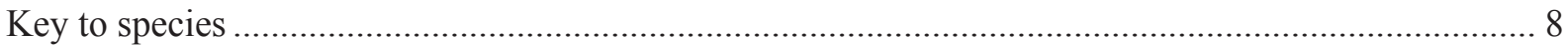

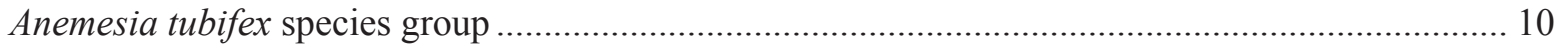

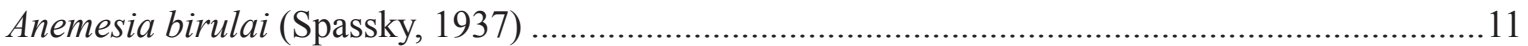

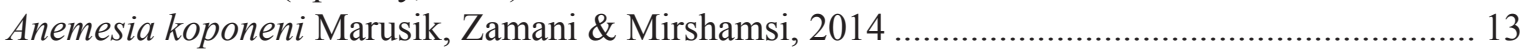

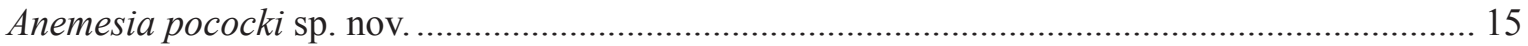

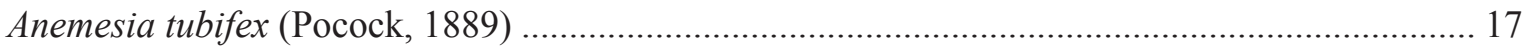

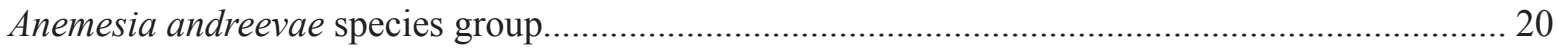

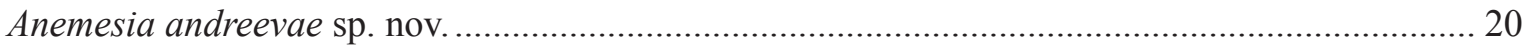

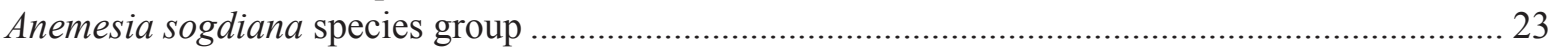

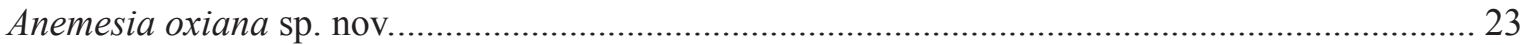

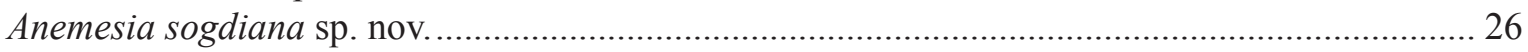

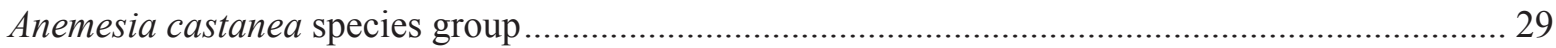

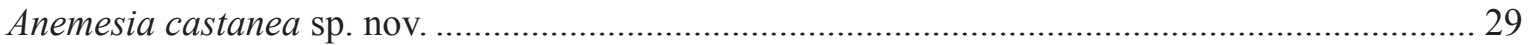

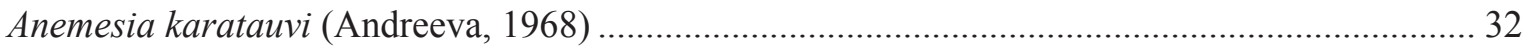

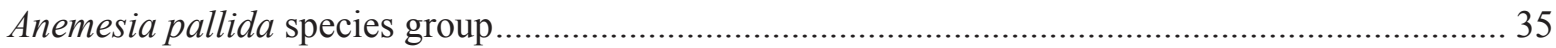

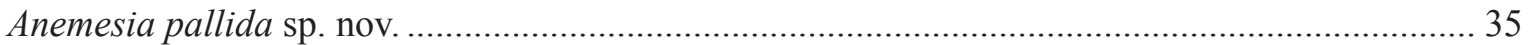

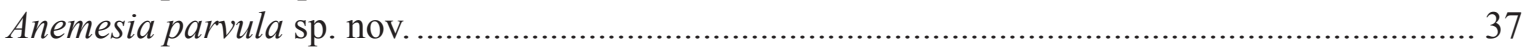

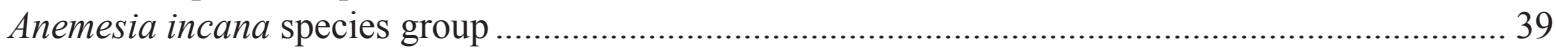

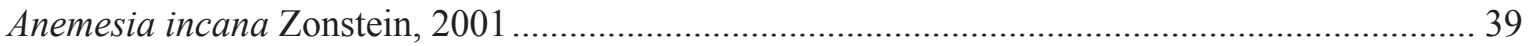

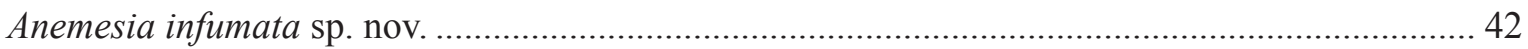

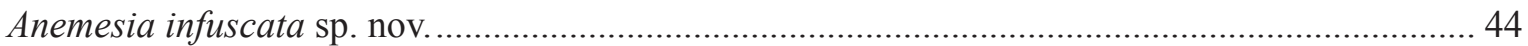

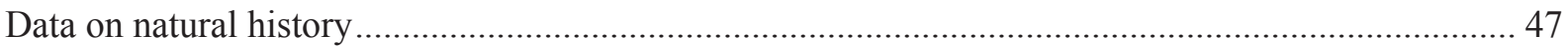

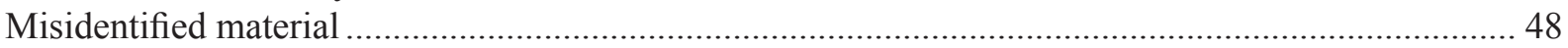

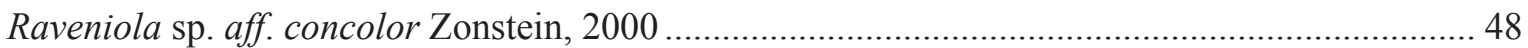

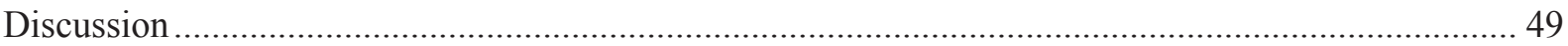

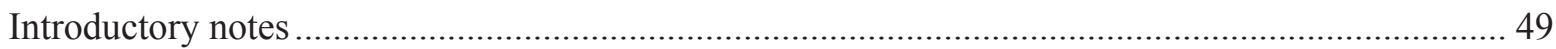

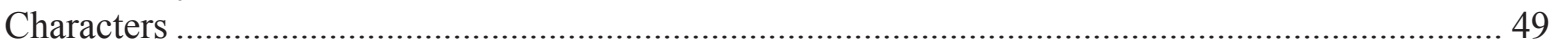




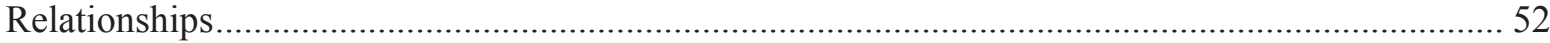

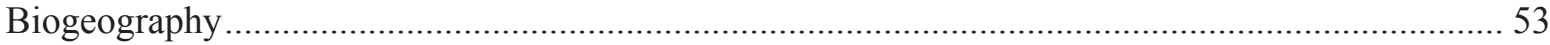

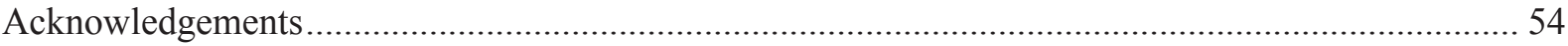

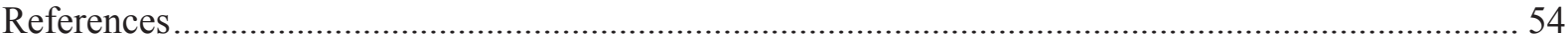

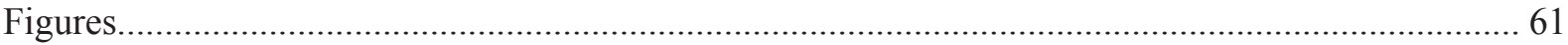

Abstract. The Central Asian spider genus Anemesia Pocock, 1895 is rediagnosed and revised. The genus

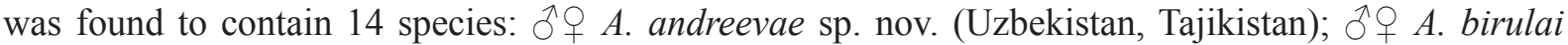

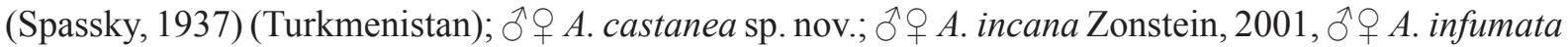

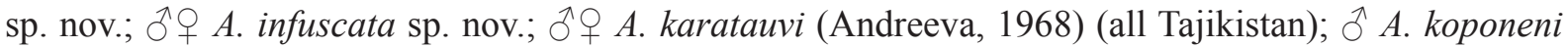

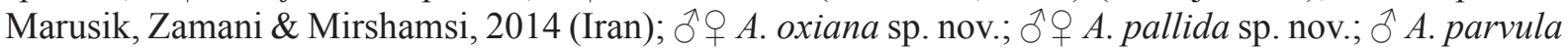

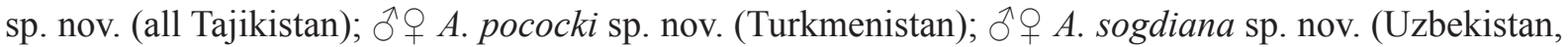
Tajikistan) and $\delta^{\top}+$ A A. tubifex (Pocock, 1889), the type species (Afghanistan, Turkmenistan). Nine species are newly described; others are redescribed from types and/or conspecific material. Males of A. tubifex and females of $A$. birulai, hitherto unknown, are described for the first time. Data on the variability, relationships, distribution, and ecology of all considered species are provided.

Keywords. Taxonomy, burrowing spiders, Mygalomorphae, new species, ecology, Central Asia.

Zonstein S. 2018. A revision of the spider genus Anemesia (Araneae, Cyrtaucheniidae). European Journal of Taxonomy 485: 1-100. https://doi.org/10.5852/ejt.2018.485

\section{Introduction}

The genus Anemesia was established by Pocock (1895) as a monotypic taxon comprising the single species, Nemesia tubifex which he had described a few years earlier (1889) from zoological material of the British Afghan delimitation commission. When establishing the new genus, Pocock used as a distinguishing character the fact that the burrow of the only collected female had an open entrance, whereas all then known Mediterranean representatives of Nemesia Audouin, 1826 were considered to build burrows with a trapdoor. The genus was originally placed in the family Ctenizidae Thorell, 1887 . Simon (1903) assigned Anemesia to the ctenizid genera of the tribe Nemesiae Simon, 1889.

For several decades, Anemesia was known only from the holotype of $N$. tubifex which had also been heavily damaged prior to the description, presumably when collected. Denis (1958) erroneously (see below) assigned a few female mygalomorphs collected in Afghanistan to this species. He noted that these spiders were considerably larger than the holotype. Most generic features, including the shape of the spinneret group, configuration of the female spermathecae and all male characters, were unknown until 2001. For almost a century the definitive characters of Anemesia were unclear. Raven (1985), who first elevated Simon's Nemeseae to family rank, placed the monotypic Anemesia in synonymy with Nemesia in the absence of reliable data that could indicate a group, rather than an individual character.

Zonstein (1987) considered two of seven Central Asian species described in Brachythele Ausserer, 1871 (treated in a very broad sense until 1985) as belonging to Anemesia, however without providing a formal transfer and using the new combinations. These species, B. birulai and B. karatauvi, described by Spassky (1937) and Andreeva (1968) from Turkmenistan and Tajikistan, respectively, were first listed by Mikhailov (1996) as members of the nemesiid Anemesia. Later, the finding of adult male congeners enabled a redefinition of the generic diagnosis; Anemesia was assigned to the genera of the Cyrtaucheniidae Simon, 1889; an additional species, A. incana, was described concurrently (Zonstein 2001). The fifth known member of the genus, A. koponeni Marusik, Zamani \& Mirshamsi, 2014, was very recently described from Iran (Marusik et al. 2014). Furthermore, several undescribed species of Anemesia were found in the spider material collected in the period 1986-1993 (with some further 
additions) in Tajikistan, Turkmenistan and Uzbekistan, and new data on the distribution, biology and relationships within Anemesia were obtained. All this new information is presented here.

\section{Material and methods}

\section{Depositories}

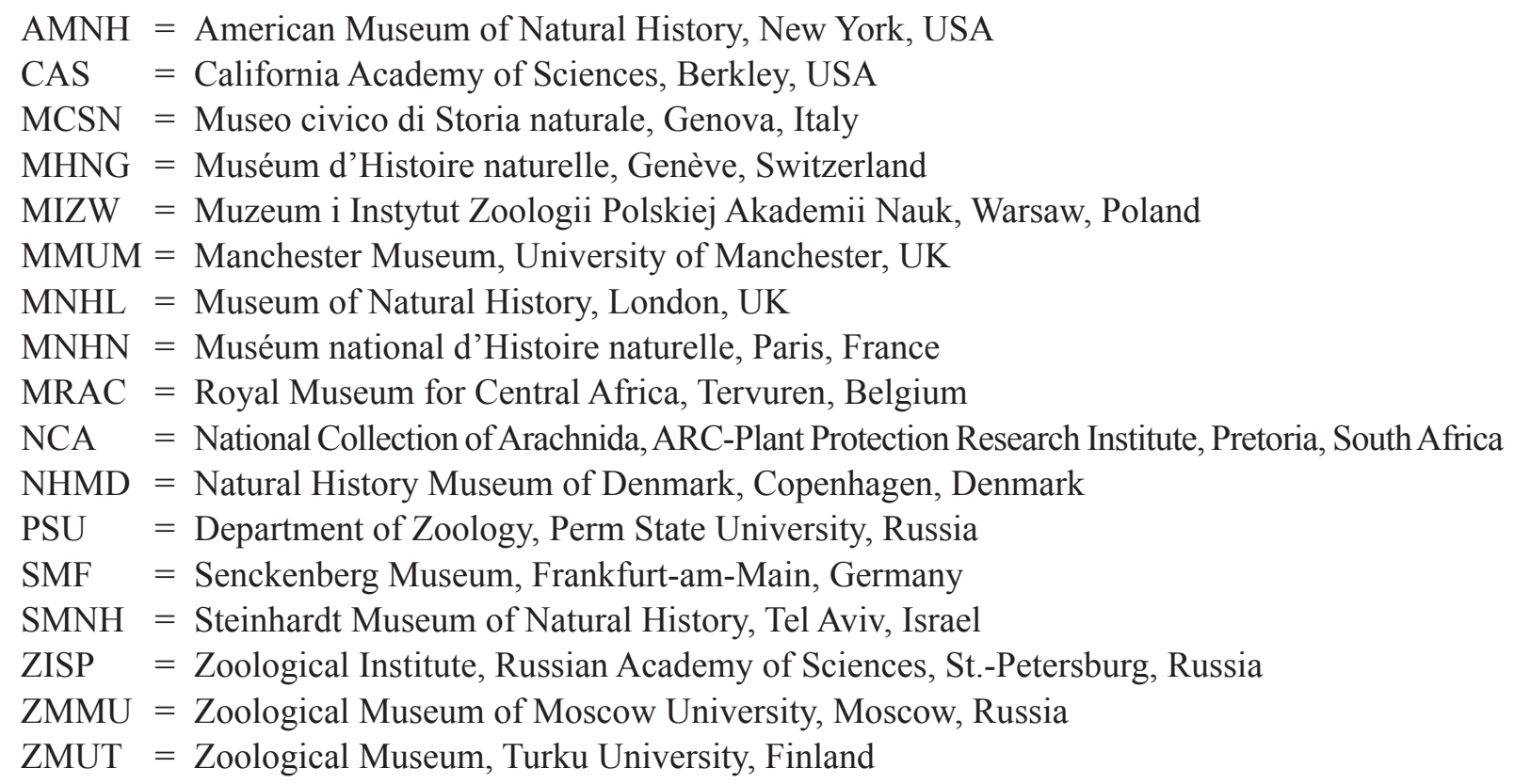

\section{Comparative material examined}

\section{Ctenizidae}

Cyrtocarenum cunicularium (Olivier, 1811): TURKEY: 2 q+9, Marmara Region, environs of Bursa, 22 Sep. 2010, S. Zonstein leg. (SMNH).

\section{Cyrtaucheniidae}

Acontius kiriba Zonstein, 2018: BURUNDI: 1 q, Rwegura, 10 Nov. 2008, B. Nzigidahera leg. (MRAC 226868); $1 \hat{\jmath}$, same collection data as for preceding but 10 Jan. 2009 (MRAC 226884).

Acontius nimba Zonstein, 2018: GUINEA: 1 §, 1 q, Nimba Mts, Mount Nimba Nature Reserve, Dec. 1957, M. Lamotte (SMF).

Amblyocarenum walckenaeri (Lucas, 1846): SPAIN: 1 ô, Tarragona Province, L'Aldea, 23 Jul. 2001, E. Gros leg. (MNHN N/A).

Ancylotrypa elongata Purcell, 1908: BOTSWANA: 2 ふぇ, 2 웅, Kalahari Desert, Lotlhake Pan, 19-28 Jul. 1973, R. Hakanen leg. (ZMUT).

Ancylotrypa pretoriae (Hewitt, 1913): SOUTH AFRICA: 1 ô, Gauteng Province, Roodepoort, 16 Nov. 2003, M. Forsyth leg. (NCA 2007/72); 1 \&, Mpumalanga Province, Two Rivers platinum site, 25 Apr. 2008, P. Hawkes leg. (NCA 2009/1358).

Ancylotrypa sp. aff. zebra (Simon, 1892): MOZAMBIQUE: 1 ô, Inhaka Isle (Maputo Bay), Inhaka, 8-22 Jan. 1994, T. Steyn leg. (MRAC 209467); 1 क, same collection data as for preceding but 30 Apr.-14 May 1994 (MRAC 209755). 
Angka hexops Raven \& Schwendinger, 1995: THAILAND: 1 क , Mt Inthanon, 28 Oct. 2000, P.J.

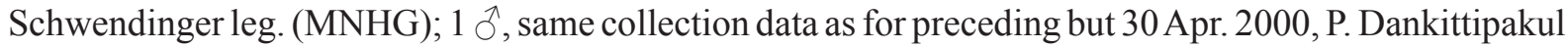
leg. (MNHG).

Cyrtauchenius maculatus (Simon, 1889): ALGERIA: 1 §, 2 우, Oran, no other data labelled (MNHN AR7076).

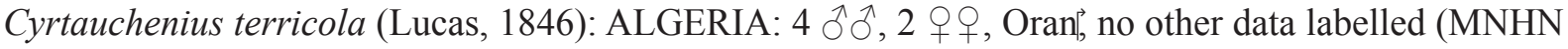
AR4296).

Homostola zebrina Purcell, 1902: SOUTH AFRICA: 1 +, Mpumalanga Province, 30 km N Graskop, 8 Mar. 2004, S. Maarlens leg. (NCA 2005/380).

\section{Euctenizidae}

Myrmekiaphila torreya Gertsch \& Wallace, 1936: USA: 2 우, Florida, Liberty County, Torreya Ravine, 31 Mar. 1964, F.A. Coyle leg. (SMNH, donated by F.A. Coyle).

\section{Nemesiidae}

Atmetochilus lehtineni Zonstein \& Marusik, 2016: INDONESIA: holotype, đ, Sumatra, Sumalumgun, Pisarani (ca $2^{\circ} 58^{\prime} \mathrm{N}, 9^{\circ} 16^{\prime} \mathrm{E}, 100-200 \mathrm{~m}$ ), 22 Sep. 1978, P. Lehtinen leg. (ZMUT); paratypes, 2 우, 1 q subad., 2 juvs, same data as for the holotype (ZMUT).

Entypesa sp. M (undescribed species): MAGADASCAR: 2 우, Fianarantsoa Province, Ranomafana

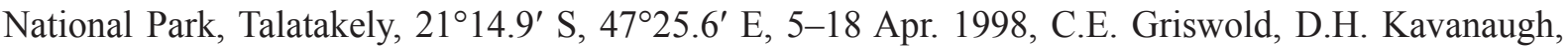
N.D. Penny, M.J. Raherilalao, J.S. Ranorianarisoa, I. Schweikert and D. Ubick leg. (CAS 9059432).

Iberesia barbara (Lucas, 1946): ALGERIA: 8 q, El Bayadh Province, El Kheiter, May 1883, E. Simon leg. (MNHN AR4481).

Nemesia ? ibiza Decae, 2005: SPAIN: 1 , Ibiza Isle, Puig de Perella, 21 Dec. 1981, J. Murphy and F. Murphy leg. (MMUM G7572.3263). Misidentified and presented as N. macrocephala Ausserer, 1871 in Murphy \& Roberts (2015: 208, pl. 11, additionally, the correct position of symbols $\delta$ and $\propto$ in the header on the noted page was reversed).

Nemesia sp. aff. africana (C.L. Koch, 1838): ALGERIA: $3 \precsim \widehat{\jmath}, 15$ 우, Blida, no date labelled (probably, 1882 or 1883), E. Simon leg. (MNHN AR4304).

Nemesia sp. aff. pannonica Herman, 1879: TURKEY: 1 ô, 5 우, Bursa Province, Oylat, 23 Sep. 2010, K.B. Kunt, E.A. Yağmur and S. Zonstein leg. (SMNH).

Pionothele capensis Zonstein, 2016: SOUTH AFRICA: holotype, ô, Western Cape Province, Cape

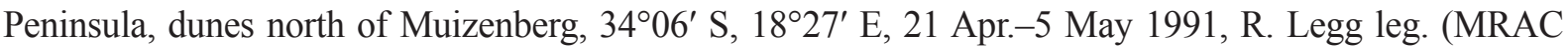
173693); paratypes, 1 §, 2 우, same collection data as for preceding but 2-16 May 1991 (MRAC 173745).

Raveniola concolor Zonstein, 2000: INDIA: holotype ô, northwestern Himalayas, Shimsha Karboo, 2900 m, 15 Apr. 1929, L. Caporiacco leg. (MCSN A.R.17); paratype, + , same region, Apis, 2800 m, 16 Apr. 1929, L. Caporiacco leg. (MCSN A.R.19).

Raveniola ferghanensis (Zonstein, 1984): KYRGYZSTAN: paratype, + of Brachythele ferghanensis, surroundings of Djalal-Abad, 950 m, 8 Apr. 1982, S. Zonstein leg. (SMNH).

Spiroctenus sp.: SOUTH AFRICA: 1 ð̄, KwaZulu-Natal Province, Sani Pass, Sep. 2007, D. Prentice leg. (NCA 2008/3423). 


\section{Structure}

Structure, sectioning, and headers follow Schwendinger (2009), Schwendinger \& Zonstein (2011) and Zonstein et al. (2018). To maintain the uniformity of species descriptions, males are described first, even in cases where the holotype is female.

\section{Terminology}

The terminology and descriptive format follows Raven $(1981,1985)$, with a few exceptions. The term megaspines was first used by Raven (1981) to designate thickened and curved thornlike spines located on anterior leg tibiae in male mygalomorphs that form the mating spurs. The terms intercheliceral tumescence and preening combs correspond to a 'pallid and soft area at the lower basal interface of the chelicerae [...] of some male mygalomorphs' (Raven 1985: 8) and to the apical combs of bristles located in some mygalomorphs on the metatarsi, respectively. The nomenclature of the spigot types is given according to Murphy \& Roberts (2015).

\section{Illustrations}

Photographs were taken using a Canon 500D digital camera with a $100 \mathrm{~mm}$ Canon macro lens (majority of the totals) and a Zeiss Discovery V20 stereo microscope with a Canon PowerShot G9 digital camera attached to it, and prepared using the Helicon Focus ver. 6.3.2 Pro software (http://www.heliconsoft.com/). Field photographs showing the biotopes, live spiders, burrows and their aggregations were taken mainly with a Canon PowerShot G1 X Mark II camera. Scanning electron micrographs were made using a JEOL JSM-5200 scanning microscope at the Zoological Museum, University of Turku, Finland. Distribution maps were drawn using ${ }^{\circledR}$ Adobe Illustrator CS5. Photographs and other figures were processed, grouped and arranged using ${ }^{\circledR}$ Adobe Photoshop CS5. Female genitalia were dissected under a Leica M80 stereo microscope. Illustrations of the spermathecae were made following the maceration of the dissected female genital area in a $10 \%$ potassium hydroxide aqueous solution, cleaning in $85 \%$ lactic acid and exposure for a few minutes in a 70\% alcohol solution of Chlorazol Black. Upon becoming transparent and gently stained, these structures were then placed in a dish with $85 \%$ lactic acid and fixed on a glass microsphere layer for image-making. Following examination, the preparations were removed, cleaned and then transferred to small microvials and placed together with the studied specimens.

\section{Measurements}

Measurements were taken through a Zeiss Discovery V20 stereo microscope to an accuracy to $0.01 \mathrm{~mm}$. All measurements are given in millimetres. The total body length includes the chelicerae, but not the spinnerets. The sternum length was measured along a straight line between the posterior tip of the sternum and the hindmost part of the labium. The lengths of leg and palp segments were measured on the dorsal side, and the lengths of spinneret segments on the ventral side, from midpoint of anterior margin to midpoint of posterior margin. The diameter of the AME is usually given as the diameter of a sharply edged AME circle (the 'pupil'). When the AME cornea was well-separated and elevated, and its diameter could be measured, the corresponding data follow in brackets. Any eye interdistances incorporating this parameter are also given in brackets.

\section{Geographical and ecological data}

The altitude is shown in meters above sea level. Coordinates are given for material collected after 1994-1995 according to the GPS data; and before this date according to the corresponding former Soviet military maps of 1:100000 or 1:200000 scale. When used without brackets, the coordinates refer to the collecting place(s). The coordinates in brackets refer to the indicated nearest locality and follow it. When necessary, the earlier obtained data were checked, specified and improved, using Google Earth $4.2^{\mathrm{TM}}$. Names and limits of orographic and biogeographic units are given according to Kryzhanovsky (2002) and Nikolaev (2002). Some of the dug spider burrows were studied and measured, and fragments 
of the prey consumed by spiders were obtained. The prey remains were identified by Y.S. Tarbinsky and S.V. Ovchinnikov (Institute of Biology, Kyrgyz Academy of Sciences).

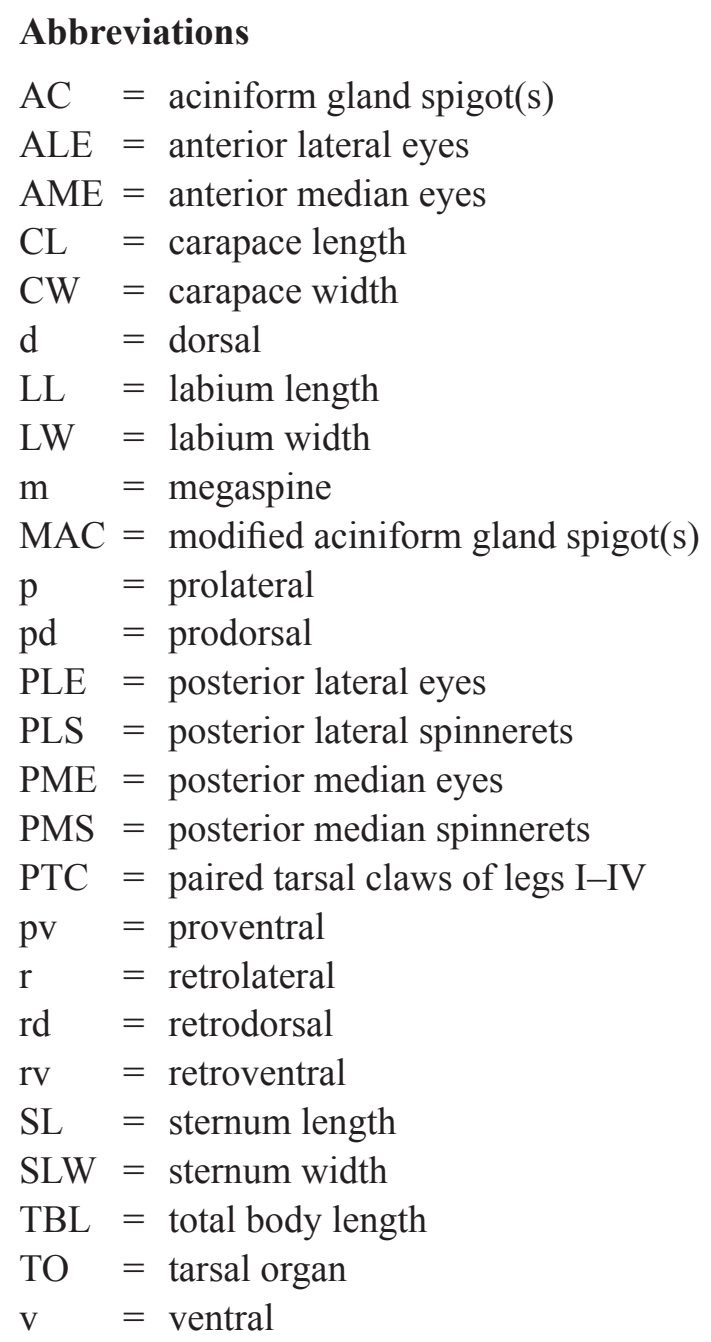

\section{Results}

\section{Taxonomic descriptions}

Class Arachnida Cuvier, 1812

Order Araneae Clerck, 1757

Family Cyrtaucheniidae Simon, 1889

Anemesia Pocock, 1895

Anemesia Pocock 1895: 194.

Anemesia - Simon 1903: 90. — Roewer 1942: 177. — Bonnet 1955: 322. —Zonstein 2001: 11; 2004: 358, fig. 22. — Marusik et al. 2014: 2.

\section{Type species}

Nemesia tubifex Pocock, 1889, by monotypy. 


\section{Emended diagnosis}

The genus differs from other known cyrtaucheniids in the following unique combination of characters: (a) a relatively broad carapace which is weakly if at all constricted posteriorly; (b) a fairly short and straight thoracic fovea; (c) a protruding triangular clypeus; (d) a long and narrow posterior pair of the sternal sigilla; (e) among types of the spigots only AC can be identified, while MAC are absent. Although these features can occur individually in other genera of the Cyrtaucheniidae, such a combination has no analogs within the family.

\section{Redescription}

Habitus. Anemesia includes mostly small or medium-sized mygalomorph spiders (body length $8-30 \mathrm{~mm})$.

Prosoma. Carapace broadly oval, mostly hirsute in males, glabrous to slightly hirsute in females. Clypeus triangular. Thoracic fovea transverse, straight or weakly procurved. Eye tubercle, normally carrying eight eyes (posterior eyes sometimes reduced), low to very low in females, more developed in conspecific males, mound carrying AMEs always distinct. Chelicerae with rastellum composed of numerous spikes on dorsodistal cheliceral edge. Cheliceral furrow with large promarginal teeth and with smaller retromarginal teeth, minute to medium-sized in females, but reduced in size in conspecific males. Fang without serration. Male intercheliceral tumescence absent. Labium moderately long, trapezoidal to subquadrate, without cuspules. Sternum domed, narrowed anteriorly. Sternal sigilla mostly distant from sternal margin, elongate, sometimes poorly developed (in A. infumata sp. nov. and A. pallida sp. nov.). Posterior sternal sigilla generally long and narrowly oval. Maxillae broadly trapezoidal. Few to numerous maxillary cuspules confined to probasal edge of maxillae. Sexual dimorphism in size of cuspules absent. Serrula not evident.

Structures of Legs I-IV. Leg formula: 4123 or 1423. Femur I usually longer than femur IV. Legs equal in width or legs III and IV slightly stouter (in females of $A$. andreevae sp. nov.). Male tibia I with one retroventral megaspine. Metatarsal preening combs absent. Tarsi entire. Most species of Anemesia have spines on tarsi III-IV (females of $A$. pococki sp. nov. and A. tubifex possess spines only on tarsus III; in females of $A$. andreevae sp. nov. all tarsi are aspinose; in males of $A$. castanea sp. nov. and A. parvula sp. nov. in addition to spinose tarsi III-IV, spines are located also on tarsus II). Scopula thin, moderately long and dense; entire and distal on metatarsi I and II; entire or narrowly divided on tarsi I and II, and on female palpal tarsus; widely divided, mixed with setae or reduced to absent on tarsi III and IV in males; usually absent on tarsi III and IV in females. Trichobothria arranged in two converging rows on tibiae, one straight row on metatarsi and one relatively narrow zigzag row on tarsi. Trichobothrial bases with longitudinal ridges. Tarsal organ low, lingulate, with weak concentric ridges. Female palp with tarsal claw possessing few teeth located prolaterally. Paired claws on tarsi I and II biserially dentate with numerous teeth, on tarsi III and IV usually with fewer teeth, in females inner teeth row may be reduced completely. Unpaired tarsal claw small, curved.

MALE PALP. Tibia moderately long to very long, slightly to distinctly swollen or cylindrical, with no, few, or numerous spines. Cymbium asymmetrical with retrolateral lobe extended, with or without spines. Male palpal bulb pyriform or asymmetrically shaped. Embolus tapering and curved, in A. incana and related species with small subapical process.

SpermatheCAE. Spermathecae may be multilobate, divided, or entire.

SPINNERETS. Two pairs of spinnerets. PMS medium-sized to small with functional spigots confined to apex only. Apical segment of PLS mostly triangular in females but usually longer (may be shortly digitiform) in conspecific males. Spigots: MAC not evident, only AC type present. 


\section{Species grouping}

To assist with identifications, the species treated here are assigned to six species groups. These assignments are preliminary, because females in some species are unknown and they are not based on a phylogenetic grouping, though these groups may indeed reflect phylogenetic relationships.

\section{Species included}

Anemesia currently includes 14 species (listed below according to their assignment to the corresponding species groups): A. birulai (Spassky, 1937), A. koponeni Marusik, Zamani \& Mirshamsi, 2014, A. pococki sp. nov., A. tubifex (Pocock, 1889), A. andreevae sp. nov., A. oxiana sp. nov., A. sogdiana sp. nov., A. castanea sp. nov., A. karatauvi (Andreeva, 1968), A. pallida sp. nov., A. parvula sp. nov., A. incana Zonstein, 2001, A. infumata sp. nov. and A. infuscata sp. nov.

\section{Distribution}

Central Asia: Afghanistan, Iran, Tajikistan, Turkmenistan and Uzbekistan.

\section{Key to species of Anemesia}

\section{Males}

1. Palpal tibia distinctly swollen and mostly aspinose (Figs 173-176, 178-179)

- Palpal tibia subcylindrical or cylindrical, and generally with numerous spines and thick bristles

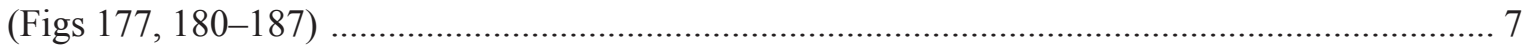

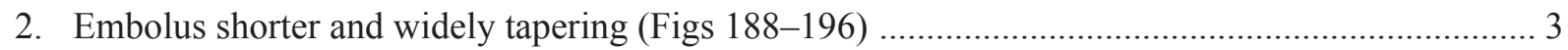

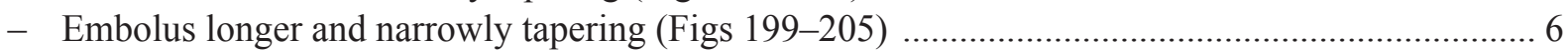

3. Distance AME-AME subequal to diameter of AME (Figs 48-50) ................................................ 4

- Distance AME-AME considerably larger then diameter of AME (Fig. 51)

A. tubifex (Pocock, 1889)

4. Carapace and legs light to medium brown; abdomen with distinct dorsal pattern (Figs 1, 3-4) ..... 5

- Carapace and legs dark brown; abdominal pattern indistinct (Fig. 2)

A. koponeni Marusik, Zamani \& Mirshamsi, 2014

5. Carapace and legs paler, light brown (Fig. 3); embolus longer (Figs 193-194) ..A. pococki sp. nov.

- Carapace and legs darker, medium brown (Fig. 1); embolus shorter (Figs 188-190)

A. birulai (Spassky, 1937)

6. Palpal tibia aspinose (Fig. 179). Embolus gradually tapering and uniformly curved (Figs 203205)

A. sogdiana sp. nov.

- Palpal tibia with numerous spines (Fig. 178). Distal part of embolus more sharply tapering and curved than its proximal part (Figs 199-202) A. oxiana sp. nov.

7. Cymbium and/or palpal tibia with spines (Figs 180-187). Embolus long to very long, with slightly curved and gradually tapering distal part (Figs 206-223)

- Palpal tibia and cymbium aspinose (Fig. 177). Embolus relatively short and bent medially, with very thin and narrow distal part (Figs 197-198) A. andreevae sp. nov.

8. Cymbium with numerous dorsal and few lateral spines (Figs 180-183). Subapical embolic keel very small and gradually elevated (Figs 206, 208, 210, 213-214). PMS small and slender (Figs 279-280, 282-284)

- Cymbium without lateral spines (Figs 184-187). Subapical embolic keel larger and noticeably dilated (Figs 147-150, 215, 218, 220). PMS stouter (Figs 285, 289) 
9. Carapace and legs paler, light brownish (Figs 10-11). Palpal tibia shorter: 3.0-3.2 times as long as wide (Figs 182-183). Tarsus IV with numerous (5-20) spines

- Carapace and legs darker, chestnut brown (Figs 8-9). Palpal tibia longer: 4.3-4.6 times as long as wide (Figs 180-181). Tarsus IV with few (1-4) spines

10. Legs longer: tibia I 4.9-5.0 times as long as wide (Fig. 127). Palpal organ pegtop-shaped, with certainly bulging anterior lobe (Figs 211-212). Dorsal abdominal pattern as in Fig. 10 ..... A. pallida sp. nov.

- Legs shorter: tibia I 4.2 times as long as wide (Fig. 128). Palpal organ comma-shaped, with weakly convex anterior lobe (Figs 213-214). Dorsal abdominal pattern as in Fig. 11 .....A. parvula sp. nov.

11. Legs longer: tibia I 5.7-5.9 times as long as wide (Fig. 125). Palpal organ with strongly bulging anterior lobe (Fig. 208)

A. castanea sp. nov.

- Legs shorter: tibia I 5.1-5.2 times as long as wide (Fig. 126). Palpal organ with weakly convex anterior lobe (Fig. 210)

A. karatauvi (Andreeva, 1968)

12. Palpal bulb noticeably (1.3-1.4 times) wider than long (Fig. 215). Clypeus wide, about 2 times exceeding diameter of ALE (Fig. 59). Posterior sigilla long, oval, and located closer to sternal margin (Fig. 101)

A. incana Zonstein, 2001

- Palpal bulb as wider as long, or very moderately (1.1-1.2 times) wider than long (Figs 218, 220). Clypeus considerably narrower, shorter than diameter of ALE, or only slightly exceeding it (Figs 6062). Posterior sigilla smaller, rounded or irregular, and located more distantly from sternal margin (Figs 102-103)

13. Legs longer: tibia I 4.8-4.9 times as long as wide (Fig. 130). Embolus more tapering, with base located closer to retrolateral side of palpal organ (Figs 217-219). Apical segment of PLS longer (Fig. 287) .....

A. infumata sp. nov.

- Legs shorter: tibia I 4.0-4.3 times as long as wide (Figs 131-132). Embolus less tapering, with base located closer to prolateral side of palpal organ (Figs 220-223). Apical segment of PLS shorter (Fig. 289)

A. infuscata sp. nov.

\section{Females}

Females of A. koponeni Marusik, Zamani \& Mirshamsi, 2014 and A. parvula sp. nov. are unknown.

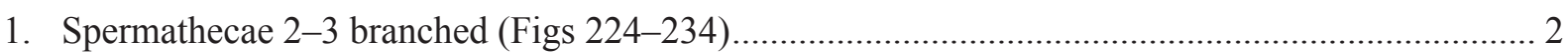

- Spermathecae entire (Figs 235-249, 251-265) or divided (Fig. 250) ............................................. 5

2. Spermathecae strictly 3-branched, with long stalks and well sclerotised receptacles (Figs 233-234). Habitus as in Fig. 18 A. andreevae sp. nov.

- Spermathecae mostly 2-branched, with shorter stalks and poorly sclerotised receptacles (Figs 224232). Habitus differs (Figs 15-17)

3. Distance AME-AME considerably larger then diameter of AME (Fig. 65). Spermathecae as in Figs 230-232. Habitus as in Fig. 17 A. tubifex (Pocock, 1889)

- Distance AME-AME subequal to diameter of AME (Figs 63-64). Habitus and spermathecae differ (Figs 15-16, 224-229)

4. Carapace and legs paler, light brown (Fig. 16). Spermathecae as in Figs 228-229

A. pococki sp. nov.

- Carapace and legs darker, medium brown (Fig. 15). Spermathecae as in Figs 224-227 
5. Spermathecae divided (Fig. 250). Dorsal abdominal pattern reduced to longitudinal median band. Habitus as in Fig. 23 A. pallida sp. nov.

- Spermathecae entire (Figs 235-249, 251-265). Habitus, including more developed dorsal abdominal pattern, differs (Figs 19-22, 24-26)

6. Carapace light yellowish brown to medium chestnut brown, chelicerae darker coloured (Figs 1922). Spermathecae with relatively long and narrow stalks (Figs 235-249)

- Carapace and chelicerae uniformly dark brown (Figs 24-26). Spermathecae with relatively short and wide stalks (Figs 251-265)

7. Carapace and legs paler, light yellowish brown (Fig. 20). Maxillae with 10-20 cuspules each. Spermathecae with moderately long stalks (Figs 235-240) A. sogdiana sp. nov.

- Carapace and legs darker, foxy to chestnut brown (Figs 19, 21-22). Maxillae with 28-85 cuspules each. Spermathecae with long to very long stalks (Figs 241-249)

8. Habitus as in Figs 19, 29. Dorsal abdominal pattern with dark longitudinal median spot having two large lateral extensions. Spermathecae with more narrowly spaced bases and conical stalks (Figs 241-244). Apical segment of PLS triangular (Fig. 276) A. oxiana sp. nov.

- Habitus as in Figs 21-22. Dorsal abdominal pattern with smaller lateral extensions. Spermathecae with more broadly spaced bases and cylindrical stalks (Figs 245-249). Apical segment of PLS shortly digitiform (as in Fig. 281)

9. Clypeus broader, AME and ALE relatively smaller (Fig. 70). Maxillae with 65-70 cuspules each. Spermathecae with narrower spaced, stronger inclined and more tapering receptacles (Fig. 245) A. castanea sp. nov.

- Clypeus narrower, AME and ALE relatively larger (Fig. 71). Maxillae with 40-55 cuspules each. Spermathecae with broader spaced, lesser inclined and less tapering receptacles (Figs 246249)

A. karatauvi (Andreeva, 1968)

10. Clypeus wide, about 2 times exceeding diameter of ALE (Fig. 73). Posterior sigilla long, oval, and located closer to sternal margin (Fig. 113). Spermathecae with widened bases and oblate receptacles (Figs 251-254)

A. incana Zonstein, 2001

- Clypeus considerably narrower, shorter than diameter of ALE, or only slightly exceeding it (Figs 7477). Posterior sigilla smaller, rounded or irregular, and located more distantly from sternal margin (Figs 114-116). Spermathecae differ (Figs 255-265) . .11

11. Tarsus IV with 3-4 spines. Spermathecae shorter, cap-like, with poorly defined receptacles (Figs 255-257) A. infumata sp. nov.

- Tarsus IV with 7-10 spines. Spermathecae longer, mushroom-like, with dilated receptacles (Figs 258-265) A. infuscata sp. nov.

\section{Anemesia tubifex species group}

\section{Diagnostic characters}

Males differ from other male congeners in possessing a distinctly swollen palpal tibia, almost or completely lacking spines (Figs 173-176), combined with a moderately long and broadly tapering embolus (Figs 188-196). Females have two or three branches in the spermathecae and relatively short stalks and weakly sclerotised receptacles (Figs 224-232).

\section{Species included}

Anemesia birulai (Spassky, 1937), A. koponeni Marusik, Zamani \& Mirshamsi, 2014, A. pococki sp. nov. and A. tubifex (Pocock, 1889). 
Anemesia birulai (Spassky, 1937)

Figs 1, 15, 48, 63, 90, 104, 117, 173, 188-190, 224-227, 266-267, 306-309, 369

Brachythele birulai Spassky, 1937: 364, fig. 2 (ふ).

Brachythele birulai - Spassky \& Minenkova 1940: 138. - Roewer 1942: 196 (§ึ). — Charitonov 1948: 301. — Spassky 1952: 193, 194. — Bonnet 1955: 911 (ふ). — Ivanov 1965: 245. — Brignoli 1972:

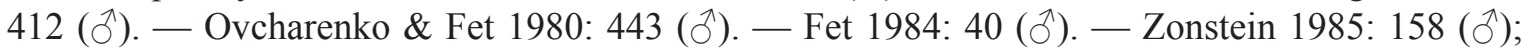
1987: 1013. - Kuznetsov \& Fet 1986: 50.

Sterrhochrotus ferghanensis - Vlasov \& Sytshevskaja, 1937: 249 ()). Misidentification, not Cteniza ferghanensis Kroneberg, 1875: 27, pl. 3, fig. 18 (우).

Nemesia birulai - Mikhailov \& Fet 1994: 502.

Anemesia birulai - Mikhailov 1996: 77; 1997: 20. — Zonstein 2001: 11. — Marusik et al. 2014: 3, fig. $11($ đ).

\section{Diagnosis}

Anemesia birulai is closest in habitus to A. pococki sp. nov. and A. tubifex; however, it differs by darker colouration from the former, and by AMEs spaced closer from the latter. Males can be also distinguished from A. pococki sp. nov. by the spinose cymbium, and from A. tubifex by a shorter and more swollen palpal tibia and by a shorter embolus (Figs 173, 188-190, cf. Figs 175-176, 193-196). Females of A. birulai possess the multilobate spermathecae with the characteristic long and slender individual receptacles (Figs 224-227).

\section{Material examined}

\section{Holotype}

TURKMENISTAN: §̊, Badhyz Plateau, Akarcheshme well, 27 Apr. 1936, L. Freiberg leg. (ZISP).

Additional material (8 $\widehat{\partial}, 10+q, 2$ + $q$ subad.)

TURKMENISTAN: 2 우 subad., surroundings of Ashgabat, 13 Apr. 1931, V. Vlasov leg., (ZMMU); 1 , , western part of Badhyz Plateau, Akarcheshme well, 850 m, 35 $47^{\prime} \mathrm{N}, 61^{\circ} 28^{\prime} \mathrm{E}, 15$ Apr. 1985,

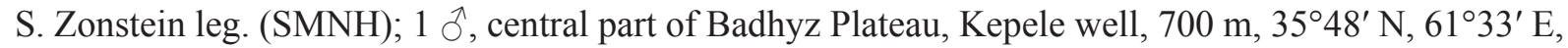
15-30 Mar. 1980, R.E. Zlotin leg. (SMNH); 2 우, same locality, 13 Apr. 1985, S. Zonstein leg.

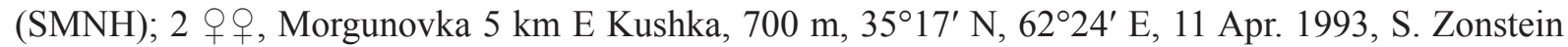
leg. (SMNH); 1 స, 1 क, Zulfagar Mts, surroundings of Nardenvaly spring, 800-1000 m, 35 $47^{\prime} \mathrm{N}$, 61 ${ }^{\circ} 21^{\prime}$ E, 13 Apr. 1993, S. Zonstein leg. (SMNH); 4 우, Eroylanduz depression S of Badhyz Plateau, 18 Mar. 1978, 450 m, V. Fet leg. (SMNH); 1 đ, Kopetdag Mts, foothills, Meana-Chaacha, 400 m, 22 Apr. 1978, G.T. Kuznetzov leg. (SMNH); 1 ô, Bikrava 9-10 km SW Ashgabat, 350 m, 28 Mar. 1977, G.T. Kuznetzov leg. (SMNH); 3 ổ ô, Berzengi 5-6 km S Ashgabat, 400-500 m, Mar.-Apr. 1980, G.T. Kuznetzov leg. (SMNH); 1 ○ै, Gyaurs 30 km ESE Ashgabat, 250-400 m, 11 Apr. 1980, O. Soyunov leg. (SMNH).

\section{Description}

Male (holotype)

Habitus. See Fig. 1).

MeAsurements. TBL 11.20, CL 4.93, CW 4.12, LL 0.65, LW 1.07, SL 2.62, CW 2.44.

Colour. Carapace and legs reddish brown, carapace with slightly darkened clypeus and eye tubercle brownish black; chelicerae dark reddish brown; sternum, labium and maxillae light reddish brown; cymbium brown; sternal sigillae brown; abdomen dorsally light brow with darker standard pattern 
consisting of broad median spot and six pairs short chevron-like lateral spots inclined backward; dorsal abdominal surface and spinnerets yellowish brown.

Prosoma. Clypeus and eye tubercle as shown in Fig 48. In holotype specimen right ALE and PLE fused. Eye diameters and interdistances: AME 0.16(0.20), ALE 0.25, PLE 0.20, PME 0.14, AMEAME 0.15(0.11), ALE-AME 0.10(0.08), ALE-PLE 0.04, PLE-PME 0.03, PME-PME 0.43. Cheliceral rastellum with 13-15 spikes located in front of fang base. Each cheliceral furrow with 7 promarginal teeth and 3-4 smaller retromarginal teeth. Sternum, labium and maxillae as shown in Fig. 90. Maxillae with 21-23 cuspules each.

Legs. Tibia and metatarsus I as shown in Fig. 117. Scopula: distal $1 / 3$ on metatarsi I-II, entire on tarsi I-II, elsewhere absent. Trichobothria: 2 rows of 8-9 each on tibiae, 7-10 on metatarsi, 11-13 on tarsi. PTC I-III: outer and inner margins with 5-6 teeth. PTC IV: 5-6 teeth on outer, 3-4 teeth on inner margin.

Spination. Palp: femur d3, pd2; patella pd1; tibia p2; tarsus d8-9. Leg I: femur d4, pd3, rd12-3; patella pd1; tibia p3, r1, v5+m; metatarsus p3, v5. Leg II: femur d4, pd3, rd3; patella pd1; tibia p3, v6-7; metatarsus p3, v5. Leg III: femur d4, pd3, rd3; patella p3; tibia d1, p2-3, r3, v7; metatarsus d1, pd2; p3, r3, v6; tarsus p1; Leg IV: femur d4, pd2-3, rd2-3; tibia p1, r3, v8; metatarsus pd2, p3, r3, v8; tarsus p1. Patella IV, and tarsi I and II aspinose.

PalP. Tibia, cymbium and palpal organ as shown in Figs 173, 188-190. Palpal tibia swollen (Fig. 173). Embolus tapering slightly curved (Figs 188-190).

SPINNERETS. See Fig. 266. PMS: length 0.36, diameter 0.17. PLS: maximal diameter 0.47; length of basal, medial and apical segments $0.80,0.65,0.42$; total length 1.87 ; apical segment triangular.

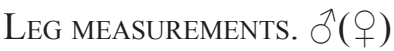

\begin{tabular}{ccccccc}
\hline & Femur & Patella & Tibia & Metatarsus & Tarsus & Total \\
\hline Palp & $2.97(4.47)$ & $1.53(2.18)$ & $2.43(3.11)$ & - & $1.03(2.57)$ & $7.96(12.23)$ \\
Leg I & $4.92(6.25)$ & $2.18(3.32)$ & $3.55(4.28)$ & $3.93(3.67)$ & $2.39(2.45)$ & $16.97(19.97)$ \\
Leg II & $4.45(5.66)$ & $2.13(3.25)$ & $3.32(3.77)$ & $3.37(3.63)$ & $2.35(2.41)$ & $15.62(18.72)$ \\
Leg III & $3.70(4.27)$ & $1.53(2.62)$ & $2.31(2.43)$ & $3.03(3.43)$ & $2.16(2.38)$ & $12.73(15.13)$ \\
Leg IV & $4.62(5.96)$ & $2.07(3.12)$ & $3.40(4.56)$ & $3.98(4.54)$ & $2.37(2.71)$ & $16.94(20.89)$ \\
\hline
\end{tabular}

Female (from Kepele; described for the first time)

Habitus. See Fig. 15.

MeAsurements. TBL 23.90, CL 7.53, CW 6.35, LL 0.83, LW 1.33, SL 3.77, SW 3.30.

Colour. Differs in some details from that of male holotype: carapace and legs ferruginous-brown; anterior half of carapace darker, anterior edge and lateral margins of carapace as well as femora, patellae and tibiae of legs I and II are even darker, brown-coloured; eye tubercle with brownish-black spots around AMEs and lateral eyes; sternum, labium, maxillae, coxae ventrally, metatarsi and tarsi III and IV yellowish-brown; abdomen light greyish-yellow with mid-brown pattern consisting of moderately narrow median stripe and six paired chevrons; spinnerets even paler greyish-yellow.

Prosoma. Clypeus and eye tubercle as in Fig. 63. Eye diameters and interdistances: AME 0.18(0.23), ALE 0.29, PLE 0.23, PME 0.16, AME-AME 0.23(0.18), ALE-AME 0.20(0.18), ALE-PLE 0.18, PLEPME 0.03, PME-PME 0.69. Cheliceral rastellum with 30-35 stout spikes in front of fang base. Each cheliceral furrow with 6-7 promarginal teeth and 3-6 smaller retromarginal teeth. Sternum, labium and maxillae as shown in Fig. 104. Maxillae with 16-15 cuspules each. 
LEGS. Scopula: entire on metatarsi I and II, palpal tarsus and tarsi I and II, elsewhere absent. Trichobothria: 2 rows of 7-9 each on tibiae, $12-14$ on metatarsi, 11-13 on leg tarsi, 6-7 on palpal tarsus. Palpal claw with 4 promarginal teeth. PTC I-II with 5-6 teeth on each margin. PTC III with 5-6 teeth on outer, 3-4 teeth on inner margins. PTC IV with $4-5$ teeth on outer, 1 tooth on inner margins.

Spination. Palp: femur pd1; patella p3; tibia p2-3, v12-13; tarsus v1. Leg I: femur pd2; patella p2; tibia p3, v5-6; metatarsus v5. Leg II: pd3; patella p2; tibia p2, v5-7; metatarsus pd1, v6-7. Leg III: pd2-3, rd3; patella r3; tibia d1, p2, r2, v7; metatarsus d1, p2-3, r3, v5-6; tarsus p2, v2; Leg IV: rd2; tibia r2, v7; metatarsus p4, r2, v9; tarsus p2-3, v2. Palpal femur and femora I-IV with 3-7 thick dorsal bristles; patella IV, and tarsi I and II aspinose.

Spermathecae. Two or three branched, as shown in Fig. 224.

SPINNERETS. See Fig. 267. PMS: length 0.86, diameter 0.40. PLS: maximal diameter 0.87; length of basal, medial and apical segments 1.92, 1.13, 0.80; total length 3.85; apical segment triangular.

\section{Variation}

The length of the carapace varies from 4.65 to 5.30 in males and in females from 6.00 to 7.85 . The coloration weakly varies across specimens from Badhyz Plateau; however, spiders collected in the surroundings of Ashgabat at a lower altitude (200-400 m vs 600-1100 m) look somewhat paler. The number of the maxillary cuspules ranges from 15 to 23 in males and from 13 to 21 in females. The variability in structure of the male palpal organ and the spermathecae is shown in Figs 188-190 and 224-227, respectively.

\section{Habitat}

The species occurs in foothill and low mountain steppes, often with shrubs or open park forest composed mainly of Pistacia vera L. The vicinity of the Kepele well, with hillsides inhabited by these spiders, is shown in Figs 307-308.

\section{Distribution}

South Turkmenistan. See Fig. 369.

\section{Notes}

Vlasov \& Sytshevskaya (1937) listed "Sterrhochrotus ferghanensis Croneb." among spider species collected from the burrows in surroundings of Ashgabat. The re-examination of two females deposited in ZMMU, herewith identified and labelled, revealed they are Anemesia. Since both these females are immature, they are provisionally assigned here to A. birulai, the only congener known in the neighbourhood; their studied characters do not contradict such assignment.

Charitonov (1969) indicated this species as also distributed in Uzbekistan. A re-examination of the material used in his study (PSU), revealed that he dealt with representatives of an undescribed species (see description of $A$. sogdiana sp. nov.). The corresponding reference is thus excluded from the synonymy list of $A$. birulai.

Anemesia koponeni Marusik, Zamani \& Mirshamsi, 2014

Figs 2, 49, 91, 118, 174, 191-192, 268, 369

Anemesia koponeni Marusik et al. 2014: 2, figs 1-8 (ð). 


\section{Material examined}

\section{Holotype}

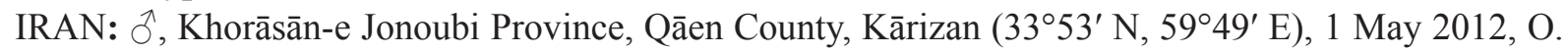
Mirshamsi leg. (SMF).

\section{Diagnosis}

By structure of the palp with a moderately swollen tibia and a widely tapering embolus, the relatively large male holotype of Anemesia koponeni resembles the large males of A. tubifex. However, it differs from them by the almost uniformly dark brown coloured body and legs (vs the lighter and more contrastingly coloured body and legs in A. tubifex; Fig. 2, cf. Fig. 4), as well as by a narrower eye group and by the closer spaced AMEs (Fig. 49, cf. Fig. 51).

\section{Description}

Male (holotype)

Habitus. See Fig. 2.

MeAsurements. TBL 15.20, CL 6.01, CW 5.20, LL 0.56, LW 0.97, SL 3.16, CW 2.52.

CoLour. Carapace, palps and most part of legs reddish brown; eye tubercle brownish black; clypeus, chelicerae, femora I-II dorsally dark reddish brown; sternum, labium, maxillae, palps and legs ventrally yellowish brown; abdomen dorsally with almost indistinct pattern consisting of short median stripe and few pairs of interrupted transverse fasciae, metatarsi III-IV, tarsi I-IV, ventral abdominal surface and spinnerets light yellowish brown.

Prosoma. Clypeus and eye tubercle as shown in Fig. 49. Eye diameters and interdistances: AME 0.17 (0.24), ALE 0.25, PLE 0.20, PME: 0.12, AME-AME 0.19(0.12), ALE-AME 0.15(0.12), ALE-PLE 0.10, PLE-PME 0.03, PME-PME 0.52. Cheliceral rastellum with 20-25 spikes in front of fang base. Each cheliceral furrow with 7 promarginal teeth and 6-7 smaller retrolateral teeth. Sternum, labium and maxillae as shown in Fig. 91. Maxillae with ca 15 cuspules each.

Legs. Tibia and metatarsus I as shown in Fig. 118. Scopula distal and entire on metatarsi I-II, entire on tarsi I-II, divided on tarsus III, absent on tarsus IV. PTC I-IV with 6-7 teeth on each margin. Trichobothria: 2 rows of 7-9 each on tibiae, 14-17 on metatarsi, 17-21 on tarsus I, 12-17 on tarsi II-IV, 8 on cymbium.

LEG MEASUREMENTS.

\begin{tabular}{ccccccc}
\hline & Femur & Patella & Tibia & Metatarsus & Tarsus & Total \\
\hline Palp & 3.56 & 2.04 & 3.30 & - & 1.14 & 10.04 \\
Leg I & 6.96 & 3.07 & 4.97 & 5.51 & 3.22 & 23.73 \\
Leg II & 6.45 & 2.96 & 4.43 & 5.22 & 3.14 & 22.20 \\
Leg III & 5.18 & 2.29 & 3.36 & 4.98 & 2.81 & 18.62 \\
Leg IV & 6.72 & 2.71 & 5.53 & 6.37 & 3.14 & 24.47 \\
\hline
\end{tabular}

Spination. Palp: femur d3, pd2; patella 1, tibia v1-2; tarsus d ca 10 small. Leg I: femur d4, pd3, rd3; patella p1-2; tibia p3, r2-3, v6-8; metatarsus d1, p1, r1, v3-4+m. Leg II: femur d4, pd3, rd3; patella p2; tibia p3, r1-2, v9; metatarsus d2, p3, r1, v5-7. Leg III: femur d3-4, pd3, rd3; patella p2, r1; tibia d1, p3, r3, v6; metatarsus p3, r4, v7; tarsus pv2, rv2. Leg IV: femur d3, pd3, rd3; tibia d1, p1, r3, v6; metatarsus $\mathrm{d} 1, \mathrm{p} 2, \mathrm{r} 5, \mathrm{v} 7-8$; tarsus pv1-4, rv1-2. Patella IV, and tarsi I and II aspinose. 
PALP. Tibia, cymbium and palpal organ as shown in Figs 174, 191-192. Palpal tibia swollen (Fig. 174). Palpal organ with embolus tapering and noticeably curved (Figs 191-192).

SPINNERETS. See Fig. 268. PMS: length 0.53; diameter 0.27. PLS: maximal diameter 0.51; length of basal, medial and apical segments $0.98,0.75,0.52$; total length 2.25 ; apical segment triangular.

\section{Female}

Unknown.

\section{Habitat}

No data.

\section{Distribution}

The species is known from the type locality only (see Fig. 369).

Anemesia pococki sp. nov. urn:lsid:zoobank.org:act:0A90722E-CDDE-4595-A948-8E2E014C2153 Figs 3, 16, 27, 50, 64, 78, 92, 105, 119, 143-144, 158-160, 175, 193-194, 228-229, 269-270, 291, 306-307, 369

\section{Diagnosis}

Anemesia pococki sp. nov. generally resembles a paler coloured version of $A$. birulai. However, it differs from the latter species by the aspinose cymbium and a less tapering embolus in males (Figs 175, 193194; cf Figs 173, 188-190), as well as by less sclerotised and more diverged receptacles in females (Figs 228-229; cf Figs 224-227).

\section{Etymology}

The specific name is a patronym in honor of Dr Reginald I. Pocock, the noted British arachnologist (1863-1947), who provided and published many studies on the Mygalomorphae; he described, in particular, both the genus Anemesia in 1895 and its type species a few years earlier (1889).

\section{Material examined}

\section{Holotype}

TURKMENISTAN: ${ }^{\lambda}$, surroundings of Nardevanly spring, Zulfagar Mts, $900 \mathrm{~m}, 35^{\circ} 47^{\prime} \mathrm{N}, 61^{\circ} 21^{\prime} \mathrm{E}$, 16 Apr. 1993, S. Zonstein leg. (SMNH).

\section{Paratypes}

TURKMENISTAN: $4 \hat{\jmath} \widehat{\partial}, 7$ $q$, , same collection data as for holotype but 600-1000 m, 16-17 Apr. 1993 (SMNH).

\section{Description}

$$
\text { Male (holotype) }
$$

Habitus. See Fig. 3.

Measurements. TBL 13.10, CL 5.63, CW 4.73, LL 0.63, LW 1.05, SL 2.77, SW 2.53.

CoLour. Carapace light brownish orange with anterior edge darker and thoracic part lighter, chelicerae light orange; palps and legs dorsally less intensive orange; sternum, labium, maxillae and legs ventrally pale brownish yellow; eye tubercle blackened; abdomen dorsally pale yellowish grey with brown pattern 
consisting of moderately wide median lanceolate spot and six paired transverse and slightly inclined short stripes, ventral part of abdomen pale yellow, spinnerets pale brownish yellow.

Prosoma. Clypeus and eye tubercle as shown in Fig. 50. Eye diameters and interdistances: AME 0.16(0.20), ALE 0.27, PLE 0.21, PME 0.10, AME-AME 0.15(0.11), ALE-AME 0.09(0.07), ALE-PLE 0.12 , PLE-PME 0.03, PME-PME 0.44. Thoracic fovea short and nearly pit-like, with anterior edge slightly recurved. Cheliceral rastellum composed of about 25 spikes grouped both in one transverse row in front of fang base and irregularly on low mound. Each cheliceral furrow with nine promarginal teeth and seven to eight smaller retromarginal teeth. Sternum, labium and maxillae as shown in Fig. 92. Maxillae with 30-32 cuspules each.

Spination. Palp: femur d3, pd2; patella pd1; tibia p1, r1, v1. Leg I: femur d5, pd3, rd2-3; patella p1; tibia p2, v5+m; metatarsus d1, pd2, v6. Leg II: femur d5, pd3, rd1; patella p1; tibia p3, v8; metatarsus p3, v7. Leg III: femur d4, pd3, rd3; patella p3, r2; tibia d1, p3, r3, v8; metatarsus pd4, p3, r2, v9; tarsus pv3. Leg IV: femur d5, p3, r3; tibia d1, p3, r3, v8; metatarsus pd2, p3, r7, v7; tarsus p2. Cymbium, patella IV and tarsi I and II aspinose.

Legs. Tibia and metatarsus I as shown in Fig. 119. Scopula: distal on metatarsi I-II, entire on tarsi I and II, divided on tarsi III, vestigial on tarsi IV. Trichobothria: 2 rows of 8 each on tibiae, 12-14 on metatarsi, $12-13$ on tarsi. PTC I-III with 9-10 teeth on both outer and inner margin, PTC IV with 8 and 5-7 teeth respectively.

Palp. Tibia, cymbium and palpal organ as shown in Figs 175, 193-194. Tibia swollen, with few spines and numerous ventral thick bristles (Fig. 175). Embolus tapering slightly curved (Figs 193-194).

SinNERETS. See Fig. 269. PMS: length 0.38, diameter 0.20. PLS: maximal diameter 0.57 ; length of basal, medial and apical segments $0.92,0.67,0.33$; total length 1.92 ; apical segment triangular.

LEG MEASUREMENTS. $\widehat{\jmath}(+)$

\begin{tabular}{ccccccc}
\hline & Femur & Patella & Tibia & Metatarsus & Tarsus & Total \\
\hline Palp & $3.29(3.53)$ & $1.67(1.84)$ & $2.76(2.37)$ & - & $0.95(2.10)$ & $8.27(9.84)$ \\
Leg I & $5.87(4.45)$ & $2.78(2.76)$ & $4.55(3.47)$ & $4.64(3.01)$ & $2.69(1.93)$ & $20.53(15.62)$ \\
Leg II & $5.43(4.06)$ & $2.71(2.57)$ & $4.22(2.83)$ & $4.40(2.76)$ & $2.67(1.87)$ & $19.43(14.07)$ \\
Leg III & $4.52(3.44)$ & $2.13(2.08)$ & $3.13(1.97)$ & $4.26(2.54)$ & $2.81(1.80)$ & $16.85(11.83)$ \\
Leg IV & $5.77(4.82)$ & $2.32(2.55)$ & $5.02(3.63)$ & $5.33(3.51)$ & $2.85(2.13)$ & $21.29(16.64)$ \\
\hline
\end{tabular}

Female (paratype)

Habitus. As shown in Figs 16, 27.

MeAsurements. TBL 18.90, CL 6.03, CW 4.74, LL 0.67, LW 1.18, SL 2.95, SW 2.62.

Colour. Similar to that of male, but slightly paler.

Prosoma. Clypeus and eye tubercle as shown in Fig. 64. Eye diameters and interdistances: AME 0.16(0.22), ALE 0.33, PLE 0.22, PME 0.12, AME-AME 0.20(0.14), ALE-AME 0.14(0.11), ALE-PLE 0.13, PLE-PME 0.03, PME-PME 0.54. Cheliceral rastellum consists of 20-25 spikes located in front of fang base and on low mound (as in Figs 143-144). Each cheliceral furrow with 7 promarginal teeth and 5-6 smaller retromarginal teeth. Sternum, labium and maxillae as shown in Fig. 92. Maxillae with 21-26 cuspules each. 
LEGS. Scopula: entire on metatarsus I, distal on metatarsus II, entire on palpal tarsus and tarsus I, narrowly divided on tarsus II, elsewhere absent. Trichobothria: 2 rows of 6-8 each on tibiae, 10-14 on metatarsi, 11-13 on tarsi, 8-9 on palpal tarsus. Trichobothrial bases and tarsal organ of leg I as shown in Figs 158-159 and 160, respectively. Palpal claw with 4 promarginal teeth. PTC I-II with 5-6 teeth on each margin; PTC III with 4-5 teeth on outer, 2-3 teeth on inner margins; PTC IV with 4 and $0-2$ teeth, respectively.

Spination. Palp: femur pd1; patella pd3, pv1; tibia pd3, p3, v9-10; tarsus v4-5. Leg I: femur pd1; patella p1; tibia p2, v4; metatarsus v5. Leg II: femur pd1; patella p1; tibia p3, v4; metatarsus p1, v7. Leg III: patella p3; tibia d1, p2-3, r1-2, v4; metatarsus d1, pd4, rd3, v7; tarsus p1, v1. Leg IV: tibia v6; metatarsus pd1, rd2, v9. All femora with dorsal median row of 6-8 long slender bristles; patella IV and tarsi I, II and IV aspinose.

Spermathecae. Multilobate with 2-3 receptacles set on common base (as in Fig. 228).

SPINNERETS. See Fig. 270. PMS: length 0.52, diameter 0.25. PLS: maximal diameter 0.60; length of basal, medial and apical segments 1.10, 0.67, 0.45; total length 2.22; apical segment triangular. Spigots as shown in Fig. 291.

\section{Variation}

The length of the carapace varies from 5.26 to 5.70 in males and from 5.15 to 6.37 in females. The colouration varies very narrowly throughout the specimens. In females the number of retromarginal cheliceral teeth ranges from 5 to 8 (as in Fig. 78). Variants in the shape of the spermathecae are shown in Figs 228-229.

\section{Habitat}

Montane cereal steppe on a stony substrate, with dominating Hordeum bulbosum L. and Andropogon sp. (Fig. 307).

\section{Distribution}

The species is known only from the type locality (see Fig. 369).

\section{Anemesia tubifex (Pocock, 1889)}

Figs 4, 17, 51, 65, 79, 93, 106, 120, 161-162, 176, 195-196, 230-232, 271-272, 306-307, 369

Nemesia tubifex Pocock, 1889: 112 (ㅇ).

Nemesia tubifex - Simon 1892: 113, 116.

Anemesia tubifex - Pocock 1895: 195, pl. V, fig. 4 ()). — Simon 1903: 907 ()). — Reimoser 1919:

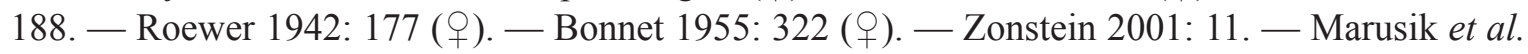
2014: 3 .

\section{Diagnosis}

Anemesia tubifex can be distinguished from all other members of the same group by an unusually wide eye group with AMEs broader spaced from each other (Figs 51, 65; cf. Figs 48-50, 63-64). Males of A. tubifex differ from those of other species in the A. tubifex group by a less swollen and moderately spinose palpal tibia (Fig. 176; cf. Figs 173-175). The conspecific females possess the characteristic bipartite spermathecae with stalks slightly shorter than in other species of this group (Figs 230-232; cf. Figs 224-229). 


\section{Material examined}

Holotype

AFGHANISTAN: + , north foothills of Paropamisus Mts, Gulran $\left(750 \mathrm{~m}, 35^{\circ} 06^{\prime} \mathrm{N}, 61^{\circ} 41^{\prime} \mathrm{E}\right)$, Mar. 1885 , J.E.T. Aitchison leg. (MNHL). The current poor condition of the holotype makes the examination of many characters (the spinnerets, etc.) impossible.

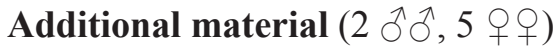

TURKMENISTAN: 1 q, Karabil Mts, surroundings of Takhta-Bazar (400 m, 35 $\left.56^{\prime} \mathrm{N}, 62^{\circ} 57^{\prime} \mathrm{E}\right), 21$

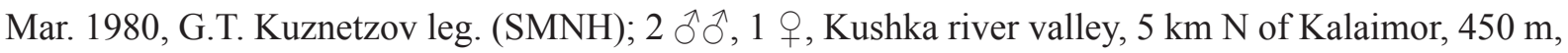
$35^{\circ} 42^{\prime} \mathrm{N}, 62^{\circ} 37^{\prime} \mathrm{E}, 19$ Apr. 1993, S. Zonstein leg. (SMNH); 2 우, , southwestern edge of Badhyz Plateau,

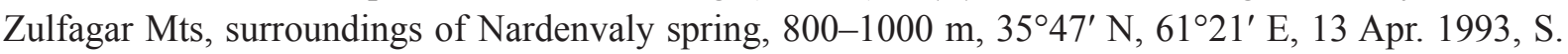
Zonstein leg. (SMNH); 1 q, 12 km SSE Gyangaly $\left(235 \mathrm{~m}, 36^{\circ} 55^{\prime} 51^{\prime \prime}\right.$ 'N, 60 $50^{\circ} 22^{\prime \prime}$ E), 3 Apr. 2002, A.V. Gromov leg. (ZMMU).

\section{Description}

Male (from Kalaimor)

Habitus. See Fig. 4.

Measurements. TBL 14.80, CL 6.55, CW 5.67, LL 0.42, LW 1.06, SL 3.10, CW 2.68.

Colour. Carapace brownish orange with eye tubercle brownish black; chelicerae, all femora, palpal patella, cymbium, patellae and tibiae I-II dark foxy brown; patellae and tibiae III-IV, metatarsi and tarsi I-IV, sternum, labium and maxillae light foxy brown; sternal sigilla brown; abdomen dorsally light brownish grey with brownish black pattern consisting of median lanceolate spot intersected with wide transverse fascia in basal third and five pairs of short chevron-like lateral spots inclined backward; dorsal abdominal surface and spinnerets pale yellowish brown.

Prosoma. Clypeus and eye tubercle as shown in Fig. 51. Eye diameters and interdistances: AME 0.15(0.22), ALE 0.30, PLE 0.26, PME 0.15, AME-AME 23(16), ALE-AME 0.16(0.13), ALE-PLE 0.10, PLE-PME 0.06, PME-PME 0.55. Cheliceral rastellum composed of 15-20 spikes located in front of claw base and on low mound. Each cheliceral furrow with 6-7 promarginal teeth and 5 smaller retromarginal teeth. Sternum, labium and maxillae as shown in Fig. 93. Maxillae with 14-15 cuspules each.

Legs. Tibia and metatarsus I as shown in Fig. 120. Scopula: distal $2 / 5$ on metatarsus I, distal $1 / 6$ on metatarsus II, entire on tarsi I-II, absent on tarsi III-IV. Trichobothria: 2 rows of 7-9 each on tibiae, 13-17 on metatarsi, 15-17 on tarsi, 9 on cymbium. Trichobothrial bases and tarsal organ of leg I as shown in Figs 161 and 162, respectively. PTC I-III with 8 teeth on each margin; PTC IV with 5 teeth on outer and 7-8 teeth on inner margins.

Spination. Palp: femur d3, pd3; patella pd1; tibia p2-3, pv1, r1-2, rv1; tarsus d6. Leg I: femur d4, pd3, rd3; patella pd2; tibia p3, r3, v7+m; metatarsus p3, r1, v2-4. Leg II: femur d4, pd3, rd3; patella pd2; tibia p3, r1, v8-9; metatarsus p3, r1, v7. Leg III: femur d4, pd3, rd3; patella d1, p1, r3; tibia d1, p3, r3, v7; metatarsus d2, p3, rd3, v7; tarsus p1; Leg IV: femur d4, p3, r2-3; tibia d1, p3, r2-3, v8; metatarsus $\mathrm{d} 2, \mathrm{pd} 2, \mathrm{p} 3, \mathrm{r} 3, \mathrm{v} 8-10$; tarsus p1. Patella IV, and tarsi I and II aspinose.

PALP. Tibia, cymbium and palpal organ as shown in Figs 176, 195-196. Tibia moderately long and weakly swollen (Fig. 176). Palpal organ with embolus tapering and noticeably curved (Figs 195-196). 
SPINNERETS. See Fig. 271. PMS: length 0.65, diameter 0.22. PLS: maximal diameter 0.52; length of basal, medial and apical segments $1.10,0.75,0.73$; total length 2.50 ; apical segment triangular.

LEG MEASUREMENTS. $ð(+)$

\begin{tabular}{ccccccc}
\hline & Femur & Patella & Tibia & Metatarsus & Tarsus & Total \\
\hline Palp & $4.31(4.55)$ & $2.16(2.08)$ & $3.37(2.94)$ & - & $1.43(2.51)$ & $11.27(12.08)$ \\
Leg I & $7.02(5.98)$ & $3.26(3.47)$ & $5.03(3.89)$ & $5.04(3.46)$ & $3.18(2.22)$ & $23.53(19.02)$ \\
Leg II & $6.58(5.23)$ & $2.95(2.88)$ & $4.73(3.23)$ & $5.04(3.07)$ & $3.15(2.16)$ & $22.45(16.57)$ \\
Leg III & $5.54(4.07)$ & $2.43(2.46)$ & $3.27(2.33)$ & $5.76(3.06)$ & $2.97(2.07)$ & $19.97(13.99)$ \\
Leg IV & $6.62(5.54)$ & $2.96(2.87)$ & $5.57(4.22)$ & $6.03(4.16)$ & $3.16(2.29)$ & $24.34(18.98)$ \\
\hline
\end{tabular}

Female (from Kalaimor)

Habitus. See Fig. 17.

MeAsurements. TBL 20.20, CL 8.63, CW 6.37, LL 0.77, LW 1.28, SL 4.75, SW 3.97.

Colour IN ALCOHOL. Similar to that of male, but carapace and legs are paler, as well as dorsal abdominal pattern is paler and less contrasted.

Prosoma. Clypeus and eye tubercle as shown in Fig. 65. Eye diameters and interdistances: AME 0.20(0.30), ALE 0.42, PLE 0.26, PME 0.19, AME-AME 0.25(0.18), ALE-AME 0.23(0.19), ALE-PLE 0.18, PLE-PME 0.04 (left) to 0.06 (right), PME-PME 0.80. Cheliceral rastellum well developed and consists of about 10 spikes in front of fang base and ca 20 spikes on mound. Each cheliceral furrow with 6 promarginal teeth and 9 smaller retromarginal teeth. Sternum, labium and maxillae as shown in Fig. 106. Maxillae with 16-17 cuspules each.

Legs. Scopula: distal on metatarsi I and II, entire on palpal tarsus and tarsi I and II, elsewhere absent. Trichobothria: 2 rows of 7-8 each on tibiae, 10-12 on metatarsi, 12-14 on tarsi. Palpal claw with 6 promarginal teeth. PTC I-II with 5-6 teeth on each margin; PTC III with 5-6 teeth on outer, 1-2 teeth on inner margins; PTC IV with 4 and 0 teeth, respectively.

Spination. Palp: femur d1, pd1; patella p2; tibia p4, v9-10; tarsus v3-4. Leg I: tibia v5-6; metatarsus v5-6. Leg II: tibia p2, v4; metatarsus v5. Leg III: patella p1; tibia d2, p2, v4; metatarsus d1, p4, v6; tarsus p1. Leg IV: tibia dr2, v4; metatarsus p3, rd2, v8. All femora with dorsal median row of 4-5 long bristles; femora III and IV also with 3 prodorsal and 3 retrodorsal bristles; patellae I, II and IV, and tarsi I, II and IV aspinose.

SpermatheCAe. Bipartite, as shown in Figs 230-232.

SPINNERETS. See Fig. 272. PMS: length 0.65 , diameter 0.35. PLS: maximal diameter 0.85 ; length of basal, medial and apical segments $1.50,0.63,0.73$; total length 2.86; apical segment triangular.

\section{Variation}

The length of the carapace varies from 6.50 to 6.55 in males and from 7.52 to 8.63 in females; the number of the maxillary cuspules ranges between 11 and 17; both the colouration and the leg spination range very narrowly.

\section{Habitat}

The species was found to inhabit at least two types of habitats, in piedmont and montane areas of the Badhyz Plateau, respectively. The only visited piedmont habitat, located in the surroundings of 
Kalaimor, is typical for the region: a true sand desert occupying the upper terrace on the left bank of Kushka River, 1-1.5 km from the floodplain. A sandy substrate features sparse herb vegetation dominated by the ephemerous desert sedge, Carex physodes M.Bueb. The visited montane habitats, confined to a relatively high south-western edging of the uplands, represent mountainous wormwood and cereal steppe on a rocky substrate, with sparse trees and shrubs (see Fig. 307).

\section{Distribution}

Northern Afghanistan and the far southern Turkmenistan (Fig. 369).

\section{Notes}

Although the holotype is in poor condition (a result of careless sampling rather than bad preservation), the identification of other specimens belonging to Anemesia tubifex is not problematic. Among all members of the considered species group, only Anemesia tubifex has such a broadly extended eye group and such broadly spaced AMEs. Within females of Anemesia, the somewhat comparable eye group can be observed only in the geographically distant $A$. andreevae sp. nov., $A$. castanea sp. nov. and A. karatauvi (see Figs 66, 70-71). However, females of $A$. andreevae sp. nov. have legs III-IV barely stouter than legs I-II (vs evenly slender legs I-IV in A. tubifex), whereas females of $A$. castanea sp. nov. and $A$. karatauvi possess more numerous maxillary cuspules (40-70 vs 14-18 cuspules in A. tubifex).

Examination of the spider material used by Denis (1958) for his work on the spider fauna of Afghanistan, revealed that he listed a new record of $A$. tubifex erroneously, since the latter was based on misidentified material (see page 48). The corresponding reference is therefore excluded from the synonymy list of this species.

\section{Anemesia andreevae species group}

\section{Diagnostic characters}

The distinguishing characters of this group are: 1) the specific form of the embolus which is relatively short and bent medially, possessing a very thin and narrow distal part; 2) the unique shape of 3-branched spermathecae, provided with strictly sclerotised receptacles.

\section{Species included}

Only one species, $A$. andreevae sp. nov.

Anemesia andreevae sp. nov. urn:1sid:zoobank.org:act:984606B5-193A-4B6B-A393-539D17EC850C

Figs 5, 18, 52, 66, 80, 94, 107, 121, 163-164, 177, 197-198, 233-234, 273-274, 310-311, 330, 370

\section{Diagnosis}

Anemesia andreevae sp. nov. is largely similar in habitus to A. pallida sp. nov. and especially to A. sogdiana sp. nov., but differs from them by the long cylindrical palpal tibia and a shorter embolus in males (Figs 177, 197-198; cf. Figs 179, 182, 203-205, 211-212) as well as by the unique branched receptacles in females (Figs 233-234; cf. Figs 235-240, 250).

\section{Etymology}

The specific name is a matronym in honour of the late Central Asian and Polish arachnologist Dr Ekaterina Andreeva (Dr Katarzyna Andrejeva-Prószyńska; 1941-2008), who made a very significant contribution to the study of the spider fauna of Tajikistan; in the course of her numerous taxonomic 
studies she described many regional spider taxa, including Brachythele karatauvi Andreeva, 1968 assigned later to Anemesia.

\section{Material examined}

Holotype

UZBEKISTAN: $\widehat{\jmath}$, Babatag Mts, north-eastern slope of Mt Zarkassa, $1.5 \mathrm{~km}$ NNE of the summit, $2100 \mathrm{~m}, 38^{\circ} 01^{\prime} 02^{\prime \prime} \mathrm{N}, 68^{\circ} 10^{\prime} 53^{\prime \prime}$ E, 5 May 1990, S. Zonstein leg. (SMNH).

Paratypes $(17+q)$

UZBEKISTAN: 2 우, same collection data as for the holotype (SMNH).

Tajikistan: 4 + 9 , foothills of Hissar Mts, $8 \mathrm{~km} \mathrm{~N}$ of Dushanbe, Varzob canyon, $1100 \mathrm{~m}, 38^{\circ} 40^{\prime} \mathrm{N}$, $68^{\circ} 47^{\prime}$ E, 18 Oct. 1987, S. Zonstein leg. (SMNH); 10 q $ᄋ$, same collection data as for preceding but 13 Apr. 1988 (SMNH); 1 , , same collection data as for preceding but 22 Apr. 1990 (SMNH).

\section{Description}

\section{Male (holotype)}

Habitus. See Fig. 5.

MeAsurements. TBL 8.26, CL 4.03, CW 3.05, LL 0.35, LW 0.63, SL 2.27, CW 1.56.

CoLour. Carapace light yellowish brown with anterior edge darker and thoracic part lighter; chelicerae, most part of palps and legs light yellowish brown; sternum, labium, maxillae and leg tarsi paler; eye tubercle blackened; abdomen dorsally pale yellowish brown with brown pattern consisting of moderately wide median lanceolate spot and few paired transverse and slightly inclined short stripes, ventral part of abdomen pale yellowish grey, spinnerets pale brownish yellow.

Prosoma. Clypeus and eye tubercle as shown in Fig. 52. Eye diameters and interdistances: AME 0.14, ALE 0.17, PLE 0.13, PME 0.07, AME-AME 0.14, ALE-AME 0.05, ALE-PLE 0.09, PLE-PME 0.02, PME-PME 0.35. Cheliceral rastellum composed of 15-20 spikes located in front of fang base. Each cheliceral furrow only with 6 promarginal teeth. Sternum labium and maxillae as shown in Fig. 94. Sternal sigilla small and weakly developed. Maxillae with 2 cuspules each.

Legs. Tibia and metatarsus I as shown in Fig. 121. Scopula: distal 0.4 on metatarsus I, entire on tarsus I, narrowly divided on tarsus II, elsewhere absent. Trichobothria: 2 rows of 6-7 each on tibiae, 10-12 on metatarsi, 9-12 on tarsi, 6 on cymbium. PTC: outer and inner margins with 6-7 teeth each on tarsi I-II, 5-6 and 4 on tarsus III, 5 and 2-3 on tarsus IV, respectively.

Spination. Palp: femur pd1. Leg I: femur d5, pd1; tibia p2, v4+m; metatarsus p1-2, v2. Leg II: femur d5, pd1; tibia p2, v5; metatarsus p2, v1-2. Leg III: femur d5, rd1; patella p1, r1; tibia d1, p2, r3, v5; metatarsus d2, pd2, p3, r3, v5. Leg IV: femur d5, rd1; tibia p3, r2, v7; metatarsus p2, r3, v7. Palpal femur with 5 dorsal bristles instead of true spines; palpal patella, tibia and cymbium, patellae I, II and IV, and tarsi I-IV aspinose.

PALP. Tibia, cymbium and palpal organ as in Figs 177, 197-198. Palpal tibia long and slender (Fig. 177). Embolus relatively short, curved, and bent, with very thin distal part (Figs 197-198).

SPINNERETS. See Fig. 273. PMS: length 0.23, diameter 0.10. PLS: maximal diameter 0.30; length of basal, medial and apical segments $0.43,0.37,0.35$; total length 1.15 ; apical segment shortly digitiform. 


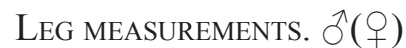

\begin{tabular}{ccccccc}
\hline & Femur & Patella & Tibia & Metatarsus & Tarsus & Total \\
\hline Palp & $3.07(3.14)$ & $1.65(1.53)$ & $2.50(2.08)$ & - & $1.07(1.87)$ & $8.29(8.62)$ \\
Leg I & $5.15(3.97)$ & $2.57(2.26)$ & $3.75(2.83)$ & $4.10(2.42)$ & $2.53(1.78)$ & $18.10(13.26)$ \\
Leg II & $4.83(3.46)$ & $2.33(2.21)$ & $3.30(2.23)$ & $3.83(2.07)$ & $2.55(1.74)$ & $16.84(11.71)$ \\
Leg III & $3.75(2.54)$ & $1.73(1.72)$ & $2.35(1.37)$ & $3.57(1.67)$ & $2.47(1.52)$ & $13.87(8.82)$ \\
Leg IV & $4.81(3.62)$ & $2.27(2.27)$ & $3.77(2.93)$ & $4.36(2.54)$ & $2.55(1.61)$ & $17.86(12.97)$ \\
\hline
\end{tabular}

Female (paratype from Babatag Mts)

Habitus. As in Fig. 18.

Measurements. TBL 20.10, CL 5.65, CW 4.32, LL 0.85, LW 1.63, SL 3.05, CW 2.52.

CoLour. Darker than that in male: carapace and legs dorsally ferruginous yellow; carapace with caput slightly darker and anterior edge including clypeus mid-brown; eye tubercle with blackish brown spots around AMEs and lateral eyes widely spaced; chelicerae reddish brown; sternum, legs ventrally, genital area and spinnerets light brownish yellow; labium, maxillae and palps with similar but slightly darker colouration; abdomen light ferruginous grey, dorsally with diffuse brownish pattern consisting of rather narrow median stripe and five pairs of lateral chevrons.

Prosoma. Clypeus and low though distinct eye tubercle as shown in Fig. 66. Eye diameters and interdistances: AME 0.15(0.24), ALE 0.24, PLE 0.14, PME 0.12, AME-AME 0.21(0.13), ALE-AME 0.18(0.14), ALE-PLE 0.23, PLE-PME 0.06, PME-PME 0.55. Cheliceral rastellum composed of 2530 spikes located in front of fang base and on low mound. Each cheliceral furrow with 6 uniform large promarginal teeth and 2-5 smaller retromarginal teeth. Sternum labium and maxillae as shown in Fig. 107. Maxillae broad, with 9-11 cuspules each.

LEgs. Scopula: distal on metatarsi I-II, entire on palpal tarsus and tarsi I-II, elsewhere absent. Trichobothria: 2 rows of 7-9 each on tibiae, $12-14$ on metatarsi, 17-18 on tarsi I and II, 12-14 on tarsi III and IV, 9-10 on papal tarsus. Trichobothrial bases and tarsal organ of leg I as shown in Figs 163 and 164, respectively. Palpal claw with 4 promarginal teeth. PTC I-II: outer and inner margins with 5-6 teeth. PTC III with 3 teeth on outer, 1 tooth on inner margins. PTC IV with 3 teeth on outer, 0(1) teeth on inner margins.

Sination. Palp: femur pd1, patella p1, tibia p5, v8-9; tarsus v2. Leg I: tibia p1-2, v5; metatarsus v5-6. Leg II: tibia p1-2, v5; metatarsus p1, v6-7. Leg III: patella p2-3; tibia d1, p1, r2, v3-4; metatarsus d2, p3, r2, v7. Leg IV: tibia r1, v6-7; metatarsus r1, v7-8. All femora with dorsal row of 5-7 long and thick bristles and with 1-3 lesser developed setae pro- and retrodorsally; patellae I, II and IV, and tarsi I-IV aspinose.

Spermathecae. Three-branched with thin stalks and well-sclerotised receptacles (Fig. 233).

SPINNERETS. See Fig. 274. PMS: length 0.49, diameter 0.20. PLS: maximal diameter 0.70; length of basal, medial and apical segments $0.93,0.48,0.45$; total length 1.86 ; apical segment triangular.

\section{Variation}

The length of the carapace varies from 4.30 to 5.53 in females and the number of maxillary cuspules ranges from 8 to 19. In females from Tajikistan (Varzob Canyon), the number of promarginal and retromarginal teeth may reach 8 and 6 , respectively (see Fig. 80). The structure of the spermathecae appears to be almost the same in females collected from the different localities (Figs 233-234). 


\section{Habitat}

The species occurs in the foothills covered with deciduous shrub with Prunus spp. and Pistacia vera L. (Fig. 310), and in the middle mountain belt. In the latter case the spiders were found inhabiting open forest biotopes dominated by Juniperus seravschanica Kom. and Acer spp. (Fig. 311).

\section{Distribution}

Southeastern Uzbekistan and western Tajikistan (Fig. 370).

\section{Anemesia sogdiana species group}

\section{Diagnostic characters}

Males in the A. sogdiana group resemble males of the A. tubifex species group in possessing a visibly swollen palpal tibia. However, they differ from the members of the latter group in having a noticeably longer and narrowly tapering embolus. Females can be distinguished in having the specific shape of undivided spermathecae with relatively long stalks narrowed apically.

\section{Species included}

Two species: A. oxiana sp. nov. and A. sogdiana sp. nov.

Anemesia oxiana sp. nov.

urn:1sid:zoobank.org:act:024DFB3E-198A-441A-B075-192CE5DA5E15

Figs $6,19,28-29,53,67,81,95,108,122-123,151-153,178,199-202,241-244$, 275-276, 292-294, 312-313, 318-321, 331, 357, 370

\section{Diagnosis}

Males and females of Anemesia oxiana sp. nov. differ from all known congeners by their contrasting dorsal abdominal pattern with the unusually large and wide anterior transverse stripe (Figs 6 and 19). Males of A. oxiana sp. nov. can be also distinguished from other Anemesia males by a short and broad palpal bulb provided with a long, thin and slightly curved embolus (Figs 199-202); the conspecific females possess the characteristic long and stout entire spermathecae (Figs 241-244).

\section{Etymology}

Oxiana (ancient Greek ' $\Omega \xi \iota \nu v \eta^{\prime}$ ') is the name of an historical area in Central Asia that existed in the antiquity and is applied to the territory located alongside the Oxus (i.e., the recent Amu-Darya River and its main component Panj River, forming the Afghanistan-Tajikistan border) which corresponds to the known range of this species. This specific epithet is a noun in apposition to the genus name, the gender is feminine.

\section{Material examined}

Holotype

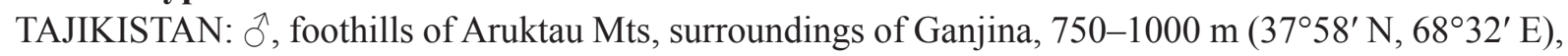
13-19 Apr. 1986, S. Zonstein leg. (SMNH).

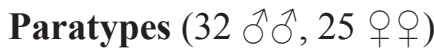

TAJIKISTAN: $1 \hat{\jmath}, 5 q$, , same collection data as for the holotype (SMNH); $1 \hat{\jmath}, 5 q q$, same collection data as for preceding but 13 Apr. $1988(\mathrm{SMNH}) ; 2 \widehat{\jmath}, 2$ + $\phi$, same collection data as for preceding but 20 Apr 1989 (SMNH); 1 ô, same collection data as for preceding but 18 Apr. 1992 (SMNH); 7 우, Aruktau Mts, foothills, Garavuti, 450 m, Mar. 1967, A. Kononenko leg. (SMNH); 1 §, Rangentau 
Mts, 2 km NNW Fahrabad Pass, 1220 m, 38²0.5' N, 6843' E, 27 Apr. 2002, S. Zonstein leg. (SMNH);

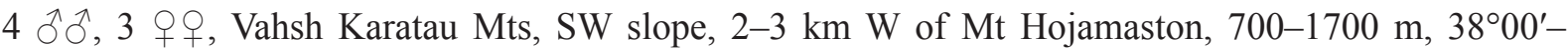

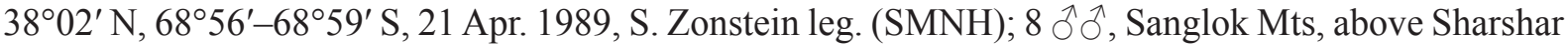

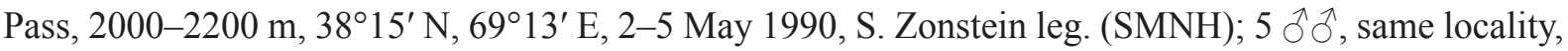
7 May 1991, S. Zonstein and S. Ovchinnikov leg. (SMNH); 7 §ో $\delta$, 1 q, Panj Karatau Mts, Mt Astana,

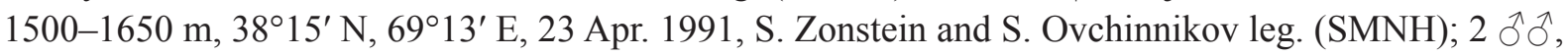

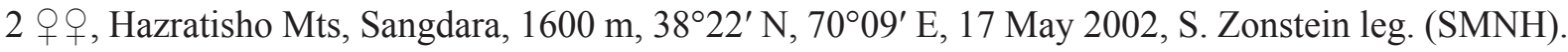

Additional material ( $9+q, 4$ juvs)

TAJIKISTAN: 4 우의, surroundings of Dahana-Kiik, 900-1000 m (38¹2' N, 68³9' E), 10-20 Mar. 1967, E. Blagovechshenskaya leg. (MIZW); 1 क, same collection data as for preceding but $800 \mathrm{~m}$ (MIZW); 4 juvs, Beshkent Valley, 20-23 Apr. 1967, E. Andreeva leg. (MIZW); 2 우, Lower Vahsh Valley, Tigrovaya Balka (Tiger Gorge) Reserve, sands, 350-400 m, 25 Jul. 1968, E. Andreeva leg. (MIZW); 1 , Aruktau Mts, Ganjina, 24 Jun. 1969, E. Andreeva leg. (MIZW); 1 q, same locality, in burrow (depth $32 \mathrm{~cm}$ ), 2 Nov. 1969, E. Andreeva leg. (MIZW).

\section{Description}

Male (holotype)

Habitus. See Fig. 6.

MeAsurements. TBL 18.70, CL 7.97, CW 6.82, LL 0.70, LW 1.27, SL 3.70, SW 3.32.

Colour. Carapace intensely foxy brown with darker rufous brown caput; eye tubercle brownish black; chelicerae, all femora, palpal patella, cymbium, patellae and tibiae I and II dark foxy brown; palpal tibia, patellae and tibiae III and IV, metatarsi and tarsi I-IV, sternum, labium and maxillae light yellowish brown; sternal sigillae dark brown; abdomen dorsally light brownish grey with darker brown pattern consisting of median longitudinal spot intersected with wide transverse fascia in basal third and five pairs short chevron-like lateral spots inclined backward; dorsal abdominal surface and spinnerets pale yellowish brown.

Prosoma. Clypeus and eye tubercle as shown in Fig. 53. Eye diameters and interdistances: AME 0.21(0.30), ALE 0.42, PLE 0.23, PME 0.15, AME-AME 0.22(0.14), ALE-AME 0.15(0.11), ALE-PLE 0.17, PLE-PME 0.07, PME-PME 0.62. Cheliceral rastellum composed of 20-25 spikes located in front of fang base. Each cheliceral furrow with 9-10 promarginal teeth and 3-9 small and acute teeth confined to basal retromargin. Sternum, labium and maxillae as shown in Fig. 95. Sternal sigilla distant from sternum edge; posterior pair long oval or comma-shaped. Maxillae with 49-50 cuspules (forming wide and laterally extended cuspular area) each.

Legs. Tibia and metatarsus I as shown in Fig. 122. Scopula: distal $1 / 3$ on metatarsi I and II, distal 1/5 on metatarsus III, entire on tarsi I and II, widely divided on tarsus III, vestigial on tarsus IV. Trichobothria: two rows of 9-11 each on tibiae, 13-15 on metatarsi, 14-17 on tarsi, 10-11 on cymbium. PTC I-III with $7-8$ teeth on each margin. PTC IV with 5-6 teeth on outer, and 6-7 teeth on inner margins.

SPination. Palp: femur d4-5, pd1, rd1; patella pd2; tibia d1, pd1, p3, r1, v6; tarsus d11-13. Leg I: femur d5-6, pd3, rd1; patella pd1; tibia p4, r3, v8+m; metatarsus p3, r1, v5. Leg II: femur d5-6, pd3, rd3; patella pd1; tibia p3, r2-3, v10; metatarsus p3, v7. Leg III: femur d5-6, pd3, rd3; patella p3, r1; tibia d2, p3, r3, v8-9; metatarsus d2, p3, rd3, v9; tarsus p1. Leg IV: femur d6-9, p3-4, r3; patella p2, r1; tibia d1, p3, r2-3, v10; metatarsus rd1-4, p4, r3, v11-13; tarsus p1, r1. Tarsi I and II lack spines. 
PaLP. Tibia, cymbium and palpal organ as shown in Figs 178 and 199-200. Palpal tibia moderately long, slightly swollen and spinose; cymbium with few apical spines (Fig. 178). Palpal organ with broad asymmetric bulb and with long, tapering and slightly curved embolus (Figs 199-200).

SPINNERETS. See Fig. 275. PMS: length 0.85, diameter 0.34. PLS: maximal diameter 0.40; length of basal, medial and apical segments 1.32, 0.88, 0.57; total length 2.77; apical segment triangular.

LEG MEASUREMENTS. $\widehat{\partial}(+)$

\begin{tabular}{ccccccc}
\hline & Femur & Patella & Tibia & Metatarsus & Tarsus & Total \\
\hline Palp & $4.55(5.26)$ & $2.44(2.33)$ & $3.82(3.41)$ & - & $1.47(3.03)$ & $12.28(14.03)$ \\
Leg I & $7.82(7.28)$ & $3.86(3.97)$ & $5.77(5.18)$ & $6.04(4.14)$ & $3.42(2.65)$ & $26.91(23.22)$ \\
Leg II & $7.21(6.43)$ & $3.53(3.75)$ & $5.08(4.17)$ & $5.54(3.98)$ & $3.43(2.66)$ & $24.79(20.99)$ \\
Leg III & $5.94(5.26)$ & $2.90(3.35)$ & $4.07(4.21)$ & $5.84(4.26)$ & $3.65(3.12)$ & $22.40(20.20)$ \\
Leg IV & $7.62(7.17)$ & $3.16(4.04)$ & $6.17(5.43)$ & $7.42(5.38)$ & $4.06(3.36)$ & $28.43(25.43)$ \\
\hline
\end{tabular}

Female (paratype from Mt Hojamaston)

Habitus. As in Fig. 19.

Measurements. TBL 26.60, CL 9.68, CW 8.10, LL 1.20, LW 1.95, SL 5.28, SW 4.22.

Colour. Differs from that of male in some details: carapace and legs light foxy brown; sternum, labium and maxillae slightly paler; caput darkened, but anterior part with pair of symmetric lighter, yellowish spots located laterally from eye tubercle; blackish brown spots surrounding AMEs and lateral eyes semifused; chelicerae dark carmine red; abdomen light greyish yellow, with dark brown pattern consisting of rather narrow transverse longitudinal spot crossed by wide transverse fascia and six pairs of lateral chevrons posteriorly; spinnerets light greyish yellow.

Prosoma. Clypeus and eye tubercle as shown in Fig. 67. Eye diameters and interdistances: AME, 0.22(0.31), ALE, 0.36, PLE, 0.20, PME: 0.16, AME-AME 0.32(0.24), ALE-AME 0.27(0.23), ALEPLE 0.29, PLE-PME 0.11, PME-PME 0.93. Cheliceral rastellum composed of numerous spikes located on frontal cheliceral surface, not on mound. Each cheliceral furrow with 9 promarginal teeth and 4-5 medium-sized mesobasal denticles. Sternum, labium and maxillae as shown in Fig. 108. Sternal sigilla distant from sternum edge; posterior pair long oval or comma-shaped. Maxillae with 69-78 cuspules (forming, as in conspecific male, wide oval cuspular area) each.

LeGs. Scopula: distal on metatarsi I-II, entire on palpal tarsus and tarsi I and II, elsewhere absent. Trichobothria: 2 rows of 11-14 each on tibiae, 16-19 on metatarsi, 18 on palpal tarsus, 24-27 on tarsi I and II, 18-22 on tarsi III and IV. Palpal claw with 4 promarginal teeth (as shown in Fig. 152). PTC I-II with 4-6 teeth on each margin (as in Figs 152-153). PTC III with 4-5 teeth on outer, 2-3 teeth on inner margins. PTC IV with 4-5 and 0-2 teeth, respectively.

SPINATIOn. Palp: pd1; patella p2; tibia p2, v12-13; tarsus v3-4. Leg I: femur pd3; patella p2; tibia p2; v5; metatarsus v3-6. Leg II: femur pd3; patella p2; tibia p2, v4-5; metatarsus p1, v5-7. Leg III: femur pd3, rd3; patella p1-2; tibia d1, p2, r2, v6; metatarsus d1, p3, r3, v7; tarsus p2. Leg IV: femur pd2-3; tibia r2, v7; metatarsus p3, rd2, v7. All femora with one basodorsal spine and few dorsal bristles; patella IV and tarsi I, II and IV aspinose.

SpermatheCAe. Entire, with long and subapically narrowed stalks (Fig. 242). 
SPINNERETS. See Fig. 276. PMS: length 1.05, diameter 0.53. PLS: maximal diameter 1.03; length of basal, medial and apical segments $1.75,1.20,0.62$; total length 3.57 ; apical segment triangle. Spigots as shown in Figs 292-294.

\section{Variation}

The length of the carapace varies from 7.10 to 8.13 in males and from 7.78 to 10.04 in females. Colouration, shape of the embolus and configuration of the spermathecae vary through specimens very narrowly (see Figs 28-29, 199-202, 241-244). In some females, the cheliceral furrow may be armed with 2-3 retromarginal teeth (see Fig. 81). The number of maxillary cuspules may range from 40 to 55 in males and from 60 to 85 in females. Tarsus III with 1-2 spines (most often occupying prolateral position); tarsus IV mostly aspinose (in some specimens with one prolateral spine).

\section{Habitats}

The most widespread and common congener in southern Tajikistan, A. oxiana sp. nov. occurs in almost all the main community types represented there (including the true desert communities in lowlands): from riverside sand deserts (Tigrovaya Balka) and piedmont semi-deserts (Garavuti) through steppe and open low forest (Ganjina, Fahrabad Pass, Vahsh Karatau Mts, Panj Karatau Mts) to forested stations in the midland mountain belt (Sanglok Mts, Hazratisho Mts).

\section{Distribution}

South Tajikistan (Fig. 370).

Anemesia sogdiana sp. nov.

urn:1sid:zoobank.org:act:15FFF793-3F27-4659-BE0D-15674535BD7A

Figs 7, 20, 30, 54, 68-69, 82, 96, 109, 124, 133-137, 154-155, 165-168, 179, 203-205, 235-240, 277-278, 295-297, 314-316, 332, 369

Brachythele birulai - Charitonov 1969: 66 (つ). Misidentified, not Brachythele birulai Spassky, 1937.

\section{Diagnosis}

In habitus, Anemesia sogdiana sp. nov. is largely similar to A. pococki sp. nov. and especially to $A$. andreevae sp. nov., but differs from them by the long, thin and gradually curved embolus in males (Figs 203-205, cf. Figs 193-194, 197-198) as well as by the entire and narrowed subapically spermathecae in females (Figs 235-240, cf. Figs 228-229, 233-234).

\section{Etymology}

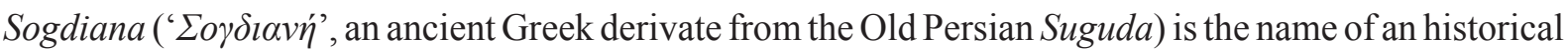
area in Central Asia that existed in the late antiquity and in the early Middle Ages (IV ${ }^{\text {th }}$ century BC - IX $^{\text {th }}$ century $\mathrm{AD}$ ) and is applied to the territory located between the Amu-Darya and Syr-Darya Rivers which corresponds to the known range of this species. This specific epithet is a noun in apposition to the genus name, the gender is feminine.

\section{Material examined}

Holotype

UZBEKISTAN: $\widehat{\partial}$, northwestern tip of Zeravshan Mts, Amankutan Pass, $1670 \mathrm{~m}, 39^{\circ} 17^{\prime} 27^{\prime \prime} \mathrm{N}$, 66 54'01" E, 5 May 1995, S. Zonstein leg. (SMNH). 
Paratypes $(4 \hat{\partial} \widehat{\partial}, 17$ $\phi$ 早)

UZBEKISTAN: $1 \hat{\gamma}$, same collection data as for the holotype (SMNH); $1 \hat{\delta}$, same locality, 16501750 m, 39¹8' N, 66²54' E, 11 Apr. 1966, V.F. Bakhvalov leg. (SMNH); 1 q, same collection data as for preceding but 7 Apr. 1989, S. Zonstein leg. (SMNH); 1 §, 9 우, same collection data as for preceding but 27 Apr. 1993 (SMNH); 2 오, Zeravshan Mts, foothills $10 \mathrm{~km} \mathrm{~N}$ of Kitab, $1000 \mathrm{~m}, 39^{\circ} 12^{\prime} \mathrm{N}$, 6654' E, 9 Apr. 1989, S. Zonstein leg. (SMNH); 1 ठ, Zeravshan Mts, Jindy-Daria Canyon, Hojakurgan, 1400-1800 m, 39 $11^{\prime} \mathrm{N}, 67^{\circ} 17^{\prime} \mathrm{E}, 14$ Apr. 1990, S. Zonstein leg. (SMNH); 2 우, same collection data as for preceding but 9 Apr. 1991 (SMNH); 2 우, same collection data as for preceding but 26 Apr. 1992 (SMNH).

Additional material ( $3 \hat{\partial} \widehat{\partial}, 45$ $q$ q, 2 q $q$ subad.)

UZBEKISTAN: $2 \hat{\partial} \hat{\partial}$, northwestern slope of Hissar Mts, surroundings of Ishkent, $1100-1300 \mathrm{~m}$

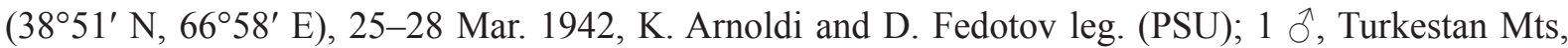
foothills near Zaamin ( $\left.700 \mathrm{~m}, 39^{\circ} 57^{\prime} \mathrm{N}, 68^{\circ} 23^{\prime} \mathrm{E}\right), 8$ Apr. 1980, F. Khassanov leg. (SMNH); 2 $q$ subad., northwestern ending of Nuratau Mts, Zafarabad (Kokcha), $400 \mathrm{~m}, 40^{\circ} 32^{\prime} \mathrm{N}, 65^{\circ} 02^{\prime} \mathrm{E}, 7 \mathrm{Apr}$. 1990, S. Zonstein leg. (SMNH); 32 q + , Baisuntau Mts, $2 \mathrm{~km}$ E Shurob, 1050-1200 m, 38 $12^{\prime} \mathrm{N}, 67^{\circ} 00^{\prime} \mathrm{E}$, 15 Apr. 1987, S. Zonstein leg. (SMNH, ZMMU); 3 q $ᄋ$, Hissar Mts, Majanak 10 km N Kokbulak, 25002650 m, 38 $41^{\prime}$ N, 66 $56^{\prime}$ E, 6 Jun. 1997, S. Zonstein leg. (SMNH); 3 qo , Kugitang Mts, Baglydara canyon, 1300-1800 m, Jul. 1983, A.B. Nenilin leg. (SMNH); 4 우, same locality, 37 $53^{\prime} \mathrm{N}, 66^{\circ} 40^{\prime} \mathrm{E}$, 1700 m, 15 May 1985, S. Zonstein leg. (SMNH); 1 ㅇ, same locality, 8 Apr. 1989, S. Zonstein leg.

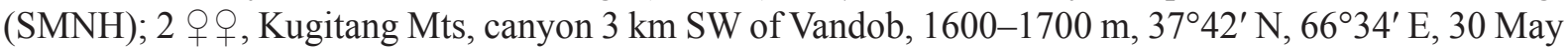
1995, S. Zonstein leg. (SMNH).

TAJIKISTAN: 3 + 9 , southern slope of Hissar Mts, foothills $8 \mathrm{~km}$ N Dushanbe, Varzob canyon, $1100 \mathrm{~m}$, $38^{\circ} 40^{\prime}$ N, $68^{\circ} 47^{\prime}$ E, 25 May 2002, S. Zonstein leg. (SMNH).

\section{Description}

Male (holotype)

Habitus. See Fig. 7.

Measurements. TBL 13.40, CL 5.15, CW 4.53, LL 0.60, LW 0.99, SL 2.86, SW 2.28.

CoLour. Carapace light yellowish brown with anterior edge darker and thoracic part paler; chelicerae, majority of palps and legs light yellowish brown; sternum, labium, maxillae and leg tarsi paler; eye tubercle blackened; abdomen dorsally yellowish grey with brown pattern consisting of moderately wide median longitudinal spot and few paired transverse and slightly inclined short stripes, ventral part of abdomen pale yellowish grey, spinnerets pale brownish yellow.

Prosoma. Clypeus and eye tubercle as in Fig. 54. Eye diameters and interdistances: AME 0.15(0.21), ALE 0.30, PLE 0.15, PME 0.06, AME-AME 0.15(0.09), ALE-AME 0.15(0.12), ALE-PLE 0.11, PLEPME 0.05, PME-PME 0.48. Weak cheliceral rastellum composed of several long bristles lacking tips and grouped in one transverse row in front of fang base and in rastellar mound. Each cheliceral furrow with 8-9 promarginal teeth and 0-1 small retrobasal teeth. Sternum, labium and maxillae as shown in Fig. 96. Sternal sigilla small, posterior pair long-oval and distant from sternum edge. Maxillae with 7-9 cuspules each.

LEGs. Tibia and metatarsus I as in Fig. 124. Scopula: entire and distal on metatarsi I and II, narrowly divided on tarsi I and II, mixed and widely divided on tarsus III, vestigial on tarsus IV. Trichobothria: two rows of 8-9 each on tibiae, 11-13 on metatarsi, 12-14 on tarsi, 10 on cymbium. PTC I-II: outer and inner margins with 6-7 teeth each. PTC III with 6-7 and 5-6; PTC IV with 6 and 3, respectively. 
Spination. Palp: femur d3, pd1; patella pd1; tibia p3, pv1; tarsus d7-8. Leg I: femur d5, pd3; patella pd1; tibia pd3, p1, r3, v6-7+m; metatarsus d1, p2, v1. Leg II: femur d5, pd3; patella p1; tibia p3, v8; metatarsus d2, p4, v7. Leg III: femur d4, p3, r2; patella p3, r1; tibia d1, p3, r3, v7; metatarsus d2, p4, r3, v8; tarsus p1-2. Leg IV: femur d5, r1; tibia d1, p3, r3, v7; metatarsus p4, r4, v8-9; tarsus p1. Patella IV and tarsi I-II unarmed.

PaLP. Tibia, cymbium and palpal organ as shown in Figs 179, 204-205. Tibia relatively short, swollen, and aspinose (Fig. 179). Palpal organ with long, tapering and slightly curved embolus (Figs 204-205).

SinNERETS. See Fig. 277. PMS: length 0.44, diameter 0.16. PLS: maximal diameter 0.54; length of basal, medial and apical segments $0.92,0.70,0.67$; total length 2.29; apical segment short-digitiform.

LEG MEASUREMENTS. $\widehat{\partial}(+)$

\begin{tabular}{ccccccc}
\hline & Femur & Patella & Tibia & Metatarsus & Tarsus & Total \\
\hline Palp & $3.09(4.03)$ & $1.65(1.91)$ & $2.49(2.54)$ & - & $1.06(2.23)$ & $8.29(10.71)$ \\
Leg I & $5.15(5.42)$ & $2.58(3.06)$ & $3.76(3.77)$ & $4.11(3.18)$ & $2.52(2.17)$ & $18.12(17.60)$ \\
Leg II & $4.83(4.56)$ & $2.34(2.63)$ & $3.31(2.98)$ & $3.82(2.76)$ & $2.53(2.09)$ & $16.83(15.02)$ \\
Leg III & $3.77(3.32)$ & $1.74(1.87)$ & $2.34(1.85)$ & $3.57(2.48)$ & $2.48(1.93)$ & $13.90(11.45)$ \\
Leg IV & $4.79(4.61)$ & $2.26(2.55)$ & $3.78(3.68)$ & $4.37(3.52)$ & $2.65(2.17)$ & $17.85(16.53)$ \\
\hline
\end{tabular}

Female (paratype from Amankutan)

Habitus. See Fig. 20.

MeAsurements. TBL 16.50, CL 6.93, SW 5.38, LL 0.87, LW 1.33, SL 3.30, SW 2.97.

Colour. Carapace and legs dorsally light yellowish foxy brown; cephalic part darkened, medium foxy brown; eye tubercle with blackish brown spots around AMEs and lateral eyes; chelicerae reddish brown; sternum, labium, maxillae and legs ventrally pale brownish yellow; abdomen light greyish brown with dark brown dorsal pattern consisting of wide median longitudinal spot and six pairs of lateral chevrons; spinnerets very pale greyish brown.

Prosoma. Clypeus and eye tubercle as in Fig. 68. Eye diameters and interdistances: AME 0.18(0.24), ALE 0.38, PLE 0.20, PME 0.15, AME-AME 0.18(0.12), ALE-AME 0.20(0.17), ALE-PLE 0.15, PLEPME 0.04, PME-PME 0.52. Cheliceral rastellum composed of about 30 spikes located mostly on low mound. Each cheliceral furrow with 8-9 promarginal teeth and one smaller retrobasal tooth. Sternum, labium and maxillae as shown in Fig. 109. Sternal sigilla minute and oval, posterior pair long-oval and distant from sternum edge. Maxillae with 14-16 cuspules each.

Spination. Palp: femur pd2; patella p1; tibia p5, v10-12; tarsus v2-3. Leg I: patella p3; tibia v7-8; metatarsus p1, v8-9. Leg II: patella p1; tibia p3, v7-8; metatarsus p2-3, v9-10. Leg III: patella p3; tibia d1; p1, r1, v7; metatarsus pd3, p4, dr3, v7; tarsus p2, v1. Leg IV: tibia v9-10; metatarsus p1, r1, v8; tarsus v2. All femora dorsally with $4-6$ true spines and several bristles; patella IV and tarsi I and II aspinose.

Legs. See Figs 133-137. Scopula entire and distal on metatarsi I and II, entire on palpal tarsus, narrowly divided on tarsi I and II, elsewhere absent. Trichobothria: two rows of 7-9 each on tibiae, 10-12 on metatarsi, 12-14 on tarsi, 10 on palpal tarsus. Palpal claw with 4 promarginal teeth. PTC I-II with 4-5 teeth on each margin. PTC III with 4-5 teeth on outer, and 2-3 teeth on inner margins; PTC IV with 3-4 and 1-2 teeth, respectively. Difference in dentition between PTC I and PTC IV as shown in Figs $154-155$. 
SPERMATHECAE. Moderately long, entire, and narrowed apically. See Fig. 236.

SPINNERETS. See Fig. 278. PMS: length 0.62, diameter 0.32. PLS: maximal diameter 0.62; length of basal, medial and apical segments $0.98,0.70,0.63$; total length 2.33; apical segment triangular. Spigots as shown in Figs 295-297.

\section{Variation}

The length of the carapace varies from 4.87 to 5.21 in males and from 4.47 to 7.33 in females. Colouration varies through specimens very narrowly (see Fig. 30). Throughout the specimens, both PLE and PME may be reduced or even lost (Fig. 69). In some females, the cheliceral furrow may be armed with 2-3 retromarginal teeth (see Fig. 82). In conspecific males, the shape of the palpal organ is almost identical (Figs 203-205). Spermathecae show some variations and can feature with straight or bent stalks (Figs 235-240).

\section{Habitat}

The known records mostly correspond to the midland mountain belt although the species can also occur in both the piedmont semi-desert (Zafarabad) and the highlands (Majanak); the preferred biotopes are represented by steppes and open forest communities with different species of Juniperus L., Crataegus Tourn. ex L. and Acer L. (see Figs 314-316).

\section{Distribution}

Central and southern Uzbekistan, and western Tajikistan (Fig. 369).

\section{Note}

Charitonov (1969) listed five males of this species collected by K. Arnoldi and D. Fedotov in 1942 in the surroundings of Ishkent as Brachythele birulai Spassky. A detailed examination of the spider collection at the Perm University $(1987,1988)$ revealed the presence of only two appropriate male specimens sampled and labelled according to the mentioned record data.

\section{Anemesia castanea species group}

\section{Diagnostic characters}

Males of the A. castanea species group resemble those of the A. pallida species group in possessing lateral spines on the cymbium. However, they differ from the members of the latter group in possessing a considerably longer palpal tibia and embolus (Figs 180-181, 206-210; cf. Figs 182-183, 211-214). Females are distinguished by the specific shape of the normally entire spermathecae provided with long cylindrical stalks (see Figs 245-249).

\section{Species included}

A. castanea sp. nov. and A. karatauvi (Andreeva, 1968).

Anemesia castanea sp. nov.

urn:1sid:zoobank.org:act:94364192-0859-45D4-9DB9-5037FD7EE663

Figs $8,21,55,70,97,110,125,180,206-208,245,279,318-321,371$

\section{Diagnosis}

Anemesia castanea sp. nov. resembles A. karatauvi in habitus, as well as in possessing the similar looking comma-shaped palpal organ provided with a long, thin and gradually curved embolus in males, and relatively long and slender tapering spermathecae in females. However, in comparison with the latter 
species, males of $A$. castanea sp. nov. have a more slender male palpal tibia, a domed ventral surface of the palpal bulb and a longer embolus (vs stouter tibia, flattened surface, and shorter embolus; Figs 180, 206-208, cf. Figs 181, 209-210). Females of A. castanea sp. nov. differ from those of $A$. karatauvi in having the closer spaced and more diverged spermathecae (Fig. 245, cf. Figs 246-249), as well as by a larger number of the maxillary cuspules (65-70 vs 40-55) and by a better developed cheliceral rastellum.

\section{Etymology}

The specific name is a derivative (using the feminine gender) of the Latin adjective 'castaneus' meaning 'chestnut-brown'; the name is derived from the colouration of the specimens.

\section{Material examined}

\section{Holotype}

TAJIKISTAN: ${ }^{\wedge}$, foothills of Aruktau Mt. R., $0.5 \mathrm{~km}$ SE of Ganjina Village, $750 \mathrm{~m}, 37^{\circ} 58^{\prime} \mathrm{N}, 68^{\circ} 32^{\prime} \mathrm{E}$, 14 Apr. 1991, S. Zonstein leg. (SMNH).

\section{Paratypes}

TAJIKISTAN: $4 \hat{\jmath}$ ô same collection data as for the holotype but S. Zonstein and S. Ovchinnikov leg. (SMNH).

\section{Additional material}

TAJIKISTAN: 1 q, Ganjina, under stone, 9 Apr. 1967, E. Andreeva leg. (MIZW), 1 (dried), Lower Vahsh Valley, Tigrovaya Balka (Tiger Gorge) Reserve, 12-18 Apr. 1967, E. Andreeva leg. (MIZW). See note below.

\section{Description}

Male (holotype)

HaBitus. See Fig. 8.

\section{MeAsurements. TBL 15.90, CL 6.15, CW 5.54, LL 0.56, LW 1.07, SL 2.96, SW 2.77.}

Colour. Carapace almost uniformly light chestnut brown; chelicerae, leg I entirely and most part of palps and legs II-IV light-medium to dark brown; sternum, labium, maxillae and leg tarsi paler, brownish orange; eye tubercle black; abdomen dorsally yellowish grey with dark brown pattern consisting of dentate median stripe anteriorly and few paired transverse and slightly inclined chevrons posteriorly; ventral part of abdomen and spinnerets pale yellowish grey.

Prosoma. Clypeus and eye tubercle as in Fig. 55. Eye diameters and interdistances: AME 0.15(0.23), ALE 0.25, PLE 0.22, PME 0.18, AME-AME 0.21(0.13), ALE-AME 0.12(0.08), ALE-PLE 0.12, PLEPME 0.02, PME-PME 0.47. Cheliceral rastellum consists of about 20-25 spikes in front of fang base and on very low mound. Each cheliceral furrow with 7 promarginal teeth and 5-7 smaller retromarginal teeth. Sternum, labium and maxillae as shown in Fig. 97. Sternal sigilla small oval, posterior pair considerably distant from sternum edge. Maxillae with ca 35 cuspules each.

Legs. Tibia and metatarsus I as in Fig. 125. Scopula: distal and entire on metatarsi I and II, narrowly divided on tarsi I and II, widely divided on tarsi III, absent on tarsi IV. Trichobothria: two rows with 9-11 each on tibiae, 20-24 on metatarsi, 16-20 on tarsi, 13-14 on cymbium. PTC I-II with 11-13, PTC III-IV with 9-10 teeth on each margin, respectively.

Spination. Palp: femur d4, pd4, rd1; patella p1; tibia d1, p3-4, pv3, rv7; tarsus d6-7. Leg I: femur d4, pd3-4, rd3; tibia p3-4, r2, v9+m; metatarsus pd3, v5-7. Leg II: femur d4, pd3-4, rd3-4; tibia p3, 
v7-8; metatarsus p4, v5-6; tarsus p2. Leg III: femur d4, pd3, rd3; patella p3, r2; tibia d2-3, p3, r3, v7; metatarsus dp4, r3-4, v7-8; tarsus p2-4. Leg IV: femur d4, p3, r2-3; patella r1; tibia d1, p3, r3, v8-9; metatarsus d6-7, p5, r4-5, v9-10; tarsus p2, r2. Patellae I, II, and tarsus I aspinose.

Palp. Tibia, cymbium and palpal organ as shown in Figs 180, 207-208. Palpal tibia very long, slender and cylindrical, with spines and numerous stout bristles (Fig. 180). Palpal organ with embolus very long, tapering and slightly curved (Figs 207-208).

SpinNerets (see Fig. 279). PMS: length 0.46, diameter 0.20. PLS: maximal diameter 0.57; length of basal, medial and apical segments $0.94,0.68,0.76$; total length 2.38 ; apical segment shortly digitiform.

LEG MEASUREMENTS. $\widehat{\partial}(+)$

\begin{tabular}{ccccccc}
\hline & Femur & Patella & Tibia & Metatarsus & Tarsus & Total \\
\hline Palp & $3.85(4.54)$ & $1.91(2.01)$ & $3.39(2.97)$ & - & $1.25(2.91)$ & $10.40(12.43)$ \\
Leg I & $6.95(6.97)$ & $3.12(3.84)$ & $5.61(4.98)$ & $5.51(4.48)$ & $3.18(2.76)$ & $24.37(23.03)$ \\
Leg II & $6.09(5.93)$ & $2.63(2.82)$ & $4.56(4.05)$ & $4.98(3.78)$ & $3.12(2.75)$ & $21.38(19.33)$ \\
Leg III & $4.96(4.48)$ & $1.97(2.51)$ & $3.43(2.84)$ & $4.40(3.61)$ & $3.42(2.65)$ & $18.18(16.09)$ \\
Leg IV & $6.07(6.43)$ & $2.54(3.22)$ & $5.18(4.86)$ & $6.91(5.01)$ & $3.78(3.31)$ & $23.40(22.83)$ \\
\hline
\end{tabular}

Female (from Ganjina)

Habitus. See Fig. 21.

MeAsurements. TBL 25.20, CL 8.39, CW 7.44, LL 1.01, LW 1.60, SL 4.26, SW 4.16.

Colour. As in male.

Prosoma. Clypeus and eye tubercle as shown in Fig. 70. Eye diameters and interdistances: AME 0.15(0.25), ALE 0.32, PLE 0.24, PME 0.26, AME-AME 0.36(0.26), ALE-AME 0.28(0.23), ALE-PLE 0.27, PLE-PME 0.01, PME-PME 0.83. Cheliceral rastellum represented by approximately 40 spikes located in front of fang base and on low mound. Each cheliceral furrow with 9 promarginal teeth and 10-11 smaller retromarginal teeth. Sternum, labium and maxillae as shown in Fig. 110. Sternal sigilla small; posterior pair distant from sternum edge, narrowly oval. Maxillae with ca 70 cuspules each.

LEGS. Scopula dense, occupies $5 / 6$ ventral surface of metatarsus I, distal on metatarsus II, entire on palpal tarsus and tarsus I, widely divided on tarsus II, elsewhere absent. Palpal claw with 5 promarginal teeth. Trichobothria: 2 rows of $10-13$ each on tibiae, $14-17$ on metatarsi, 13-15 on leg tarsi, 13 on palpal tarsus. PTC I-II with 6-7 teeth on each margin. PTC III with 5-6 teeth on outer, 4-5 teeth on inner margins; PTC IV with 4-5 and 0-4 teeth, respectively.

Spination. Palp: femur pd1; patella p2; tibia p2, v14-15; tarsus v2. Leg I: femur pd1; patella p1; tibia v5; metatarsus v5. Leg II: femur pd2; patella p2; tibia p2, v5; metatarsus p2, v5-6. Leg III: femur pd2, rd3; patella p2; tibia d1; p3, r2, v7; metatarsus pd2, p3, rd3, v8-9; tarsus p1, v2. Leg IV: femur rd2; tibia r1, v6; metatarsus pd1, p2, rd2, v7-11; tarsus v2. All femora with 1 basodorsal spine and dorsal row of few bristles. Patella IV, and tarsi I and II aspinose.

SPERMATHECAE. Entire with thin stalks inclined outwards and narrowed subapically (Fig. 245).

SPINNERETS. PMS: length 0.71, diameter 0.34. PLS: maximal diameter 0.80; length of basal, medial and apical segments $1.47,0.73,0.80$; total length 3.00 ; apical segment shortly digitiform. 


\section{Variation}

The length of the carapace varies from 5.80 to 6.25 in males and from 7.73 to 8.39 in females. The colouration varies through specimens very narrowly. The number of maxillary cuspules ranges from 32 to 40 in males and from 65 to 70 in females. The variation in the shape of the palpal organ and the length of the embolus seems to be almost imponderable (see Figs 206-207).

\section{Habitat}

The species occurs in the piedmont sandy desert (Tigrovaya Balka Nature Reserve) and in the woodless steppe foothills near Ganjina. Curiously, despite intensive collecting, $A$. castanea sp. nov. has never been found in the less harsh montane zone of the Aruktau Mts, occupied by A. incana and some other congeners.

\section{Distribution}

The species is known from far southwestern Tajikistan only (Fig. 371).

\section{Notes}

Andreeva (1968) included both conspecific females in the type series of Brachythele karatauvi. To avoid a situation of the same specimen being listed as a paratype in two different species, these females are not included in the types of Anemesia castanea sp. nov., despite definitely belonging to the latter congener.

Anemesia karatauvi (Andreeva, 1968)

Figs 9, 22, 31, 56, 71, 83, 98, 111, 126, 145-146, 169-170, 181, 209-210, 246-249, 280-281, 298-301, 313, 317, 333-336, 362, 371

Brachythele karatauvi Andreeva, 1968: 70, fig. 2a-b (ぷ+

Brachythele karatauvi - Andreeva 1976: 14, figs 6-7 (ぷ). — Brignoli 1983: 123. — Fet 1984: 40. — Zonstein 1985: 159; 1987: 1013.

Anemesia karatauvi - Mikhailov 1996: 77; 1997: 20. — Zonstein 2001: 11; 2004: 352, fig. 6 (q). — Marusik et al. 2014: 3, fig. 10 (ふ).

\section{Diagnosis}

Males of Anemesia karatauvi differ from those of A. castanea sp. nov. by a stouter male palpal tibia, a flattened ventral surface of the palpal bulb and a shorter embolus (vs a slender tibia, a domed surface, and a longer embolus; Figs 181, 209-210, cf. Figs 180, 206-208). Females of $A$. karatauvi can be distinguished from those of $A$. castanea sp. nov. in having less diverged spermathecae which arise more distantly from each other (Figs 246-249, cf. Fig. 245), by relatively larger AME and ALE (Fig. 71, cf. Fig. 70), by a lesser number of the maxillary cuspules (40-55 vs 65-70) and by a weaker cheliceral rastellum.

\section{Type material}

\section{Holotype}

TAJIKISTAN: đ̂, Vahsh Karatau Mts., no locality data, 23-25 Apr. 1967, E. Andreeva leg. (absent in the type series of Brachythele karatauvi kept in MIZW, seems lost and thus not examined)..

\section{Paratypes}

TAJIKISTAN: 7 q + , same collection data as for the holotype (MIZW; examined). See notes below.

Additional material examined $(2 \hat{\partial}, 25$ $+q)$

TAJIKISTAN: 1 ㄱ, 6 우, western slope of Vahsh Karatau Mts, 950-1200 m, 38 $01^{\prime}$ N, 68 $57^{\circ}$ E, $3 \mathrm{~km}$ NNW of Mt Hojamaston, 21-25 Apr. 1989, S. Zonstein leg. (SMNH); 1 $\curvearrowright, 5$ 우, same collection data 
as for preceding but 26 Apr. 1990 (SMNH); 3 q, Vahsh Karatau Mts, $1.5 \mathrm{~km}$ W of Mt Hojamaston, 1040 m, 38 $38^{\circ} 04.6^{\prime} \mathrm{N}, 68^{\circ} 57.2^{\prime}$ E, 24 Apr. 2015, S. Zonstein leg. (SMNH); 9 우, Vahsh Karatau Mts, Chimsai Gorge, 700-1200 m, 3800' N, 68 $56^{\circ}$ E, 22 Apr. 1986, S. Zonstein and A. Zyuzin leg. (SMNH); 2 우, foothills $3 \mathrm{~km} \mathrm{SE}$ of Yavan, 800-1000 m, 38 $8^{\circ} 18^{\prime} \mathrm{N}, 69^{\circ} 05^{\prime} \mathrm{E}, 19$ Apr. 1988, S. Zonstein leg. (SMNH).

\section{Description}

Male (from Mt Hojamaston area)

Habitus. See Fig. 9.

Measurements. TBL 13.10, CL 5.95, CW 5.07, LL 0.63, LW 1.05, SL 2.77, SW 2.53.

COLOUR IN ALCOHOL. Carapace medium foxy brown with anterior edge darker and thoracic part lighter: chelicerae, most part of palps and legs light yellowish brown; sternum, labium, maxillae and leg tarsi paler; eye tubercle blackened; abdomen dorsally yellowish grey with brown pattern consisting of moderately wide median stripe and few paired transverse and slightly inclined short stripes, ventral part of abdomen pale yellowish grey, spinnerets pale brownish yellow.

Prosoma. Clypeus and eye tubercle as in Fig. 56. Eye diameters and interdistances: AME 0.16(0.22), ALE 0.23, PLE 0.19, PME 0.16, AME-AME 0.22(0.16), ALE-AME 0.14(0.11), ALE-PLE 0.14, PLEPME 0.02, PME-PME 0.49. Cheliceral rastellum consists of 20-25 spikes grouped in one transverse row. Each cheliceral furrow with 7 promarginal teeth and 4 smaller retromarginal teeth. Sternum, labium and maxillae as shown in Fig. 98. Sternal sigilla small oval, posterior pair considerably distant from sternum edge. Maxillae with 30-32 cuspules each.

LeGs. Tibia and metatarsus I as in Fig. 126. Scopula: distal and entire on metatarsi I and II, narrowly divided on tarsi I and II, widely divided on tarsi III, absent on tarsi IV. Trichobothria: 2 rows of $8-9$ each on tibiae, $12-14$ on metatarsi, $12-15$ on tarsi, 7 on cymbium. PTC I-II with 7 teeth on each margin. PTC III-IV with 8 teeth on outer and 5-6 teeth on inner margin.

Spination. Palp: femur d4, pd3, rd1; patella pd1; tibia d1, p3, r1, pv2, v6; tarsus d13-16. Leg I: femur d5, pd3, rd1; tibia pd4, p1, r3, v8+m; metatarsus d1, pd2, v6. Leg II: femur d5, pd3, rd1; tibia p3, v8; metatarsus p3, v7. Leg III: femur d4, pd3, rd3; patella p3, r2; tibia d1, p3, r3, v8; metatarsus pd4, p3, r2, v9; tarsus pv3. Leg IV: femur d5, p3, r3; tibia d1, p3, r3, v8; metatarsus pd2, p3, r7, v7; tarsus p2. Patellae I, II and IV, and tarsi I and II aspinose.

Palp. Tibia, cymbium and palpal organ as shown in Figs 181, 209-210. Palpal tibia long, slender, and slightly swollen, with numerous stout bristles (Fig. 181). Palpal organ with embolus tapering and slightly curved (Figs 209-210).

SpINNERETS. See Fig. 280. PMS: length 0.51, diameter 0.22. PLS: maximal diameter 0.53; length of basal, medial and apical segments $0.90,0.65,0.83$; total length 2.38 ; apical segment shortly digitiform.

LEG MEASUREMENTS. $\overbrace{}^{\lambda}(+)$

\begin{tabular}{ccccccc}
\hline & Femur & Patella & Tibia & Metatarsus & Tarsus & Total \\
\hline Palp & $3.87(4.46)$ & $1.84(2.27)$ & $3.37(4.41)$ & - & $1.19(2.84)$ & $10.27(12.98)$ \\
Leg I & $6.47(7.14)$ & $2.98(3.57)$ & $5.23(4.68)$ & $4.94(4.73)$ & $3.13(2.62)$ & $22.75(22.74)$ \\
Leg II & $6.09(5.80)$ & $2.77(3.34)$ & $4.52(3.77)$ & $4.57(4.65)$ & $3.13(2.59)$ & $21.08(20.15)$ \\
Leg III & $4.82(4.26)$ & $2.05(2.65)$ & $3.29(2.58)$ & $4.26(3.59)$ & $3.26(2.66)$ & $17.68(15.74)$ \\
Leg IV & $5.90(5.78)$ & $2.66(3.54)$ & $5.04(4.53)$ & $5.58(5.06)$ & $3.61(2.97)$ & $22.79(21.88)$ \\
\hline
\end{tabular}


Female (from Mt Hojamaston area)

Habitus. See Fig. 22.

Measurements. TBL 23.50, CL 8.07, CW 7.45, LL 0.88, LW 1.53, SL 4.35, SW 3.87.

Colour. Similar to that of male, but darker: caput, palps and anterior legs chestnut-brown; chelicerae dark copper-brown; dorsal abdominal pattern dark brown; in addition to setae, chelicerae covered with tiny copper-coloured iridescent hairs.

Prosoma. Clypeus and eye tubercle as shown in Fig. 71. Eye diameters and interdistances: AME 0.18(0.25), ALE 0.33, PLE 0.22, PME 0.18, AME-AME 0.24(0.18), ALE-AME 0.20(0.17), ALE-PLE 0.20 , PLE-PME 0.04, PME-PME 0.75 . Cheliceral rastellum represented by approximately 20 spikes located in front of fang base and on low mound. Each cheliceral furrow with 7 promarginal teeth and 7 smaller retromarginal teeth (see Fig. 83). Sternum, labium and maxillae as shown in Fig. 111. Sternal sigilla small; posterior pair distant from sternum edge, oval, or of irregular shape, but anyway extended. Maxillae with 43-52 cuspules each.

Legs. Scopula dense, occupies $5 / 6$ ventral surface of metatarsus I, distal on metatarsus II, entire on palpal tarsus and tarsi I-II, elsewhere absent. Trichobothria: 2 rows of 8-12 each on tibiae, 14-18 on metatarsi, 14-18 on leg tarsi, 12 on palpal tarsus. Palpal claw with 3-4 promarginal teeth. PTC I-III with 5-6 teeth on outer, 4-6 teeth on inner margin; PTC IV with 5-6 and 2-3 teeth, respectively.

SPinAtion. Palp: femur pd1; patella d1, p1, pv1, rv2-3; tibia p2, v13-14; tarsus p1, v2-3. Leg I: femur pd1; tibia p1, v4; metatarsus v6. Leg II: femur pd1; tibia p3, v6-7; metatarsus p1, v6. Leg III: femur pd1-3, rd3; patella p3; tibia d1, p3, r1, v6-7; metatarsus pd2, p4, rd3, v7; tarsus p2. Leg IV: femur rd1; tibia rd2, v6-7; metatarsus pd1, p2, rd2, v8-9; tarsus v1. All femora except dorsal row of bristles with 1 basodorsal spine; patellae I, II, and IV, and tarsi I and II aspinose.

SPERMATHECAE. Normally entire with stalks narrowed subapically (Fig. 246).

SinNERETS. See Fig. 281. PMS: length 0.83, diameter 0.35. PLS: maximal diameter 0.85; length of basal, medial and apical segments $1.45,0.87,0.85$; total length 3.63 ; apical segment shortly digitiform.

\section{Variation}

The length of carapace varies from 5.78 to 5.90 in males and from 5.82 to 9.23 in females. The colouration varies through specimens very narrowly. The number of maxillary cuspules ranges from 28 to 32 in males and from 40 to 55 in females. No significant variation in structure of the palpal organ is evident. The spermathecae are generally uniform (Figs 246, 248-249); however, occasionally the stalks are divided subapically (see Fig. 247).

\section{Habitats}

The species occurs in woodless steppe foothills at $700-1000 \mathrm{~m}$, as well as in the scarcely forested midland area above, with shrubs and low trees represented by Acer, Prunus and Pistacia (see Figs 313, 317).

\section{Distribution}

Contrary to the distribution provided with the original description, the range of this species is confined to the Vahsh Karatau Mts in southwestern Tajikistan only, as shown in Fig. 371 (see below). 


\section{Notes}

A captured live male is shown in Fig. 31 (a positive slide made in 1989). The cheliceral rastellum, trichobothrial bases and tarsal organ of leg I, and spigots are shown in Figs 145-146, 169-170, and 298-301, respectively.

Andreeva $(1968,1976)$ listed as paratypes of $B$. karatauvi $17 q q$ collected together with the holotype and 8 q 9 collected in 1966-1967 in other regions of southern Tajikistan. As noted above, the type series comprises only 7 q $q$ from Karatau Mts. All other females originally included in the type series are reidentified and considered here as belonging to other species of Anemesia.

\section{Anemesia pallida species group}

\section{Diagnostic characters}

The group comprises small, pale-coloured species. Males in this group resemble those of the castanea species group in possessing a laterally spinose cymbium, but differ from them in the considerably shorter palpal tibia and embolus (Figs 182-183, 211-214, cf. Figs 180-181, 206-210). Females of Anemesia pallida sp. nov. can be distinguished from other congeners in the reduced dorsal abdominal pattern (Fig. 23) and in the specific shape of the deeply divided spermathecae (Fig. 250).

\section{Species included}

Anemesia pallida sp. nov. and A. parvula sp. nov.

Anemesia pallida sp. nov.

urn:lsid:zoobank.org:act:8CF0BF65-A760-49B5-9B6F-1DB683314DD4

Figs 10, 23, 57, 72, 99, 112, 127, 182, 211-212, 250, 282-283, 313, 318-321, 337, 372

\section{Diagnosis}

Anemesia pallida sp. nov. is a minute, pale-coloured species, with a dark dorsal abdominal pattern reduced to a longitudinal median spot. The configuration of the male palpal organ in this new taxon resembles that in males of $A$. castanea sp. nov. and $A$. karatauvi, but both the male palpal tibia and the embolus in A. pallida sp. nov. are considerably shorter (Figs 211-212, cf. Figs 206-210). Anemesia pallida sp. nov. differs from $A$. parvula sp. nov., another member of the same species group known only from males, in the shape of the bulb (which is pegtop-shaped, with a strongly bulging anterior lobe vs comma-shaped bulb with a weakly convex anterior lobe in A. parvula sp. nov.; Figs 211-212, cf. Figs 213-214). Females of $A$. pallida sp. nov. differ from all other known female congeners by their unique diverging and divided receptacles (Fig. 250).

\section{Etymology}

The specific name is derived from the Latin adjective 'pallidus' meaning 'pale', and reflects the general light colouration of the specimens; the gender is feminine.

\section{Material examined}

\section{Holotype}

TAJIKISTAN: ${ }^{\lambda}$, foothills of Aruktau Mts, $1 \mathrm{~km}$ NE of Ganjina Village, $750 \mathrm{~m}, 37^{\circ} 58^{\prime} \mathrm{N}, 68^{\circ} 32^{\prime} \mathrm{E}$, 14 Apr. 1986, S. Zonstein leg. (SMNH).

Paratypes $(11 \hat{\jmath}, 2$ 우 $)$

TAJIKISTAN: $4 \widehat{ठ} \widehat{\partial}, 1$ क , same collection data as for preceding but 13-19 Apr. 1986 (SMNH); $1 \hat{\partial}$, same collection data as for preceding but 9 Apr. 1988 (SMNH); $3 \hat{\partial} \hat{\partial}$, same collection data as 
for preceding but 15 Apr. 1991 (SMNH, ZMMU); 1 ô, southernmost tip of Aruktau Mts, Garavuti, 3 Apr. 1974, A. Kononenko leg. (ZMMU); 1 đ’, Rangontau Mts, Yavan Pass, 1200 m, 38²4' N, 68 58' E, 29 Apr. 1986, S. Zonstein leg. (SMNH); 1 + , Vahsh River valley, Tigrovaya Balka (Tiger Gorge) Nature

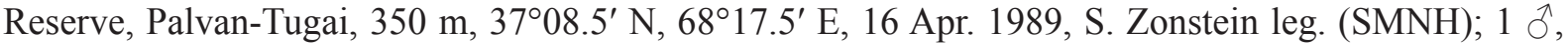
Vahsh Karatau Mts, western slope of Mt Hojamaston, 1040 m, 3801.2' N, 6857.1' E, 24 Apr. 2015, S. Zonstein leg. (SMNH).

\section{Description}

Male (holotype)

Habitus. See Fig. 10.

Measurements. TBL 10.80, CL 4.75, CW 4.03, LL 0.40, LW 0.75, SL 2.15, SW 2.03.

CoLour. Carapace pale yellowish orange with brownish clypeus and blackish-brown spots surrounding AMEs and lateral eyes; chelicerae, palps and legs dorsally yellowish orange with femora and patellae slightly darker; sternum, labium, maxillae, palps and legs ventrally pale brownish yellow; abdomen dorsally greyish-yellow with simple brown pattern consisting of relatively narrow median lanceolate spot only, ventral part of abdomen pale yellowish grey, spinnerets pale brownish yellow.

Prosoma. Clypeus and eye tubercle as in Fig. 57. Eye diameters and interdistances: AME 0.14(0.20), ALE 0.27, PLE 0.12, PME 0.07, AME-AME 0.16(0.10), ALE-AME 0.09(0.06), ALE-PLE 0.14, PLEPME 0.03, PME-PME 0.44. Cheliceral rastellum consists of 20-25 spikes located in front of fang base and on low mound. Each cheliceral furrow with 7 promarginal teeth and 3-4 smaller medial teeth. Sternum, labium and maxillae as in Fig. 99. Sternal sigilla very small but well defined. Maxillae with 22-27 cuspules each.

Legs. Tibia and metatarsus I as in Fig. 127. Scopula entire and distal on metatarsus I, narrowly divided on tarsi I and II, elsewhere absent. Trichobothria: 2 rows of 7-8 each on tibiae, 11-12 on metatarsi, 11-12 on tarsi, 7-8 on cymbium. PTC I-IV with 5-6 teeth on each margin.

Spination. Palp: femur d6-7, pd4, rd2; patella p1; tibia d2-3, p3, r4-5, v9-10; tarsus d13-15. Leg I: femur d6-7, pd3, rd3; tibia p3-5, r3, v7+m; metatarsus p3, v6. Leg II: femur d5, pd3, rd1; tibia p3, v8; metatarsus p3, v7. Leg III: femur d4, pd3, rd3; patella p3, r2; tibia d1, p3, r3, v8; metatarsus pd4, p3, r2, v9; tarsus p5, r3. Leg IV: femur d5, pd3, rd3; tibia d1, p3, r3, v8; metatarsus pd2, p3, r7, v7; tarsus p5, r6, v3. Patellae I-II and IV, and tarsi I-II aspinose.

Palp. Tibia, cymbium and palpal organ as shown in Figs 182, 211-212. Palpal tibia short cylindrical and spinose (Fig. 182). Palpal organ with embolus tapering and slightly curved (Figs 211-212).

SPINNERETS. See Fig. 282. PMS: length 0.37, diameter 0.15. PLS: maximal diameter 0.40; length of basal, medial and apical segments $0.73,0.75,0.44$; total length 1.92 ; apical segment triangular.

LEG MEASUREMENTS. $\widehat{\jmath}(+)$

\begin{tabular}{ccccccc}
\hline & Femur & Patella & Tibia & Metatarsus & Tarsus & Total \\
\hline Palp & $2.83(2.48)$ & $1.48(1.27)$ & $2.27(1.61)$ & - & $1.03(1.43)$ & $7.61(6.79)$ \\
Leg I & $5.13(3.43)$ & $2.56(2.06)$ & $3.77(2.27)$ & $3.51(1.92)$ & $2.36(1.37)$ & $17.34(11.05)$ \\
Leg II & $4.81(2.78)$ & $2.03(1.62)$ & $3.46(1.96)$ & $3.63(1.82)$ & $2.36(1.33)$ & $16.29(9.51)$ \\
Leg III & $3.79(2.26)$ & $1.84(1.52)$ & $2.66(1.33)$ & $3.68(1.94)$ & $2.57(1.47)$ & $14.54(8.52)$ \\
Leg IV & $4.64(3.02)$ & $2.09(2.04)$ & $4.32(2.71)$ & $4.97(2.90)$ & $2.91(1.66)$ & $18.93(12.33)$ \\
\hline
\end{tabular}


Female (paratype from Ganjina)

Habitus. See Fig. 23.

MeAsurements. TBL 13.30, CL 4.43, CW 3.65, LL 0.46, LW 0.93, SL 2.41, SW 2.20.

CoLour. Similar to that of male, but slightly paler.

Prosoma. Clypeus and eye tubercle as in Fig 72. Eye diameters and interdistances: AME 0.14(0.20), ALE 0.28, PLE 0.14, PME 0.07, AME-AME 0.14(0.06), ALE-AME 0.13(0.10), ALE-PLE 0.12, PLEPME 0.05, PME-PME 0.39. Cheliceral rastellum strong and consists of about 15 stout thornlike spikes located in front of fang base and on low mound. Each cheliceral furrow with 6 promarginal teeth and $0-1$ smaller teeth alongside. Sternum, labium and maxillae as in Fig. 112. Sternal sigilla very small, submarginal, and lacking certain edges. Maxillae with 30-32 cuspules each.

Legs. Scopula: distal on metatarsi I and II, entire on palpal tarsus, narrowly divided on tarsi I and II, elsewhere absent. Trichobothria: 2 rows of 6-8 each on tibiae, 14-15 on metatarsi I and II, 12 on metatarsus III, 13 on metatarsus IV, 13 on tarsi I and II, 10 on tarsus III and on palpal tarsus, 12 on tarsus IV. Palpal claw with 4 promarginal teeth. PTC I-II with 3-4 teeth on each margin. PTC III with 3-4 teeth on outer, 3 teeth on inner margins; PTC IV with 3 teeth and 1 tooth, respectively.

Spination. Palp: femur pd1-2; patella p1; tibia p3-4, v9-10; tarsus v2-3. Leg I: femur pd1; tibia p1, v5; metatarsus v6. Leg II: femur pd1; patella p1; tibia p2-3, v4-5; metatarsus p1, v7. Leg III: patella d1, p3; tibia d1, p2, r2, v6-7; metatarsus pd2, p2-3, rd4, v7-8; tarsus p1. Leg IV: tibia r2, v6; metatarsus pd 2, rd1-2, v11-12; tarsus $\mathrm{p}+\mathrm{r}+\mathrm{v}$ : ca 20 . All femora with dorsal median row of 5-8 long slender bristles; femora III and IV also with pro- and retrodorsal rows of 2-4 spine-like bristles in each row; patellae I and IV, and tarsi I and II aspinose.

Spermathecae. With diverging and branched stalks (see Fig. 250).

SPINNERETS. See Fig. 283. PMS: length 0.48, diameter 0.17. PLS: maximal diameter 0.50; length of basal, medial and apical segments $0.84,0.60,0.39$; total length 1.83 ; apical segment triangular.

\section{Variation}

The length of the carapace varies from 4.10 to 4.55 in paratype males, the dorsal abdominal pattern may be developed somewhat better and represent the more contrasted variant than that shown in Fig. 10. The number of tarsal spines varies as follows: leg II: 0-3; leg III: 6-12; leg IV: 9-20; the number of the maxillary cuspules ranges as $21-27$ in males and $28-32$ in females.

\section{Habitat}

See the corresponding data for A. incana and A. karatauvi.

\section{Distribution}

Southwestern Tajikistan. See Fig. 372.

Anemesia parvula sp. nov. urn:1sid:zoobank.org:act:213F941D-1936-4F56-AB60-A8D24B6A7F8B

Figs 11, 58, 100, 128, 183, 213-214, 284, 324, 372

\section{Diagnosis}

Males of Anemesia parvula sp. nov. differ from those of A. pallida sp. nov. in the shape of the bulb (which is comma-shaped with a weakly convex anterior lobe in the former species, but pegtop-shaped with a strongly bulging anterior lobe in the latter; Figs 213-214, cf. Figs 211-212). 


\section{Etymology}

The specific name is derived from the Latin adjective 'parvulus' meaning 'small', and reflects the minute size of the specimens; the gender is feminine.

\section{Material examined}

\section{Holotype}

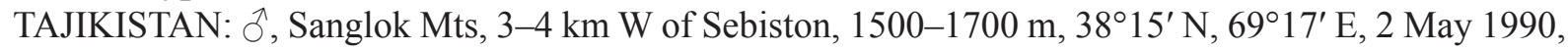
S. Zonstein leg. (SMNH).

\section{Paratype}

TAJIKISTAN: 1 đ̊, same locality, 5 May 1991, S. Ovchinnikov leg. (SMNH).

\section{Description}

Male (holotype)

Habitus. See Fig. 11.

Measurements. TBL 10.10, CL 4.08, CW 3.46, LL 0.38, LW 0.70, SL 2.04, SW 1.90.

CoLour. Prosoma, palps and legs pale yellowish orange with slightly darker brownish orange chelicerae, clypeus and radial grooves of carapace; eye tubercle blackish brown; most part of abdomen and spinnerets milky white; dorsal abdominal pattern represented with narrow and interrupted brown longitudinal stripe and five pairs of brownish chevrons posteriorly.

Prosoma. Clypeus and eye tubercle as in Fig 58. Eye diameters and interdistances: AME 0.12(0.20), ALE 0.25, PLE 0.12, PME 0.08, AME-AME 0.15(0.07), ALE-AME 0.08(0.04), ALE-PLE 0.10, PLE-PME 0.04, PME-PME 0.44. Cheliceral rastellum consists of ca 20 spikes located in front of fang base and on low mound. Each cheliceral furrow with 7-8 promarginal and 4 small retromarginal teeth. Sternum, labium and maxillae as in Fig. 100. Sternal sigilla very small, rounded posterior pair set relatively close to sternal edge. Maxillae with approximately 20 cuspules each.

LEGS. Tibia and metatarsus I as in Fig. 128. Scopula entire and distal on metatarsus I, narrowly divided on tarsi I and II, elsewhere absent. Trichobothria: 2 rows of 7-8 each on tibiae, 12-14 on metatarsi, 10-12 on tarsi, 10 on cymbium. PTC I-II, III and IV with $6-8,4-6$ and $4-5$ teeth on each margin, respectively.

LEG MEASUREMENTS.

\begin{tabular}{ccccccc}
\hline & Femur & Patella & Tibia & Metatarsus & Tarsus & Total \\
\hline Palp & 2.19 & 1.13 & 1.99 & - & 0.69 & 7.00 \\
Leg I & 4.20 & 1.96 & 3.08 & 2.89 & 1.93 & 14.06 \\
Leg II & 3.71 & 1.65 & 2.52 & 2.78 & 1.95 & 12.61 \\
Leg III & 3.25 & 1.39 & 2.07 & 2.92 & 1.87 & 11.50 \\
Leg IV & 4.22 & 1.47 & 3.66 & 3.92 & 2.20 & 15.47 \\
\hline
\end{tabular}

Spination. Palp: femur d4, pd1; tibia d3-4, p2-3, r1, pv4; tarsus d18-20. Leg I: femur d6, pd3, rd3-4; patella p1; tibia p3, pv4, rv3+m; metatarsus p3, v6. Leg II: femur d5, pd3, rd2-3; patella p1; tibia p3, v8; metatarsus p3, v7; tarsus p2. Leg III: femur d5-6, pd3, rd3; patella p3, r1; tibia d1, p3, r3, v8; metatarsus d2, p4, r3, v7; tarsus p8-10, r4. Leg IV: femur d6, p3, r3; patella p2, r1; tibia d1, p3, r3, v9; metatarsus $\mathrm{d} 2$, p5-6, r3-4, v10-11; tarsus p10-11, r5-6. Only palpal patella and tarsus I aspinose.

PaLP. Tibia, cymbium and palpal organ as shown in Figs 183, 213-214. Palpal tibia short cylindrical and spinose (Fig. 183). Palpal organ with embolus tapering and slightly curved (Figs 213-214). 
SPINNERETS. See Fig. 284. PMS: length 0.37, diameter 0.15. PLS: maximal diameter 0.40; length of basal, medial and apical segments $0.73,0.75,0.44$; total length 1.92 ; apical segment triangular.

\section{Female}

Unknown.

\section{Variation}

The carapace length is 4.44 in the only paratype male; the colouration, including the dorsal abdominal pattern, looks completely the same as in the holotype and distinctive from that in males of $A$. pallida sp. nov.

\section{Habitat}

See the corresponding data for $A$. infuscata sp. nov.

\section{Distribution}

Known only from the type locality in the central part of Tajikistan (Fig. 372).

\section{Anemesia incana species group}

\section{Diagnostic characters}

This group comprises intensely dark-coloured medium-sized and large species. Members of this species group can be easily distinguished from other congeners due to the unique membranous process near the embolus apex in males (see Figs 148, 150), and to a specific shape of the entire spermathecae with unusually wide stalks in females (Figs 251-265). Unlike most other members of Anemesia, all three species of the considered group have relatively large PMS (Figs 285-286, 288-290; cf. Figs 268-270, 274, 277-284).

\section{Species included}

Anemesia incana Zonstein, 2001, A. infumata sp. nov. and A. infuscata sp. nov.

Anemesia incana Zonstein, 2001

Figs 12 , 24, 32-33, 35, 43-44, 59, 73, 84-85, 101, 113, 129, 138-142, 147-150, 156-157, $171-172,184,215-216,251-254,285-286,302-305,318-321,338-344,363,373$

Anemesia incana Zonstein, 2001: 11, figs 1-8 (ぷํ)

Anemesia incana - Zonstein 2007: 211, fig. 9 (ㅇ). — Marusik et al. 2014: 3, fig. 9 (す).

\section{Diagnosis}

Anemesia incana differs from the closely related and similar-looking A. infumata sp. nov. and A. infuscata sp. nov. in a considerably wider clypeus and noticeably smaller eyes both in males and females (Figs 59, 73; cf. Figs 60-62, 74-77). Additionally, males of $A$. incana are well distinguishable due to their wider palpal organ (Figs 215-216; cf. Figs 217-223), and the conspecific females due to their oblate receptacles (Figs 251-254; cf. Figs 255-265).

\section{Material examined}

\section{Holotype}

TAJIKISTAN: ${ }^{\wedge}$, foothills of Aruktau Mts, $1 \mathrm{~km} \mathrm{NE}$ of Ganjina Village, $750 \mathrm{~m}, 37^{\circ} 58^{\prime} \mathrm{N}, 68^{\circ} 32^{\prime} \mathrm{E}$, 13 Apr. 1987, S. Zonstein leg. (AMNH). 
Paratypes $(15 \hat{\jmath}, 15$ 우)

TAJIKISTAN: 12 ठోळ, 9 우, Aruktau Mts, surroundings of Ganjina, 700-1000 m, 9-13 Apr. 1987,

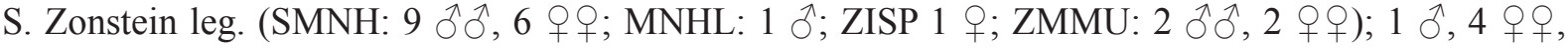
same collection data as for preceding but $11 \mathrm{Apr} .1988$ (SMNH); 1 §, 1 \%, same collecting data as for preceding but 22 Apr. 1992 (SMNH).

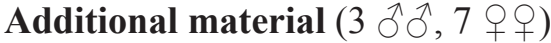

TAJIKISTAN: 1 q, Aruktau Mts, surroundings of Ganjina, 800-950 m, 19 Apr. 1989, S. Zonstein leg.

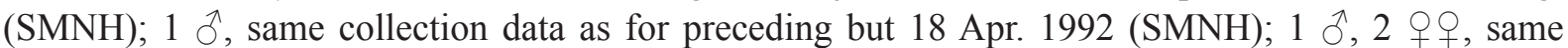
collection data as for preceding but 22 Apr. 2015 (SMNH); 3 + $\odot$, same collection data as for preceding but 27 Apr. 2002, S. Zonstein and A. Feodorov leg. (SMNH); 1 J, Panj Karatau Mts, vicinity of Mt

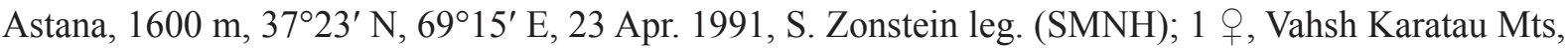

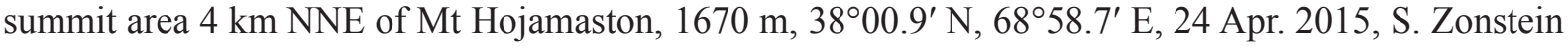
leg. (SMNH).

\section{Redescription}

Male (holotype)

Habitus. See Fig. 12.

MeAsurements. TBL 14.50, CL 6.87, CW 5.63, LL 0.63, LW 1.05, SL 4.25, SW 3.30.

Colour. Carapace, chelicerae, sternum, labium, most part of palps and legs intensely dark reddish brown; maxillae, coxae, metatarsi, tarsi and sternal sigilla dark brownish orange; eye tubercle blackened; abdomen dorsally dark grey with brown pattern consisting of wide median longitudinal spot and few paired transverse and slightly inclined short stripes, ventral part of abdomen dark yellowish grey, spinnerets pale yellow.

Prosoma. Clypeus wide. Eye tubercle as in Fig 59. Eye diameters and interdistances: AME 0.19(0.27), ALE 0.28, PLE 0.15, PME 0.14, AME-AME 0.24(0.16), ALE-AME 0.22(0.18), ALE-PLE 0.22, PLEPME 0.08, PME-PME 0.57. Weak cheliceral rastellum consists of about 20 spikes grouped in front of cheliceral fang and on low mound. Each cheliceral furrow with 7 promarginal teeth and 3-4 smaller teeth confined to basal retromargin. Sternum, labium and maxillae as shown in Fig. 101. Sternal sigilla oval; posterior pair relatively large, long oval, and located distantly from sternal margin. Maxillae with $4-5$ cuspules each.

Legs. Tibia and metatarsus I as shown in Fig. 129. Scopula distal on metatarsi I and II, very narrowly divided on tarsi I and II, widely divided on tarsus III, mixed, rudimentary, and widely divided on tarsus IV. Trichobothria: 2 rows of 9-10 each on tibiae, 14-17 on metatarsi, 14-17 on tarsi, 8 on cymbium. PTC I-IV with 6-7 teeth on each margin.

Spination. Palp: femur d3, p2; patella p2; tibia p3, r2, v3; tarsus d5-6. Leg I: femur d5, pd2; tibia p3, v6-7+m; metatarsus p2, v7. Leg II: femur d5, pd1; patella p3-4; tibia p3, v8; metatarsus p3, v6. Leg III: femur d4-5, pd3, r2; patella p4-5; tibia d1, p3, r3, v10-11; metatarsus d1, p3, r3, v10; tarsus v9-10. Leg IV: femur d5, p2, r3; tibia r3, v9-11; metatarsus p4, r2, v7-8; tarsus v7-10. Patellae I and IV, and tarsi I-II aspinose.

PalP. Tibia, cymbium and palpal organ as shown in Figs 184, 215-216. Palpal tibia long, cylindrical and spinose (Fig. 184). Palpal organ with wide asymmetrical bulb and tapering and slightly curved embolus (Figs 215-216). 
SPINNERETS. See Fig. 285. PMS: length 0.63, diameter 0.30. PLS: maximal diameter 0.53; length of basal, medial and apical segments 1.45, 1.07, 0.95; total length 3.47; apical segment shortly digitiform.

LEG MEASUREMENTS. $\overbrace{}^{\lambda}(+)$

\begin{tabular}{ccccccc}
\hline & Femur & Patella & Tibia & Metatarsus & Tarsus & Total \\
\hline Palp & $4.03(4.00)$ & $2.15(2.75)$ & $3.23(3.25)$ & - & $1.45(2.37)$ & $10.86(12.37)$ \\
Leg I & $6.57(6.17)$ & $3.05(3.70)$ & $5.17(4.37)$ & $5.27(3.77)$ & $2.83(2.80)$ & $22.89(21.81)$ \\
Leg II & $6.43(5.55)$ & $3.00(3.43)$ & $4.65(4.05)$ & $4.57(3.60)$ & $2.83(2.57)$ & $21.48(19.20)$ \\
Leg III & $5.75(4.30)$ & $2.55(3.35)$ & $3.30(3.23)$ & $4.65(3.37)$ & $2.27(2.85)$ & $18.52(17.10)$ \\
Leg IV & $6.83(5.57)$ & $3.20(3.67)$ & $5.57(4.55)$ & $5.63(5.10)$ & $3.05(3.03)$ & $24.34(21.92)$ \\
\hline
\end{tabular}

Female (paratype)

Habitus. See Fig. 24.

Measurements. TBL 17.50, CL 8.15, CW 7.07, LL 0.85, LW 1.63, SL 4.75, SW 3.97.

CoLour. Similar to that of male, except even darker chelicerae.

Prosoma. Clypeus and eye tubercle as in Fig 73. Eye diameters and interdistances: AME 0.23(0.30), ALE 0.28, PLE 0.20, PME 0.18, AME-AME 0.20(0.13), ALE-AME 0.20(0.17), ALE-PLE 0.22, PLE-PME 0.05, PME-PME 0.53. Weak cheliceral rastellum as in male. Each cheliceral furrow with 7-8 promarginal teeth and 5-6 smaller retromarginal teeth. Sternum, labium and maxillae as shown in Fig. 113. Sternal sigilla as in male. Maxillae with 7-10 cuspules each.

Spination. Palp: tibia p5, v18-20; tarsus v1. Leg I: tibia v8-10; metatarsus p1, v10. Leg II: tibia p3, v8-9; metatarsus p3, v8-10. Leg III: patella r2; tibia p2-3, r2, v9-10; metatarsus p3-4, r3, v12-14; tarsus v6-8. Leg IV: tibia r2, v10-12; metatarsus r2, v11-12; tarsus ventrally ca 20 . All femora and most part of patellae with long and relatively thin bristles instead of spines; tarsi I and II unarmed.

LEGS. Scopula distal on metatarsi I and II, entire on palpal tarsus, very narrowly divided on tarsus I, narrowly divided on tarsus II, elsewhere absent. Trichobothria: 8-10 in each row on tibiae, $16-20$ on metatarsi, 15-18 on tarsi. Palpal claw with 4 promarginal teeth. PTC I-II with 6-7 teeth on each margin. PTC III with 6 teeth on outer margin, 3 teeth on inner margin; PTC IV with 3 teeth and one tooth, respectively.

SPERmatheCAE. Entire with short stout stalks and considerably oblate receptacles (Fig. 251).

SPINNERETS. See Fig. 286. PMS: length 0.67, diameter 0.50. PLS: maximal diameter 0.93; length of basal, medial and apical segments $1.55,1.13,0.95$; total length 3.63 ; apical segment shortly digitiform.

\section{Variation}

The length of the carapace varies from 6.30 to 7.92 in males and from 5.96 to 8.43 in females. The colour of the carapace and legs varies from very dark reddish brown to deep blackish-brown. Number of maxillary cuspules varies from 2 to 11 .

\section{Habitat}

Foothills and low mountain ridges at an altitude of 600-1700 m, covered with ephemerous grasslands and subshrubs (mostly species of Artemisia), often with tall shrubs or low open forest (Pistacia vera L., different species of Prunus, Crataegus and Acer). The typical biotopes preferred by these spiders are shown in Figs 318-321. 


\title{
Distribution
}

South-western Tajikistan (Fig. 273).

\section{Notes}

Some illustrations of Anemesia incana used in this study are partially based on the additional (non-type) material. Live spiders are presented in Figs 32-33, 35, 43-44. The dentition of the cheliceral furrow in female and male paratypes is shown in Figs 84 and 85, respectively. The separated female palps and legs I-IV are shown in Figs 138-142. The SEM micrographs include those of the palpal organ $(147,149)$, the tip of the embolus (Figs 148, 150), the tarsal claws (Figs 156-157), the trichobothrial base and the tarsal organ of leg I (Figs 171 and 172, respectively), and spigots of PLE (Fig. 302) and PME (Figs 303-305).

\author{
Anemesia infumata sp. nov. \\ urn:1sid:zoobank.org:act:E256AE02-439D-4044-BB6C-5355A94CA677 \\ Figs $13,25,36-37,60,74-75,86,102,114,130,185,217-219,255-257$, \\ $287-288,322-323,345,364,373$
}

\section{Diagnosis}

Anemesia infumata sp. nov. differs from $A$. incana by a considerably narrower clypeus and noticeably larger eyes in both males and females (Figs 60, 74-75; cf. Figs 59, 73). From the most similarly-looking $A$. infuscata sp. nov., males of $A$. infumata sp. nov. differ in the more tapering embolus which arises closer to the retrolateral side of the palpal organ (Figs 217-219; cf. Figs 220-223), while the conspecific females differ by their short and uniformly stout spermathecae (Figs 255-257; cf. Figs 258-265).

\section{Etymology}

The specific epithet is derived from the Latin adjective 'infumatusi', meaning 'smoked', referring to the mostly darkened (blackened) colouration of these spiders. The gender is feminine.

\section{Material examined}

\section{Holotype}

TAJIKISTAN: ${ }^{\wedge}$, Panj Karatau Mts, surroundings of Mt Astana, $1400-1600$ m, 37 $23^{\prime} \mathrm{N}, 69^{\circ} 15^{\prime} \mathrm{E}$, 23 Apr. 1991, S. Zonstein leg. (SMNH).

\section{Paratypes $(1 \hat{0}, 6$ 우)}

TAJIKISTAN: 1 O, 5 oq 9 , same collection data as for the holotype but 22-24 Apr. 1991, S. Zonstein and S. Ovchinnikov leg. (SMNH); 1 , same collecting date as for preceding but $0.3 \mathrm{~km} \mathrm{E}$ of summit, $1670 \mathrm{~m}, 37^{\circ} 23.2^{\prime} \mathrm{N}, 69^{\circ} 14.8^{\prime} \mathrm{E}, 4$ May 2015, S. Zonstein leg. (SMNH).

\section{Additional material}

TAJIKISTAN: 2 우, same ridge, Akkutal Pass 35 km NNE of Panj Town, ca 800 m, 37 $18^{\circ} \mathrm{N}, 69^{\circ} 18^{\prime} \mathrm{E}$, 23-25 Apr. 1967, E. Andreeva leg. (MIZW).

\section{Description}

Male (holotype)

Habitus. See Fig. 13.

Measurements. TBL 18.30, CL 6.65, CW 5.88, LL 0.58, LW 1.22, SL 3.75, SW 3.39.

CoLour. Carapace intensely dark mahogany, with darker brown clypeus, margins, thoracic grooves, and numerous small spots forming reticulate pattern on mahogany background; eye tubercle brownish black; 
chelicerae, palps, leg I entirely, leg II from femur to tibia, femora III and IV dark chestnut brown; other segments of legs III and IV, and metatarsus and tarsus II light to medium brownish orange; maxillae orange, sternum and labium medium brownish orange; abdomen greyish, dorsally with dark coffee brown pattern consisting of median longitudinal stripe, very broad in anterior half, but narrow and fused with several paired chevrons in posterior half; spinnerets pale brownish yellow.

Prosoma. Clypeus and eye tubercle as in Fig. 60. Eye diameters and interdistances: AME 0.18(0.26), 0.38, 0.24, 0.18, AME-AME 0.20(0.12), ALE-AME 0.19(0.15), ALE-PLE 0.16, PLE-PME 0.04, PME-PME 0.49. Cheliceral rastellum composed of ca 40 stout bristles lacking tips and located in front of fang base and on weakly developed low mound. Cheliceral furrow with 7-8 promarginal teeth and 7-10 smaller retromarginal teeth each (Fig. 86). Sternum, labium and maxillae as shown in Fig. 86. Sternal sigilla poorly defined; posterior sigillum divided into two separate parts. Each maxilla with 12 cuspules confined to probasal maxillary edge.

LeGs. Tibia and metatarsus I as shown in Fig. 130. Scopula entire and distal on metatarsus I, mixed and distal on metatarsus II, very narrowly divided on tarsus I, narrowly divided on tarsus II, widely divided on tarsi III, absent on tarsi IV. Trichobothria: 2 rows of 10-11 each on tibiae; 16-19 on metatarsi; 13-14 on tarsi, 11 on cymbium. PTC I-IV with 8-10 teeth on each margin.

Spination. Palp: femur d4, pd3, rd3-4; patella p1; tibia p4, v7-8 stout bristles; tarsus d5. Leg I: femur d5, pd3, rd3-4; patella p1; tibia p3, v6-7+m; metatarsus v4-5. Leg II: femur d5, pd4, rd2-4; patella p1-2; tibia p3, v8-9; metatarsus p2, v7. Leg III: femur d4, pd3, rd3; patella p3, r2; tibia d1, p3, r3, v7; metatarsus d2, p7, r3, v11-12; tarsus p6. Leg IV: femur d5, p3, r3; patella r1-2; tibia r3, v7-8; metatarsus d2, p4, r2, v13-15; tarsus pv8-9, r1-2. Tarsi I and II aspinose.

PaLP. Tibia, cymbium and palpal organ as in Figs 185, 217-219. Tibia cylindrical with numerous thick ventral bristles (Fig. 185). Embolus tapering, slightly curved, embolic tip with small membranous keel (Figs 217-219).

SPINNERETS. See Fig. 287. PMS: length 0.63, diameter 0.31. PLS: maximal diameter 0.64; length of basal, medial and apical segments $1.38,0.74,0.91$; total length 3.03 ; apical segment shortly digitiform.

LEG MEASUREMENTS. $\delta(q)$

\begin{tabular}{ccccccc}
\hline & Femur & Patella & Tibia & Metatarsus & Tarsus & Total \\
\hline Palp & $4.27(4.51)$ & $2.05(2.40)$ & $3.41(3.01)$ & - & $1.44(2.74)$ & $11.17(12.66)$ \\
Leg I & $6.58(6.35)$ & $3.26(3.31)$ & $4.85(4.22)$ & $4.98(3.83)$ & $2.88(2.55)$ & $22.49(20.26)$ \\
Leg II & $5.96(5.31)$ & $2.92(2.78)$ & $4.27(3.47)$ & $4.53(3.38)$ & $2.87(2.54)$ & $20.55(17.44)$ \\
Leg III & $4.68(4.54)$ & $2.15(2.45)$ & $3.09(2.42)$ & $4.45(3.26)$ & $2.73(2.51)$ & $17.10(15.18)$ \\
Leg IV & $6.38(5.65)$ & $2.71(3.16)$ & $5.41(4.40)$ & $5.67(4.62)$ & $3.14(2.76)$ & $23.31(20.59)$ \\
\hline
\end{tabular}

Female (paratype)

Habitus. See Figs 25, 36-37.

MeAsurements. TBL 25.10, CL 8.19, CW 6.51, LL 0.92, LW 1.73, SL 4.24, SW 4.07.

Colour. Almost identical to that in male.

Prosoma. Clypeus and eye tubercle as in Fig. 74. Eye diameters and interdistances: AME 0.19(0.33), ALE 0.46, PLE 0.40, PME 0.25, AME-AME 0.23(0.09), ALE-AME 0.23(0.16), ALE-PLE 0.14, PLEPME 0.03, PME-PME 0.59. Cheliceral rastellum composed of numerous spikes located in front of fang base and on low mound. Each cheliceral furrow with 7 promarginal teeth and 6-7 smaller retrolateral teeth. Sternum, labium and maxillae as shown in Fig. 102. Sternal sigilla poorly defined; posterior sigillum fragmentary. Each maxilla with ca 20 cuspules. 
Legs. Scopula entire and distal on metatarsus I, distal and widely divided on metatarsus II, entire on palpal tarsus and tarsus I, widely divided on tarsus II, elsewhere absent. Trichobothria: 10-11 in each row on tibiae; $17-21$ on metatarsi; $16-17$ on leg tarsi, 14 on palpal tarsus. Palpal claw with 4 promarginal teeth. PTC I and II with 5-7 teeth on each margin, PTC III-IV with 6-7 teeth, respectively.

Spination. Palp: patella p1; tibia p3-4, v22-25; tarsus v4. Leg I: femur pd1; tibia p2, v5; metatarsus v4. Leg II: femur pd1-2; patella p1; tibia p2, v5; metatarsus p1, v7-9. Leg III: femur p0-2; patella p5, r1; tibia d1, p3, r2, v7-8; metatarsus d1, pd3, r6, v9; tarsus p2. Leg IV: tibia r2, v8-10; metatarsus p3, r2, v12-15; tarsus p4. All femora with 5-7, 2-3, and 3-4 long bristles instead of true spines, located medially, pro- and retrodorsally, respectively; patellae I and IV, and tarsi I and II aspinose.

Spermathecae. Entire, short and evenly stout (Fig. 255).

SPINNERETS. See Fig. 288. PMS: length 0.78, diameter 0.43. PLS: maximal diameter 0.89; length of basal, medial and apical segments $1.46,0.73,0.96$; total length 3.15 ; apical segment triangular to shortly digitiform.

\section{Variation}

The length of the carapace varies from 6.65 to 6.78 in males and in females from 5.58 to 8.09. There are small variations in the eye size and arrangement as shown in Figs 74-75. The shape of the palpal organ in both collected male congeners looks practically the same. The configuration of the spermathecae does not show any noticeable difference (Figs 255-257).

\section{Habitat}

As in A. incana (see above); however, A. infumata sp. nov. has been hitherto encountered in low and middle montane areas between 800 and $1700 \mathrm{~m}$, with slopes covered by rarely standing trees (Acer, Crataegus), shrubs and steppe vegetation (Figs 322-323).

\section{Distribution}

Known currently from a few localities in South Tajikistan only, see Fig. 273.

\section{Note}

Two females from Akkutal Pass deposited in MIZW were collected, according to the cover label, by K. Andrejeva-Prószyńska, on the same date as the type series of Brachythele karatauvi: 23-25 Apr. 1967. It is likely, however, that these data are correct and that both groups of spiders were sampled during the same short-distance collecting trip. The measured air distance between Akkutal and Vahsh Karatau Mts is only $60-90 \mathrm{~km}$, depending on the localities.

Anemesia infuscata sp. nov. urn:lsid:zoobank.org:act:84CDD144-26EB-4DFF-8BE2-F878AA5C7471

Figs 14, 26, 38-41, 45-47, 61-62, 76-77, 87-89, 103, 115-116, 131-132, 186-187, 220-223, 258$265,289-290,324-329,346-353,365-367,373$

\section{Diagnosis}

Anemesia infuscata sp. nov. differs from $A$. incana in a considerably narrower clypeus and noticeably larger eyes both in males and females (Figs 61-62, 76-77; cf. Figs 59, 73). From the most similarlooking $A$. infumata sp. nov., males of $A$. infuscata sp. nov. differ by a less tapering embolus which arises closer to the prolateral side of the palpal organ (Figs 220-223; cf. Figs 217-219), while the conspecific females differ in their longer cone spermathecae ending with certainly dilated receptacles (Figs 258-265; cf. Figs 255-257). 


\section{Etymology}

The specific epithet is derived from the Latin adjective 'infuscatus', meaning 'infuscate', referring to the entirely darkened (blackened) colouration of these spiders. The gender is feminine.

\section{Material examined}

\section{Holotype}

TAJIKISTAN: ${ }^{\lambda}$, foothills of Hissar Mts, Varzob Canyon, $7 \mathrm{~km} \mathrm{~N}$ of Dushanbe, vicinity of Harangon, 1060 m, 38 40'04" N, 6846'56" E, 27 May 2002, S. Zonstein leg. (SMNH).

\section{Paratypes $(19 \lesssim \widehat{\jmath}, 37$ 우)}

TAJIKISTAN: 1 , 2 + $q$, same collecting data as for the holotype (SMNH); 1 , same area, environs of Harangon $5 \mathrm{~km} \mathrm{~N}$ of Dushanbe, $1100 \mathrm{~m}, 38^{\circ} 39.9^{\prime} \mathrm{N}, 68^{\circ} 47.7^{\prime} \mathrm{E}, 3$ May 2015, S. Zonstein leg.

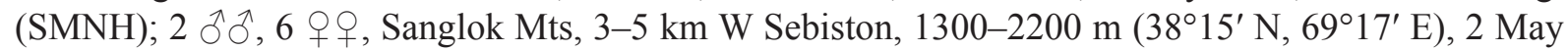

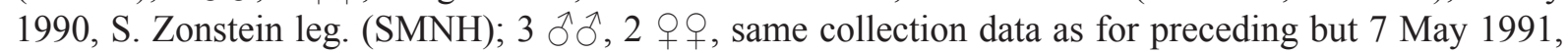
S. Ovchinnikov and S. Zonstein leg. (SMNH); $2 \hat{\jmath}, 5$ 우, same collection data as for preceding but 16-18 May 2002, S. Zonstein leg. (SMNH); 4 우, same collection data as for preceding but 29 Apr. 2015, S. Zonstein leg. (SMNH); $6 \partial^{\lambda}{ }^{\lambda}, 8$ 우, Hazratisho Mts, Sangdara Gorge, $1650 \mathrm{~m}, 38^{\circ} 22^{\prime} \mathrm{N}$, $70^{\circ} 09^{\prime} \mathrm{E}, 19-25 \mathrm{May} 2002$, S. Zonstein leg. (SMNH); 5 วิ $^{\lambda}$, same area, Iokunj Gorge, 1600-2000 m, $38^{\circ} 23^{\prime} \mathrm{N}, 70^{\circ} 10^{\prime} \mathrm{E}, 23-26$ May 2002, S. Zonstein leg. (SMNH); 3 우우, Kuhitek Mts, $7 \mathrm{~km}$ NE of Hovaling, 1850 m, 38²1.6' N, 7003.9' E, 28 Apr. 2015, S. Zonstein leg. (SMNH, ZMMU); 3 우으,

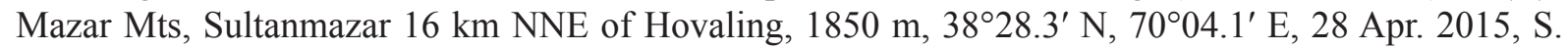
Zonstein leg. (SMNH); 3 우, same area, Darai-Mukhtor $5 \mathrm{~km} \mathrm{NW}$ of Hovaling, $1600 \mathrm{~m}, 38^{\circ} 23.6^{\prime} \mathrm{N}$, 6957.9' E, 28 Apr. 2015, S. Zonstein leg. (SMNH).

\section{Other material examined $(8 \circ \rho, 2$ 우 subad.)}

TAJIKISTAN: 1 ㅇ, Rangentau Mts, Fahrabad Pass, 1200-1300 m, 38²0' N, 6843’ E, 3 Apr. 1967, E. Andreeva leg. (MIZW); 1 q subad., Hazratisho Mts, $25 \mathrm{~km} \mathrm{E} \mathrm{of} \mathrm{Muminabad,} 24$ May 1966, E. Andreeva leg. (MIZW); 1 q subad., same collection data as for preceding but $13 \mathrm{~km} \mathrm{NE}$ of Muminabad, 13 Jun. 1966, E. Andreeva leg. (MIZW); 7 우, Kuhitek Mts, 1 km E of Hovaling, 1600-1700 m, $38^{\circ} 20^{\prime} \mathrm{N}, 69^{\circ} 59^{\prime} \mathrm{E}, 11$ Oct. 1987, S. Zonstein and S. Ovchinnikov leg. (SMNH, ZMMU).

\section{Description}

Male (holotype)

Habitus. See Fig. 14.

Measurements. TBL 17.80, CL 7.17, CW 6.28, LL 0.80, LW 1.24, SL 3.63, SW 3.33.

CoLour. Carapace, palps and legs predominantly intensive dark reddish brown; anterior edge and lateral margins of carapace, chelicerae and femora even darker; whole eye tubercle brownish black; sternum, labium, maxillae and leg coxae light coffee brownish coloured, metatarsi and tarsi III-IV brownish orange; abdomen yellowish brown with dark chocolate brown pattern consisting of very broad median longitudinal stripe crossed medially and posteriorly with six wide procurved fasciae, and numerous small and partially fused spots located between them; ventral abdominal surface with darker horse-shoe spot covering genital area; book-lungs paler, light yellowish brown; spinnerets even paler, light yellow.

Prosoma. Clypeus and eye tubercle as in Fig. 61. Eye diameters and interdistances: AME 0.20(0.29), 0.30, 0.27, 0.22, AME-AME 0.23(0.13), ALE-AME 0.23(0.19), ALE-PLE 0.14, PLE-PME 0.02, PME-PME 0.49. Cheliceral rastellum composed of 15-20 stout bristles lacking tips and located in front of fang base and on low mound. Cheliceral furrow with 6 promarginal teeth and 9-10 smaller retromarginal teeth each. Sternum, labium and maxillae as shown in Fig. 103. Sternal sigilla small, 
posterior pair broadly oval and located distantly from sternal margin. Each maxilla with 11-12 cuspules confined to probasal maxillary edge.

Spination. Palp: femur d3, pd1; patella p1; tibia d1, p3, r1, v1+ca 20 stout bristles; tarsus d5-6. Leg I: femur d4, pd2; tibia p2, v6-7+m; metatarsus v5. Leg II: femur d4, pd2, rd1; patella p1; tibia p3, v8-9; metatarsus p1, v8. Leg III: femur d4, pd3, rd3-4; patella p2, r1; tibia d1, p3, r3, v7; metatarsus pd5, p5, r3, v9-11; tarsus p3. Leg IV: femur d4, p3, r3; patella r1; tibia r3, v9; metatarsus pd1, p2, r3, v13-15; tarsus pv9-10, r2. Patella I, tarsi I and II aspinose.

Legs. Tibia and metatarsus I as shown in Fig. 132. Scopula entire and distal on metatarsi I and II, very narrowly divided on tarsi I and II, widely divided on tarsi III, absent on tarsi IV. Trichobothria: 2 rows of 9-11 each on tibiae; 10-12 on metatarsi; 16 on tarsi I and II; 13 on tarsi III and IV, 9-10 on cymbium. PTC I-II with 7 teeth on each margin; PTC III-IV with 7 teeth on outer and 6 teeth on inner margins.

Palp. Tibia, cymbium and palpal organ as in Figs 187, 220-221, 223. Tibia cylindrical with numerous thick ventral bristles (Fig. 187). Embolus tapering, slightly curved, embolic tip with small membranous keel (Figs 220-221, 223).

SPINNERETS. See Fig. 289. PMS: length 0.51, diameter 0.22. PLS: maximal diameter 0.53; length of basal, medial and apical segments $0.90,0.65,0.83$; total length 2.38 ; apical segment shortly digitiform.

LEG MEASUREMENTS. $\widehat{\jmath}(+)$

\begin{tabular}{ccccccc}
\hline & Femur & Patella & Tibia & Metatarsus & Tarsus & Total \\
\hline Palp & $4.14(4.84)$ & $2.13(2.54)$ & $3.48(3.07)$ & - & $1.57(2.90)$ & $11.32(13.35)$ \\
Leg I & $6.87(6.82)$ & $3.41(3.37)$ & $4.94(4.17)$ & $4.87(4.04)$ & $3.07(2.67)$ & $23.16(21.07)$ \\
Leg II & $6.16(5.44)$ & $3.04(3.15)$ & $4.28(3.68)$ & $4.44(3.43)$ & $2.95(2.48)$ & $20.87(18.18)$ \\
Leg III & $5.13(4.87)$ & $2.26(2.74)$ & $3.21(3.53)$ & $4.25(3.24)$ & $2.93(2.47)$ & $17.78(16.85)$ \\
Leg IV & $6.33(5.84)$ & $2.86(3.39)$ & $5.29(4.42)$ & $5.63(4.41)$ & $3.24(2.86)$ & $23.35(20.92)$ \\
\hline
\end{tabular}

Female (paratype, Varzob canyon)

Habitus. See Fig. 26.

MeAsurements. TBL 22.30, CL 8.55, CW 7.32, LL 1.12, LW 1.82, SL 4.70, SW 4.11.

Colour. Similar to that of male, but carapace and leg more intensive reddish coloured; dark brown dorsal abdominal pattern is even better developed; ventral brownish yellow surface of abdomen with numerous dense and tiny brown spots located irregularly between last pair of book lings to spinnerets.

Prosoma. Clypeus and eye tubercle as in Fig. 76. Eye diameters and interdistances: AME 0.21(0.30), ALE 0.38, PLE 0.28, PME 0.19, AME-AME 0.24(0.19), ALE-AME 0.25(0.20), ALE-PLE 0.21, PLEPME 0.15, PME-PME 0.56. Cheliceral rastellum composed of numerous spikes located in front of fang base and on low mound. Each cheliceral furrow with 7-8 promarginal teeth and 9-13 smaller retrolateral teeth (as in Fig. 87). Sternum, labium and maxillae as shown in Fig. 115. Sternal sigilla small, posterior pair broadly oval and located distantly from sternal margin. Maxillae with 10-11 cuspules each.

LEGs. Scopula entire and distal on metatarsi I and II, entire on palpal tarsus, very narrowly divided on tarsi I and II, elsewhere absent. Trichobothria: 2 rows of 8-9 each on tibiae; $15-18$ on metatarsi; $12-17$ on tarsi. Palpal claw with 4 promarginal teeth. PTC I-II with 5-6 teeth on outer and 4-5 teeth on inner margins; PTC III with 4-5 and 2-3; PTC IV with 3-4 and 1-2 teeth, respectively. 
Spination. Palp: femur pd1; patella p1; tibia p3, v12-14; tarsus v3. Leg I: femur pd1; tibia p3, v6-7; metatarsus v5-7. Leg II: femur pd1; patella p1; tibia p3, v8-9; metatarsus v9-10. Leg III: femur r2; patella p3; tibia p2, v7; metatarsus d1, p3, r3, v9-10; tarsus p2. Leg IV: tibia v7-8; metatarsus p4, v11-12; tarsus pv7-8. All femora with 3-5 long bristles located medially, femora III and IV also with prodorsal and retrodorsal rows of bristles, with $2-3$ bristles in each row; patellae I and IV, and tarsi I and II aspinose.

Spermathecae. Entire and mushroom-shaped with wide tapering stalks and rounded receptacles (Fig. 259).

SPINNERETS. See Fig. 290. PMS: length 0.79, diameter 0.48. PLS: maximal diameter 1.02; length of basal, medial and apical segments $1.52,0.75,0.97$; total length 3.24 ; apical segment triangular to shortly digitiform.

\section{Variation}

The length of the carapace varies from 6.48 to 6.97 in males and from 6.89 to 9.47 in females. The colour varies narrowly from somewhat lighter and more reddish to an even darker brown than that of the holotype. The thoracic fovea are sometimes slightly recurved. Variations in shape, arrangement and structure are shown for the eyes (Figs 61-62, 76-77), the cheliceral furrow (Figs 87-89), the sternum (Figs 115-116), the male tibia and the metatarsus I (Figs 131-132), the male palpal tibia and the cymbium (Figs 186-187), the palpal organ (Figs 220-223), and the spermathecae (Figs 258-265). The number of maxillary cuspules ranges from 10 to 14 .

\section{Habitat}

Anemesia infuscata sp. nov. seems to be the most mesophilic congener inhabiting shrubby and forested slopes between 1000 and 2300 m (Figs 324-329).

\section{Distribution}

Tajikistan. See Fig. 373.

\section{Notes}

Some illustrations of Anemesia infuscata sp. nov. are based on the additional paratype specimens; these include the images showing variations (see above) and photos of live spiders presented in Figs 38-41 and $45-47$.

\section{Data on natural history}

\section{Burrows}

All known species of Anemesia, living mostly in large colonies, build open burrows lacking the wafer-lid or trap-door (see Figs 330-367). The length of the burrows generally varies from 25 to $40 \mathrm{~cm}$ (Andreeva 1968 and own data), although in some populations of A. tubifex inhabiting the sandy desert biotopes, it can reach $60 \mathrm{~cm}$ in length. In adult congeners the diameter of the burrow entrance, always with a raised rim, ranges from 0.5 to $1.5 \mathrm{~cm}$. In A. incana this rim is more developed and resembles a tower-like or mushroom-like surface soil turret $2-3 \mathrm{~cm}$ in height and $1.5-4 \mathrm{~cm}$ in diameter (Figs 340-344). The entrance leads to a narrow burrow neck which then becomes wider; this dilated burrow section, lined by silk, ends with a wide living chamber (Figs 362-367). A variant of the general form is observed in $A$. oxiana sp. nov., in which the burrow is provided with a lateral chamber, either ending with an additional entrance located close to the main one (Fig. 332), or blind and closely reaching the soil surface. 


\section{Phenology}

Data on the phenology of the congeners are sparse and based completely on fragmentary field observations. The collecting data indicate that the wandering adult males of Anemesia occur in MarchApril in lowland localities at 200-1300 m and from mid-April to at least the end of May in midland localities at 1300-2300 m. Females with egg sacs containing 30-40 eggs were found only in October (A. infuscata sp. nov.). They have never been observed during the spring months, despite intensive collecting.

\section{Feeding}

Several burrows built by adult Anemesia females (11 burrows of A. karatauvi and 45 burrows of A. incana) were examined to reveal the character of the prey remains accumulated at the burrow bottom. Almost all these burrows, with minor exceptions, contained fragments (the head capsules, parts of the legs, the separate thoracal and abdominal sclerites) of the carpophagous foraging ants belonging to two species of Messor Forel, 1890: M. inermis Kuznetsov-Ugamsky, 1929 and M. structor (Latreille, 1798).

\section{Other arthropod remains}

These were represented in one to six samples, when found. Most of them belonged to the following representatives of the Coleoptera Linnaeus, 1758: Carabidae Latreille, 1802: Poecilus liosomus Chaudoir, 1876 and Pterostichus medvedevi Kryzhanovskij \& Mikhailov, 1972; Chrysomelidae Latreille, 1802: Chrysolina sacarum (Weise, 1890) and Entomoscelis adonidis (Pallas, 1771); Curculionidae Latreille, 1802: Lixus sp.; Elateridae Leach, 1815: one unidentified species; Scarabaeidae Latreille, 1802: Tropinota turanica Reitter, 1889, Madotrogus sp. aff. ferganensis Protzenko, 1962), Euonthophagus sp. aff. amyntas (Olivier, 1789) and one unidentified representative of the Melolonthinae Samouelle, 1819; Tenebrionidae Latreille, 1802: Stalagmoptera sp. A few other remains belonged to ants of the genera Cataglyphis Förster, 1850 and Camponotus Mayr, 1861 (Hymenoptera Linnaeus, 1758: Formicidae Latreille, 1809, and to the terrestrial crustaceans of the genera Hemilepistus Budde-Lund, 1879 and Protracheoniscus Verhoeff, 1917 (Isopoda Latreille, 1817: Agnaridae Schmidt, 2003 and Trachelipodidae Strouhal, 1953, respectively).

\section{Predators}

Data on the predators feeding on Anemesia spp. are currently known only for a few taxa of the spider wasps (Hymenoptera: Pompilidae Latreille, 1804). The pompilids preying on Anemesia spp. belong to the genera Pareiocurgus Haupt, 1962 (Pompilinae Latreille, 1804) and Claveliocnemis Wolf, 1968 (Pepsinae Lepeletier, 1845). Pareiocurgus bactriacus Wolf, 1968 in Turkmenistan and P. latigena (F. Morawitz, 1893) in Uzbekistan and Tajikistan feed on different burrowing spiders, including representatives of Anemesia (Zonstein 2000), whereas all three known species of Claveliocnemis C. incisipennis Wolf, 1968, C. brachypteris (Gussakovskij, 1935) and C. alata Zonstein, 2007 - are specialized predators feeding only on these cyrtaucheniids (Zonstein 2001, 2007).

\section{Misidentified material}

Raveniola sp. aff. concolor Zonstein, 2000

Anemesia tubifex - Denis 1958: 82 (ㅇ). Misidentified.

\section{Material examined}

AFGHANISTAN: 1 q, Koh-i-Baba Mts, Tarapas, 3200 m, 23 Jul. 1948, N. Haarløv leg. (NHMD); 6 우우, same ridge, Puistangoli, 3000-3400 m, 1 Aug. 1948, N. Haarløv leg. (NHMD); 5 우오, same ridge, Sar-i-Djedjaghana, 3000-3400 m, 8 Aug. 1948, N. Haarløv leg. (NHMD). 


\section{Notes}

The re-examination of these specimens, identified by Denis (1958) as Anemesia tubifex, shows that they actually represent an undescribed alpine species of the nemesiid Raveniola Zonstein, 1987, closely related to $R$. concolor from the highlands of northern India. The characters missed by Denis (a short and wide labium, a broadly rounded sternum, a fairly rounded and submarginal posterior pair of the sternal sigilla, the characteristic divided spermathecae, as well as many less significant features) contradict his identification and confirm the given re-assignment. The species is planned to be described in a revision of Central Asian Raveniola spp. (Zonstein, in prep.).

\section{Discussion}

\section{Introductory notes}

In this review Anemesia has been compared with the putatively related genera of the Cyrtaucheniidae, the related family Euctenizidae, and the similarly looking members of two subfamilies of the Nemesiidae: Nemesiinae s. str. (without Raveniola, tentatively included in this subfamily for want of a better assignment), and Bemmerinae. Several characters of other nemesiids have also been included. The Bemmerinae are considered here without Pionothele Purcell, 1902 which was tentatively included in this subfamily by Raven (1985). Prior to 1985, all these taxa were considered as members of the same family, Ctenizidae s. lat. Raven (1985) elevated the earlier tribes of Simon, Cyrtaucheniae and Nemesiae, to family rank, Bemmereae to the subfamily of the Nemesiidae, and established the Euctenizinae as a new cyrtaucheniid subfamily. Bond et al. (2012b) raised the latter taxon to family rank. Currently, the monophyletic status of both Cyrtaucheniidae and Nemesiidae is debated (Goloboff 1993; Bond \& Opel 2002; Hedin \& Bond 2006; Bond et al. 2012b; Garrison et al. 2016; Wheeler et al. 2017). These families are expected to be radically revised in the near future. Therefore, all the obtained data and results listed below should be considered as approximate and preliminary.

\section{Characters}

CARAPACE. In species of Anemesia, as well as generally in Nemesia and other nemesiid genera, a posterior portion of the carapace is broadly and gradually rounded or only slightly constricted (Figs 1-26, 4247; cf. Decae et al. 2015: fig. 4A, C, E). By contrast, the common trend observed in the members of Cyrtaucheniidae and Euctenizidae is that the posterior half of the carapace is narrowed and constricted laterally, as shown in Fig. 374 (Buchli 1966: figs 21, 28; Raven 1985: figs 192, 197, 213; Bond et al. 2012a: figs 3-4, 10-11; Bond \& Godwin 2013: figs 2, 23-24, 37, 58; Decae et al. 2014: figs 3AI, 4A-C, 8-9; Decae \& Bosmans 2014: figs 2-5). Exceptions are found in the cyrtaucheniid genera Bolostromoides Schiapelli \& Gerschman, 1945, Angka Raven \& Schwendinger, 1995 and Fufus Simon, 1888 , where this part of the carapace is broadly rounded or only slightly constricted (Schiapelli \& Gerschman 1945: pl. II; Raven \& Schwendinger 1995: fig. 6A; Ortega et al. 2013: figs 7, 10, 12, 21, 25 , $32,35,42,44)$. An opposite situation can be observed within the Nemesiidae, where a weak posterior constriction of a generally rounded carapace occurs in some species (see Figs 381-382). In view of all the above, a posteriorly rounded carapace in Anemesia seems to be a low-value character which cannot be used to clarify the possible relationships between this genus and any representatives of the abovementioned groups.

ClyPeus. The anteriorly protruded clypeus is shared by almost all Anemesia spp.; this character seems less developed in males than in the conspecific females (see Figs 48-77). It does not represent, however, the unique feature of this genus since a somewhat similar though less pronounced clypeus is observed in some Eucteniza Ausserer, 1875 (Euctenizidae) (Bond \& Godwin 2013: figs 2, 23; Valdez-Mondragón \& Cortez-Roldán 2016: fig. 47). Other euctenizids (possibly except Apomastus Bond \& Opel, 2002; see Bond 2004: fig. 5a), most genera of Cyrtaucheniidae (save Anemesia and some Ancylotrypa Simon, 1889 ) and the majority of nemesiids lack a pronounced clypeus (see Raven 1985). Curiously, Raveniola 
spp., taxonomically distant from species of Anemesia but often inhabiting the same biotopes in Central Asia, also possess a protruded clypeus (Zonstein 2009: fig. 2; Zonstein et al. 2018: figs 102-128).

Thoracic Fovea. In Anemesia the thoracic fovea appears mostly straight or varies from slightly procurved to weakly recurved. It thus differs from the recurved fovea characteristic for the majority of the nemesiine genera and some cyrtaucheniids (most species of Fufius), as well as from a well-cambered procurved fovea known for the most genera of Cyrtaucheniidae, Euctenizidae and bemmerine nemesiids (see Raven 1985, 1987; Bond \& Opel 2002; Decae \& Cardoso 2006; Ortega et al. 2013; Siliwal et al. 2015). Since cyrtaucheniid Angka also possess a weakly modified (slightly procurved) thoracic fovea (Fig. 380; Raven \& Schwendinger 1995, fig. 6A), this feature in principle might be considered a character grouping the genus with Anemesia.

Cheliceral teeth. Most Cyrtaucheniidae, Euctenizidae, and Nemesiidae possess the cheliceral furrow with normally developed teeth set only on the promargin, while the opposite retromarginal or median row is shortened and represented by small to tiny denticles often restricted to a patch (like those shown in Figs 385-387, 390-391, 393-395). However, Eucteniza (Euctenizidae), Homostola Simon, 1892 (Cyrtaucheniidae), and at least one species of Spiroctenus Simon, 1889 (Nemesiidae) possess a second, retromarginal row of smaller teeth sometimes interspersed with denticles (Raven 1985; Bond \& Opel 2002; Dippenaar-Schoeman 2002, 2014; Bond \& Godwin 2013; Valdez-Mondragón \& CortezRoldán 2016: figs 47-48; see also Figs 388-389, 392). It should be noted that this second row differs in shape from the true retromarginal teeth series known for the Ctenizidae and their closest affinities (see Fig. 384). In some species of Anemesia the retromarginal teeth row resembles similar structures in Homostola more than the mesobasal denticles in most taxa of Cyrtaucheniidae and Nemesiidae (Figs 78, 83-84, 86-88, 378-379; cf. Figs 386-387, 390-391, 393-395), that might serve as an argument to group the mentioned genera. In males of Anemesia spp. this retromarginal row is always shorter and composed of smaller teeth than in conspecific females (see Figs 85, 89; cf. Figs 84, 87-88). This fact can be regarded as a weighty argument in favour of the assumption that in other congeners, possessing fewer retromarginal teeth (Figs 79-82), the second row has become reduced.

Legs I-IV. Within Anemesia, the female legs I-IV are generally equal in width; while in A. andreevae sp. nov. legs III-IV are slightly stouter than legs I-II (Fig. 18). In most members of Cyrtaucheniidae and Euctenizidae the legs III-IV in females, and often in the conspecific males, are thicker than legs I-II (as shown in Figs 374, 376; Raven 1995: figs 192, 197, 213; Bond \& Godwin 2013: figs 2-7, 23; Decae \& Bosmans 2014: figs 4-5). However, in Bolostromoides, Angka, Fufius and some Homostola legs III-IV are similar to legs I-II in width or only slightly exceed them (see Schiapelli \& Gerschman 1945: pl. II; Raven \& Schwendinger 1985: fig. 2A; Dippenaar-Shoeman 2002: fig. 22; Ortega et al. 2013: fig. 44). The same is true for Acontius Karsch, 1879 and some species of Ancylotrypa Simon, 1889 (as shown in Figs 375, 377-378). Among members of the Nemesiinae all legs are similarly slender (as shown in Fig. 381; Decae et al. 2015: figs 2-3, 10; Leavitt et al. 2015: fig. 4). Regarding the Bemmerinae, legs III-IV are not modified in Damarchus Thorell, 1891 (Zonstein \& Marusik 2014: fig. 7) and Spiroctenus (Dippenaar-Shoeman 2002: fig. 57). However, in Atmetochilus Simon, 1887 they may be almost unmodified in some species (Simon 1892: fig. 73) and slightly thicker in other congeners (Zonstein \& Marusik 2016: fig. 2b, e). Therefore, in relation to Anemesia this character has a particular significance; it can neither confirm, nor disprove the current assignment of this genus.

Leg microstructures. Among the surveyed taxa, the trichobothrial bases seem to be almost uniformly corrugated and thus very similar in representatives of all three considered families (Figs 158-159, 161, 163, 165-166, 169, 171, 396, 399, 403, 405; Raven 1983: pl. II, figs 1, 4; Raven \& Schwendinger 1995: figs 4B, 5A-D; Bond 2012: fig. 43). However, the structure of a lingulate TO in Anemesia spp. (Figs $160,162,164,167-168,170,172$ ) seems to be similar to the comparably flattened TO of the 
cyrtaucheniids Acontius, Ancylotrypa, Cyrtauchenius Thorell, 1869 (Figs 397, 400, 402, respectively) and Rhytidicolus (Goloboff 1993: fig. 7), as well as for the euctenizid Aptostichus (Bond 2012: figs 42, 63). It appears equally dissimilar to the domed TO of Nemesia (Fig. 407) and to the craterous TO of the nemesiid Entypesa Simon, 1902 (Fig. 403). Unfortunately, the scarcity of the corresponding data (structure of the tarsal organ and the trichobothrial bases remains unknown for most cyrtaucheniids and euctenizids) makes these characters limited in value when being used in relation to Anemesia spp.

Spermathecae. Raven (1985) listed the multilobate spermathecae (which have been found in several species of Anemesia) among the diagnostic characters of the Cyrtaucheniidae. This feature may have a limited taxonomic significance because the multi-branched spermathecae have been recently described also for some nemesiids (see Goloboff 1995: figs 66E, 68, 71, 74A; Ferretti \& Pompozzi 2016: fig. 10). Within the latter family, however, both the Bemmerinae and Nemesiinae possess entire or sometimes divided, but never multilobate, spermathecae (Raven 1985: fig. 54, 1987: fig. 8; Lazarov 2005: fig. 5; Decae \& Cardoso 2006: figs 15-16; Decae 2012: fig. 2Da-Fd; Zonstein \& Marusik 2014: figs 14-15, 2016, fig. 12a-d). Among the genera of Cyrtaucheniidae the entire and multilobate spermathecae can occur within a pair of the related genera, or even within the same genus. The members of Cyrtauchenius possess the spermathecae either entire or branched; while in Amblyocarenum Simon, 1892 they are only integral (Raven 1985; Decae et al. 2014: fig. 7A-E; Decae \& Bosmans 2014: figs 18-19). For some genera of Cyrtaucheniidae, however, the structure of the vulva still remains either unknown or known and shown only for single species (Raven 1985: figs 201, 208; Rudloff 1996: fig. 5). Regarding Anemesia, the pronounced differences in shape of the spermathecae may be considered a criterion for clustering congeners into the well-defined species groups, as it has been shown for the nemesiid Raveniola (see Zonstein et al. 2018).

SPINNERETs. As in some nemesiids and almost all euctenizids (see Murphy \& Roberts 2015: pls 14, 23-24), the species of Anemesia possess only AC spigots, evenly distributed on the ventral side of PLS (all three segments) and clustered on of the PMS apex (Figs 291-305). Meanwhile, the Cyrtaucheniidae, as well as representatives of the Nemesiinae (the situation in the Bemmerinae still remains unknown) possess also a few MAC spigots mixed with more numerous ACs (Figs 398, 408-409; Murphy \& Roberts 2015: pls 10-11, 25). The full absence of MAC spigots can thus be potentially considered a feature shared by Anemesia and Euctenizidae and concurrently, as a character distinguishing this genus from Cyrtaucheniidae. However, contrary to Murphy \& Roberts (2015), within the former family at least Eucteniza possesses a few spigots certainly belonging to the MAC type (see Bond \& Opel 2002: fig. 4D). Additionally, Anemesia spp. also lack the inflated-base spigot type known for the anamine nemesiids (Goloboff 1995: figs 48-49, 56), cyrtaucheniids Acontius and Cyrtauchenius (Bond \& Opel 2002: fig. 3D; Decae \& Bosmans 2014: fig. 6a), and euctenizids Neoapachella Bond \& Opel, 2002 and Eucteniza (Bond \& Opel 2002: fig. 3E-F). Since the latter spigot type seems to be missing also in many nemesiids, and in some cyrtaucheniids and euctenizids (see Goloboff 1995; Bond 2012: fig. 65; Decae \& Bosmans 2014: fig. 7a), its taxonomic significance in relation to Anemesia spp. seems to be vastly limited.

Burrow CONSTRUCTION. Among the genera of Cyrtaucheniidae, burrow entrances are usually protected with wafer-lids in Ancylotrypa and Homostola (Dippenaar-Schoeman 2002). The same is true for species of Amblyocarenum Simon, 1892 (see Buchli 1966: figs 34-35; Decae et al. 2014: figs 12A-D, 13). Within Cyrtauchenius Thorell, 1869, most species construct wafer-lids, while a few of them, e.g., C. inops (Simon, 1889) build open burrows extending into the elevated surface turrets (Simon 1889: pl. XII, fig. 5). According to Raven \& Schwendinger (1995), females of Angka hexops in captivity can build a short simple burrow almost completely lacking any silk-lining. The South American Bolostromoides builds burrows with an open entrance lacking any protection (Vellard 1945). An open burrow was also described for at least one species of Acontius (Blandin \& Célérier 1977). According to the known 
data on the life history of the Nemesiinae, the spiders belonging to Nemesia and Iberesia close their burrows with trap doors or wafer-lids (Decae 1996: fig. 2a-j, 2005: figs 68-82), whereas members of Brachythele and Calisoga build burrows with an unprotected entrance (see Smith 1908; Decae 1996: fig. 1e; Thaler \& Knoflach 2001). Regarding the Asian nemesiid genera belonging to the Bemmerinae, Damarchus Thorell, 1891 and Damarchulus Siliwal, Molur \& Raven, 2015 build open burrows provided with an entrance turret (Abraham 1924; Siliwal et al. 2015); the character of burrows in Atmetochilus Simon, 1887 remains unknown. In South African Spiroctenus Simon, 1889 the burrows demonstrate a wide array of constructions which may be entire, chambered, with or without trap doors, lids and turrets (Dippenaar-Schoeman 2002: table 6). Among the above-listed variations, a great number of burrow variants used by Anemesia spp. resemble the similar open tower constructions of some South African cyrtaucheniids (Dippenaar-Schoeman 2014: text-figure on p. 386; cf. Figs 330-361).

\section{Relationships}

As noted earlier (Zonstein 2001), females of Anemesia spp. possess several characters listed by Raven (1985), as indicative for the family Cyrtaucheniidae: (1) the carapace glabrous or only slightly hirsute; (2) an incomplete biserial dentition of PTC III and IV; (3) the characteristic comb of spines on the prodistal edge of femur IV; (4) the multilobate spermathecae (at least in some species); (5) the leg tarsi with few to numerous spines, and tarsi I-II with fewer (if any) spines than tarsi III-IV. Some exceptions include a hirsute carapace in some species of Cyrtauchenius, the aspinose leg tarsi I-IV, and the biserially and multidentate PTC III-IV in some Aporoptichinae (Op. cit.). Nevertheless, the placing of Anemesia in the Cyrtaucheniidae is problematic.

Superficially, Anemesia resembles the aporoptichine genera. It differs, however, significantly in the structure of the chelicerae, labium, sternum and sigilla which makes a close relationship between these groups improbable. Regarding other cyrtaucheniid genera, the situation looks less obvious. Amblyocarenum, Cyrtauchenius and Ancylotrypa share with Anemesia the anteriorly narrowed sternum, with the posterior pair of sigilla located relatively far apart the sternal edge, and lack of the metatarsal preening combs (entirely or in some species). Even so, in comparison with Anemesia, these genera possess a more elevated cephalic portion of the posteriorly narrowed carapace, a predominantly procurved thoracic fovea, the distinctly thickened female legs III-IV, and a considerably better developed cheliceral rastellum (Figs 374, 376; Raven 1985: figs 191-205; Dippenaar-Schoeman 2002: fig. 25b-f; Jocqué \& Dippenaar-Schoeman 2006: fig. 30e; Decae \& Bosmans 2014: figs 2-5, 10-11; Decae et al. 2014: figs 3A-I, 4A-C, 10A-B; cf. Figs 1-47, 90-116, 143-146). Hence, the relationships between Anemesia and the three above-listed genera do not seem to be close.

Among the remaining cyrtaucheniid genera, the monotypic Asian Angka (Cyrtaucheniidae incertae sedis) shares with Anemesia some characters such as a retrolateral localisation of megaspines on the male tibia I, the almost uniformly slender legs I-IV lacking the metatarsal preening combs, the maxillae with a deep and rounded heel, a straight thoracic fovea, and a moderately arched cephalic portion of the carapace both in males and females (Raven \& Schwendinger 1995: figs 6B, 6E, 6F, 6J, respectively). Concurrently, Angka differs from Anemesia in having a rounded (as in most nemesiids) sternum with small submarginal sigilla, the aspinose leg tarsi with equally and evenly bipectinate PTC (op. cit., fig. 3D), and tiny PMS. It can also be distinguished from the latter by the absence of an eye tubercle or any developed clypeus, and the apical spine cluster on the female femur IV. No characters demonstrating a common specialisation shared by these genera, except possibly the same type of megaspine localisation, are evident. In other words, despite several characters shared by Angka and Anemesia, most of them are here considered symplesiomorphic and thus not indicating the close relationship between these genera.

Owing to the presence of the second teeth row, Anemesia shows some resemblance to Homostola; additional similarity is based on the fact that in the latter genus legs I-II either equal in width to legs 
III-IV, or only slightly thicker than the posterior legs, and the congeners appear habitually to resemble Anemesia (Bond \& Hedin 2006: fig. 1B; Hedin \& Bond 2006: fig. 2M). Unfortunately, in this case no male characters could be compared, because all five species of Homostola still remain known exclusively from females (information concerning males of $H$. zebrina is based on misidentifications; see Raven 1985). The differences between Homostola and Anemesia relate mainly to the shape of the thoracic fovea and the apical segment of PLS (mostly procurved and domed in the former genus vs more or less straight and triangular to shortly digitiform in the latter one). Apart from Anemesia, members of Homostola possess the scarcely toothed PTC I-IV (not only PTC III-IV, as in the former genus), and the metatarsal preening combs on legs III-IV. Within the Cyrtaucheniidae, Homostola appears currently to be the least distant genus from Anemesia.

The remaining variants can be presented here as follows. The Euctenizidae are strictly distinguishable from Anemesia in a great array of parameters, including the family level features listed by Raven (1985), Bond \& Opel (2002) and Bond et al. (2012b). Unlike Anemesia, the genera of Nemesiinae generally have a normally hirsute carapace, a rounded sternum with small submarginal sigilla, unarmed leg tarsi with equally multi-dentate PTC, a shortened male palpal tibia, and predominantly ventral or prolateral megaspines (only males representing the monotypic Mexentypesa Raven, 1987 possess a sessile retroventral megaspine; see Raven 1987: fig. 2). The members of Bemmerinae, although they also have the sigilla located distantly from the sternal edge, differ from Anemesia in having male PTC with a single S-shaped teeth row, and megaspines located ventrally and/or prolaterally. Thus, until both families, Cyrtaucheniidae and Nemesiidae, are revised and the character polarity is specified for these groups, Anemesia could be tentatively considered as a representative of the Cyrtaucheniidae incertae sedis, with the reservation that the genus seems to be more closely related to Homostola rather than to other cyrtaucheniid genera.

\section{Biogeography}

As a member of the Cyrtaucheniidae, the Central Asian Anemesia is isolated geographically from the prime range of this family which covers, according to the World Spider Catalog (2018), Central and South America, the entire African continent and the Western Mediterranean. Hence, the genus appears to be separated from this main family range by a vast area, including the fairly well-studied Eastern Mediterranean, where cyrtaucheniids have not been detected. In relation to Anemesia, the geographically closest family members are known from Algeria (Cyrtauchenius), mainland Italy, Sardinia and Sicily (Amblyocarenum), and Ethiopia (Ancylotrypa). Such isolation, however, does not represent anything extraordinary. In comparison with Anemesia, the South-East Asian cyrtaucheniid Angka appears to be isolated from other genera of this family to a much greater extent.

Biogeographically, the distribution of Anemesia is limited to the area of Turkmen-Khorassan and the Turkestan multi-zonal provinces belonging to the arid Sahara-Gobian Region of the Palearctic realm (see Kryzhanovski 1965, 2002). The known range of the genus is thus confined to the north-eastern part of the Turkmen-Horassan biogeographic province (Kopetdag and Piropamiz Mts, Badhyz and Karabyl Plateaus) and to the adjoining south-western part of the Turkestan biogeographic province (the western Hissar-Alaj Mts and Afghan-Tajik Depression). Within this range, two centres of species diversity can be currently observed; one in each of the noted provinces, respectively.

The first of these is restricted to the south-western Badhyz, where three of the four known members of tubifex species group are sympatric. The second centre of species diversity, even more defined, is located in the territory of the Afghan-Tajik Depression. Regarding the Tajik part of this region, many of the investigated localities are known to host three and some of them (e.g., Ganjina) four sympatric congeners. Three of six species groups and eight of fourteen species of Anemesia are represented only here (see Figs 370-373). Outside the mentioned centres and at the range periphery, the genus is 
represented by a few sub-allopatric species (in the localities situated closer to the diversity centres, these species, $A$. andreevae sp. nov., A. birulai and $A$. sogdiana sp. nov., are sympatric with some other congeners).

Unfortunately, the scarcity of data regarding the spider fauna of Iran and Afghanistan (Logunov \& Zamanpoore 2005; Mirshamsi 2005; Logunov 2010) leaves some questions open. It is thus impossible at present to determine whether these two diversity centres are indeed isolated from one another, or whether we are able to see here only the two visible endings of a single invisible arc stretching across the northern face of the Hindu Kush, from Horassan in the west to the Pamirs in the east.

\section{Acknowledgements}

I am deeply grateful to all the curators and managers of spider collections, who generously allowed me to examine a considerable part of the material used in this study. The holotype of Nemesia tubifex was examined by courtesy of Janet Beccaloni (NHML), during my visit to London in 2010. Vladimir Ovcharenko, the former curator of the ZISP spider collection, helped me to obtain the holotype of Brachythele birulai. Wioletta Wawer (MIZW) kindly provided me on loan the paratypes of Brachythele karatauvi and many other specimens of Anemesia from Tajikistan. Ansie Dippenaar-Schoeman and Petro Marais (NCA), Charles Griswold and Lauren Esposito (CAS), Peter Jäger and Julia Altmann (SMF), Rudy Jocqué and Arnaud Henrard (MRAC), Seppo Koponen (ZMUT), Dmitri Logunov (MMUM), Christine Rollard and Elise-Anne LeGuin (MNHN) and Peter Schwendinger (MHNG) generously helped with obtaining on loan the comparative material used in this study. Additionally, special thanks are due to Rudy Jocqué, Seppo Koponen and Yuri Marusik (Institute for Biological Problems of the North, Magadan, Russia), for providing me with museum facilities and help in SEM studies. The considerate help of Kirill Mikhailov (ZMMU), Nikolai Pakhorukov (PSU) and Nikolaj Scharff (NHMD) allowed me to examine some doubtful material noted by Vlasov \& Sytshevskaya (1935), Denis (1958) and Charitonov (1969).

Andrey Feodorov (Institute of Zoology, Almaty, Kazakhstan), Yuri Marusik, Rustam Muratov (Institute of Zoology and Parasitology, Dushanbe, Tajikistan) and Murod Saidov (Dushanbe, Tajikistan) helped in organising and providing collecting trips in Turkmenistan and Uzbekistan in March-May 1993, and Tajikistan in April-May 2002 and April-May 2015.

An early draft of the manuscript was kindly edited by Naomi Paz (Tel-Aviv University). The completion of this study was possible due to the financial support provided by the Ministry of Absorption, Israel.

\section{References}

Abraham H.C. 1924. Some mygalomorph spiders from the Malay Peninsula. Proceedings of the Zoological Society of London 1924: 1091-1124. https://doi.org/10.1111/j.1096-3642.1924.tb03332.x

Andreeva E.M. 1968. Materialy po faune paukov Tajikistana [Materials to the spider fauna of Tajikistan]. III. Mygalomorphae. Doklady AN Tadzhikskoi SSR 11 (7): 68-71.

Andreeva E.M. 1976. Pauki Tajikistana [Spiders of Tajikistan]. Donish, Dushanbe.

Blandin P. \& Célérier M.-L. 1977. Observations sur les mygales terricoles récoltées à la Station d'écologie tropicale de Lamto (Côte d'Ivoire). Revue Arachnologique 1: 75-83.

Bond J.E. 2004. Systematics of the Californian euctenizine spider genus Apomastus (Araneae: Mygalomorphae: Cyrtaucheniidae): the relationship between molecular and morphological taxonomy. Invertebrate Systematics 18: 361-376. 
Bond J.E. \& Godwin R.L. 2013. Taxonomic revision of the trapdoor spider genus Eucteniza Ausserer (Araneae, Mygalomorphae, Euctenizidae). ZooKeys 356: 31-67.

https://doi.org/10.3897/zookeys.356.6227

Bond J.E. \& Hedin M. 2006. A total evidence assessment of the phylogeny of North American euctenizine trapdoor spiders (Araneae, Mygalomorphae, Cyrtaucheniidae) using Bayesian inference. Molecular Phylogenetics and Evolution 41: 70-85. https://doi.org/10.1016/j.ympev.2006.04.026

Bond J.E. \& Opel B.D. 2002. Phylogeny and taxonomy of the genera of south-western North American Euctenizinae trapdoor spiders and their relatives (Araneae: Mygalomorphae, Cyrtaucheniidae). Zoological Journal of the Linnean Society 136: 487-534. https://doi.org/10.1046/j.1096-3642.2002.00035.x

Bond J.E., Hamilton C.A., Garrison N.L. \& Ray C.H. 2012a. Phylogenetic reconsideration of Myrmekiaphila systematics with a description of the trapdoor spider species Myrmekiaphila tigris (Araneae, Mygalomorphae, Cyrtaucheniidae, Euctenizinae) from Auburn, Alabama. ZooKeys 190: 94 -109. https://doi.org/10.3897/zookeys.190.3011

Bond J.E., Hendrixson B.E., Hamilton C.A. \& Hedin M. 2012b. A reconsideration of the classification of the spider infraorder Mygalomorphae (Arachnida: Araneae) based on three nuclear genes and morphology. PLoS ONE 7 (6): e38753. https://doi.org/10.1371/journal.pone.0038753

Bonnet P. 1955. Bibliographia araneorum Vol. 2 (1). Douladoure, Toulouse.

Brignoli P.M. 1972. Une nouvelle Brachythele de l'Iran (Arachnida, Araneae, Dipluridae). Revue Suisse de Zoologies 79: 409-413.

Brignoli P.M. 1983. A Catalogue of Araneae Described between 1940 and 1981. Manchester University Press, Manchester.

Buchli H.H.R. 1966. Notes sur la mygale terricole Amblyocarenum simile (Ausserer 1871) (Arach., Araneae). Senckenbergiana Biologica 47: 11-22.

Charitonov D.E. 1948. Pauki - Araneina [Spiders - Araneina]. In: Pavlovsky E.N. (ed.) Zhivotnyi mir SSSR [Animal World of the USSR], vol. 2: 297-304. Akademiya Nauk USSR, Moscow-Leningrad.

Charitonov D.E. 1969. Materialy po faune paukov SSSR [Materials to the Spider Fauna of the USSR]. Uchenye Zapiski Permskogo Universiteta 179: 59-133.

Decae A.E. 1996. Variation in burrow morphology of Mediterranean trapdoor spiders (Ctenizidae, Cyrtaucheniidae, Nemesiidae). Revie suisse de Zoologie, Volume hors série 1: 135-140.

Decae A.E. 2005. Trapdoor spiders of the genus Nemesia Audouin, 1826 on Majorca and Ibiza: taxonomy, distribution and behaviour (Araneae, Mygalomorphae, Nemesiidae). Bulletin of the British Arachnological Society 13: 145-168.

Decae A.E. 2012. Geography-related sub-generic diversity within the Mediterranean trapdoor spider genus Nemesia (Araneae, Mygalomorphae, Nemesiidae). Arachnologische Mitteilungen 43: 24-28. https://doi.org/10.5431/aramit4304

Decae A.E. \& Bosmans R. 2014. Synonymy of the trapdoor spider genera Cyrtauchenius Thorell, 1869 and Amblyocarenum Simon, 1892 reconsidered (Araneae, Mygalomorphae, Cyrtaucheniidae). Arachnology 16 (5): 182-192.

Decae A. \& Cardoso P. 2006. Iberesia, a new genus of trapdoor spiders (Araneae, Nemesiidae) from Portugal \& Spain. Revista Ibérica de Aracnología 12: 3-11.

Decae A., Colombo M. \& Manunza B. 2014. Species diversity in the supposedly monotypic genus Amblyocarenum Simon, 1892, with the description of a new species from Sardinia (Araneae, Mygalomorphae, Cyrtaucheniidae). Arachnology 16 (6): 228-240. 
Decae A., Pantini P. \& Isaia M. 2015. A new species-complex within the trapdoor spider genus Nemesia Audouin 1826 distributed in northern and central Italy, with descriptions of three new species (Araneae, Mygalomorphae, Nemesiidae). Zootaxa 4059 (3): 525-540. https://doi.org/10.11646/zootaxa.4059.3.5

Denis J. 1958. Araignées (Araneidea) de l'Afghanistan. I. Videnskabelige Meddelelser fra Dansk Naturhistorisk Forening 120: 81-120.

Dippenaar-Schoeman A.S. 2002. Baboon and Trapdoor Spiders of Southern Africa: an Identification Manual. Plant Protection Research Institute Handbook 13, Pretoria.

Dippenaar-Schoeman A.S. 2014. Field Guide to Spiders of South Africa. LAPA Publishers Ltd, Pretoria.

Ferretti N. \& Pompozzi G. 2016. Description of the male of Stenoterommata uruguai (Araneae: Mygalomorphae: Nemesiidae) from Northeastern Argentina, with notes on its natural history. Revista Mexicana de Biodiversidad 87: 527-530.

Fet V.Y. 1984. Novyi vid paukov iz Turkmenskoi SSR: Brachythele kopetdagensis sp. nov. (Aranei, Dipluridae) [A new species of spider from the Turkmen SSR: Brachythele kopetdagensis sp. nov. (Aranei, Dipluridae)]. In: Utochkin A.S. (ed.) Fauna i ekologiya paukoobraznyh [Fauna and Ecology of Arachnids]: 37-41. University of Perm, Perm.

Garrison N.L., Rodriguez J., Agnarsson I., Coddington J.A., Griswold C.E., Hamilton C.A., Hedin M., Kocot K.M., Ledford J.M. \& Bond J.E. 2016. Spider phylogenomics: untangling the Spider Tree of Life. PeerJ, 4: e1719. https://doi.org/10.7717/peerj.1719

Goloboff P.A. 1993. A reanalysis of the mygalomorph spider families (Araneae). American Museum Novitates 3056: 1-32.

Goloboff P.A. 1995. A revision of the South American spiders of the family Nemesiidae (Araneae, Mygalomorphae). Part I: species from Peru, Chile, Argentina, and Uruguay. Bulletin of the American Museum of Natural History 224: 1-189.

Hedin M. \& Bond J.E. 2006. Molecular phylogenetics of the spider infraorder Mygalomorphae using nuclear rRNA genes (18S and 28S): conflict and agreement with the current system of classification. Molecular Phylogenetics and Evolution 41: 454-471. https://doi.org/10.1016/j.ympev.2006.05.017

Ivanov A.V. 1965. Pauki, ih stroenie,obraz zhizni i znachenie dlya cheloveka [Spiders, their Structure, Mode of Life and Significance for the Human Being]. Academy of Sciences of USSR, Leningrad.

Jocqué R. \& Dippenaar-Schoeman A.S. 2006. Spider Families of the World. Musée Royal de l'Afrique Central, Tervuren.

Kroneberg A.I. 1875. Araneae. In: Fedchenko A.P. (ed.) Puteshestvie v Turkestan. Reisen in Turkestan. Zoologischer Theil. Nachrichten der Gesellschaft der Freunde der Naturwissenschaften zu Moskau 19 (3): 1-58. [In Russian.]

Kryzhanovsky O.L. 1965. Sostav i proiskhozhdenie nazemnoi fauny Srednei Azii [The Composition and Origin of the Terrestrial Fauna of Middle Asia]. Nauka, Moscow-Leningrad.

Kryzhanovsky O.L. 2002. Sostav i rasprostranenie entomofaun zemnogo shara [Composition and Distribution of the Insect Faunas of the World]. KMK Press, Moscow.

Kuznetsov G.T. \& Fet V.Y. 1986. Materialy po faune paukov Kopetdaga [Materials on the spider fauna of Kopetdag Mts]. In: Shcherbak N.N (ed.) Priroda Tsentral'nogo Kopetdaga [The nature of the Central Kopetdag]: 48-67. Ylym, Ashkhabad. [In Russian.]

Lazarov S.P. 2005. A new spider species from Bulgaria, Brachythele langourovi sp. n. (Araneae, Nemesiidae). Revue suisse de Zoologie 112: 189-193. https://doi.org/10.5962/bhl.part.80294 
Leavitt D.H., Starrett J., Westphal M.F. \& Hedin M. 2015. Multilocus sequence data reveal dozens of putative cryptic species in a radiation of endemic Californian mygalomorph spiders (Araneae, Mygalomorphae, Nemesiidae). Molecular Phylogenetics and Evolution 91: 56-67.

https://doi.org/10.1016/j.ympev.2015.05.016

Logunov D.V. 2010. Taxonomic notes on a collection of jumping spiders from Iran (Araneae, Salticidae). Bulletin of the British Arachnological Society 15: 85-90

Logunov D.V. \& Zamanpoore M. 2005. Salticidae (Araneae) of Afghanistan: an annotated check-list, with descriptions of four new species and three new synonymies. Bulletin of the British Arachnological Society 13: 217-232.

Marusik Y.M., Zamani A. \& Mirshamsi O. 2014. Three new species of mygalomorph and filistatid spiders from Iran (Araneae, Cyrtaucheniidae, Nemesiidae and Filistatidae). ZooKeys 463: 1-10. https://doi.org/10.3897/zookeys.463.8692

Mikhailov K.G. 1996. A checklist of the spiders of Russia and other territories of the former USSR. Arthropoda Selecta 5 (1-2): 75-137.

Mikhailov K.G. 1997. Catalogue of the Spiders of the Territories of the Former Soviet Union (Arachnida, Aranei). ZMMU Publications, Moscow.

Mikhailov K.G. \& Fet V. 1994. Fauna and zoogeography of spiders (Aranei) of Turkmenistan. In: Fet V. \& Atamuradov K.I. (eds) Biogeography and Ecology of Turkmenistan: 499-524. Kluwer Academic Publishers, Dordrecht/Boston/London.

Mirshamsi O. 2005. Faunistic study of spiders in Khorasan Province, Iran (Arachnida: Araneae). Iranian Journal of Animal Biosystematics 1 (1): 59-66.

Murphy J.A. \& Roberts M.J. 2015. Spider Families of the World and their Spinnerets. Volumes 1 and 2. British Arachnological Society, York.

Nikolaev V.G. 2002. Afghan-Tajik Depression: architecture of sedimentary cover and evolution. Russian Journal of Earth Sciences 4 (6): 399-421.

Ortega D.R.M., Nagahama R.H., Motta P.C. \& Bertani R. 2013. Three new species of Fufius Simon, 1888 (Araneae, Cyrtaucheniidae) from Brazil with the redescription of Fufius funebris Vellard, 1924 and description of the female of Fufius lucasae Guadanucci \& Indicatti, 2004. ZooKeys 352: 93-116. https://doi.org/10.3897/zookeys.352.6189

Ovcharenko V.I. \& Fet V.Y. 1980. Fauna i ekologiya paukov (Aranei) Badhyza (Turkmenskaya SSR) [Fauna and Ecology of Spiders (Aranei) of Badhyz (Turkmenian SSR)]. Entomologicheskoe Obozrenie 59 (2): 442-447.

Pocock R.I. 1889. The zoology of Afghan delimitation commission. Arachnida, Myriapoda and Crustacea. Transactions of Linnean Society of London 5 (3): 110-121.

Pocock R.I. 1895. Descriptions of new genera and new species of trapdoor spiders belonging to the group Trionychi. Annals and Magazine of Natural History 6 (16): 187-197.

Raven R.J. 1981. A review of the Australian genera of the mygalomorph spider subfamily Diplurinae (Dipluridae: Chelicerata). Australian Journal of Zoology 29: 321-363.

Raven R.J. 1983. Notes on some mygalomorph spiders in the Musée Royal de l'Afrique Centrale (Dipluridae, Hexathelidae, Ctenizidae: Araneae). Revue zoologique africaine 97: 549-562.

Raven R.J. 1985. The spider infraorder Mygalomorphae (Araneae): cladistics and systematics. Bulletin of American Museum of Natural History 182 (1): 1-180. 
Raven R.J. 1987. A new mygalomorph spider genus from Mexico (Nemesiinae, Nemesiidae, Arachnida). Journal of Arachnology 14: 357-362.

Raven R.J. \& Schwendinger P.J. 1995. Three new mygalomorph spider genera from Thailand and China (Araneae). Memoirs of the Queensland Museum 38: 623-641.

Reimoser E. 1919. Katalog der echten Spinnen (Araneae) des paläarktischen Gebietes. Abhandlungen der Zoologische-Botanischen Gesellschaft in Wien 10 (2): 1-280.

Roewer C.F. 1942. Katalog der Araneae von 1758 bis 1940. Volume 1. Natura, Bremen.

Rudloff J.-P. 1996. Primer reporte de una especie de la familia Cyrtauchenidae [sic] de Cuba inclusive una descripción de una nueva especie del genéro Bolostromus (Ausserer, 1875) (Cyrtauchenidae [sic]: Mygalomorphae: Araneida). Garciana 24: 17-19.

Schiapelli R.D. \& Gerschman B.S. 1945. Parte descriptiva. In: Vellard J., Schiapelli R.D. \& Gerschman B.S. (eds) Arañas sudamericanas colleccionadas por el Doctor J. Vellard. I. Theraphosidae nuevas o poco conocidas. Acta Zoologica Lilloana 3: 165-213.

Schwendinger P.J. 2009. A taxonomic revision of the genus Phyxioschema (Araneae, Dipluridae), I: species from Thailand. Zootaxa 2126: 1-40.

Schwendinger P.J. \& Zonstein S.L. 2011. A taxonomic revision of the genus Phyxioschema (Araneae, Dipluridae), II: species from central Asia. Zootaxa 2815: 28-48.

Siliwal M., Molur S. \& Raven R. 2015. New genus with two new species of the family Nemesiidae (Araneae: Mygalomorphae) from Arunachal Pradesh, India. Journal of Asia-Pacific Biodiversity 8: $43-$ 48. https://doi.org/10.1016/j.japb.2015.01.005

Simon E. 1889. Descriptions d'espèces africaines nouvelles de la famille des Aviculariidae. Actes de la Société Linnéenne de Bordeaux 42: 405-415.

Simon E. 1892. Histoire naturelle des araignées. Volume 1 (1). Roret, Paris.

https://doi.org/10.5962/bhl.title.51973

Simon E. 1903. Histoire naturelle des araignées. Volume 2 (4). Roret, Paris. https://doi.org/10.5962/bhl.title.51973

Smith C.P. 1908. A preliminary study of the Araneae Theraphosidae of California. Annals of the Entomological Society of America 1: 207-236.

Spassky S.A. 1937. Araneae palaearcticae novae. I. Mygalomorphae. Festschrift zum 60. Geburtstage von Professor Dr. Embrik Strand 3: 361-368.

Spassky S.A. 1952. Pauki Turanskoi zoogeografichesloi provintzii [Spiders of the Turan zoogeographical province]. Entomologicheskoe Obozrenie 32: 192-205.

Spassky S.A. \& Minenkova K. 1940. Novye dannye po paukam gryppy Mygalomorphae v SSSR i nekotorye vyvody iz ih geograficheskogo rasprostraneniya [New data on spiders of the group Mygalomorphae in the USSR and some conclusions from their geographical distribution]. Trudy Rostovskogo Biologicheskogo Obshchestva 4: 138-141.

Thaler K. \& Knoflach B. 2001. Open burrows in a nemesiid spider Brachythele sp. from Greece. British Arachnological Society Newsletter 91: 5-6.

Valdez-Mondragón A. \& Cortez-Roldán M.R. 2016. On the trapdoor spiders of Mexico: description of the first new species of the spider genus Aptostichus from Mexico and the description of the female of Eucteniza zapatista (Araneae, Mygalomorphae, Euctenizidae). ZooKeys 641: 81-102. https://doi.org/10.3897/zookeys.641.10521 
Vellard J. 1945. Observaciones biológicas. In: Vellard J., Schiapelli R.D. \& Gerschman B.S. (eds) Arañas sudamericanas coleccionadas por el Doctor J. Vellard. I. Theraphosidae nuevas o poco conocidas. Acta Zoologica Lilloana 3: 195-213.

Vlasov Y.P. \& Sytshevskaya V.I. 1937. Pauki okrestnostei Ashkhabada [The spiders of the neighbourhood of Ashkhabad]. Problemy Parazitologii i Fauny Turkmenistana 9: 247-258.

Wheeler W.C., Coddington J.A., Crowley L.M., Dimitrov D., Goloboff P.A., Griswold C.E., Hormiga G., Prendini L., Ramírez M.J., Sierwald P., Almeida-Silva L.M., Álvarez-Padilla F., Arnedo M.A., Benavides L.R., Benjamin S.P., Bond J.E., Grismado C.J., Hasan E., Hedin M., Izquierdo M.A., Labarque F.M., Ledford J., Lopardo L., Maddison W.P., Miller J.A., Piacentini L.N., Platnick N.I., Polotow D., SilvaDávila D., Scharff N., Szüts T., Ubick D., Vink C.J., Wood H.M. \& Zhang J.X. 2017. The spider tree of life: phylogeny of Araneae based on target-gene analyses from an extensive taxon sampling. Cladistics 33 (6): 576-616. https://doi.org/10.1111/cla.12182

World Spider Catalog. 2018. World Spider Catalog. Natural History Museum Bern. Available from http://wsc.nmbe.ch, ver. 19.0 [accessed 16 Apr. 2018]. https://doi.org/10.24436/2

Zonstein S.L. 1985. Predvaritel'nye dannye po paukam podotryada Mygalomorphae fauny SSSR [Preliminary data on the spiders of the suborder Mygalomorphae of the USSR fauna]. Trudy Zoologicheskogo Instituta AN SSSR 139: 156-161.

Zonstein S.L. 1987. Novyi rod mygalomorphnyh paukov podsemeistva Nemesiinae (Aranei, Nemesiidae) fauny Palearktiki [A new mygalomorph spider genus of the subfamily Nemesiinae (Aranei, Nemesiidae) in the Palearctic fauna]. Zoologichesky Zhurnal 66 (7): 1013-1019.

Zonstein S.L. 2000. New data on Middle Asian representatives of the spider wasp genera Hemipepsis Dahlbom, 1843, Dipogon Fox, 1897, Tachyagetes Haupt, 1930, Pareiocurgus Haupt, 1962 and Pamirospila Wolf, 1970 stat. n. (Hymenoptera, Pompilidae). Tethys Entomological Research 2: 167186.

Zonstein S.L. 2001. Notes on allocation of the mygalomorph spider genus Anemesia Pocock, 1895 (Araneae), with description of a new congener from Tajikistan. Tethys Entomological Research 3: 11-14.

Zonstein S.L. 2004. The spider chelicerae: some problems of origin and evolution. In: Logunov D.V \& Penney D. (eds) European Arachnology 2003. Proceedings of the $21^{\text {st }}$ European Colloquium of Arachnology, St.-Petersburg, 4-9 August 2003. Arthropoda Selecta, Special Issue 1: 349-366.

Zonstein S.L. 2007. A new species of the spider wasp genus Claveliocnemis Wolf, with new data on distribution and biology of its congeners (Hymenoptera: Pompilidae). Israel Journal of Entomology 37: 211-220.

Zonstein S.L. 2009. A review of the mygalomorph spiders of the Raveniola caudata species-group (Araneae, Nemesiidae). Zootaxa 2217: 37-42.

Zonstein S.L. \& Marusik Y.M. 2014. A redescription of Damarchus cavernicola Abraham, 1924, with notes on Damarchus Thorell, 1891 and Atmetochilus Simon, 1887 (Aranei: Nemesiidae). Arthropoda Selecta 23 (3): 273-278.

Zonstein S.L. \& Marusik Y.M. 2016. A review of the spider genus Atmetochilus of Sumatra, Indonesia, with first analysis of male characters and description of three new species (Araneae, Nemesiidae). Zoological Studies 55 (10): 1-17. https://doi.org/10.6620/ZS.2016.55-10

Zonstein S., Kunt K.B. \& Yağmur E.A. 2018. A revision of the spider genus Raveniola (Araneae, Nemesiidae). I. Species from Western Asia. European Journal of Taxonomy 399: 1-93. https://doi.org/10.5852/ejt.2018.399 
Manuscript received: 17 May 2018

Manuscript accepted: 20 August 2018

Published on: 11 December 2018

Topic editor: Rudy Jocqué

Desk editor: Kristiaan Hoedemakers

Printed versions of all papers are also deposited in the libraries of the institutes that are members of the EJT consortium: Muséum national d'Histoire naturelle, Paris, France; Meise Botanic Garden, Belgium; Royal Museum for Central Africa, Tervuren, Belgium; Natural History Museum, London, United Kingdom; Royal Belgian Institute of Natural Sciences, Brussels, Belgium; Natural History Museum of Denmark, Copenhagen, Denmark; Naturalis Biodiversity Center, Leiden, the Netherlands; Museo Nacional de Ciencias Naturales-CSIC, Madrid, Spain; Real Jardín Botánico de Madrid CSIC, Spain; Zoological Research Museum Alexander Koenig, Bonn, Germany. 


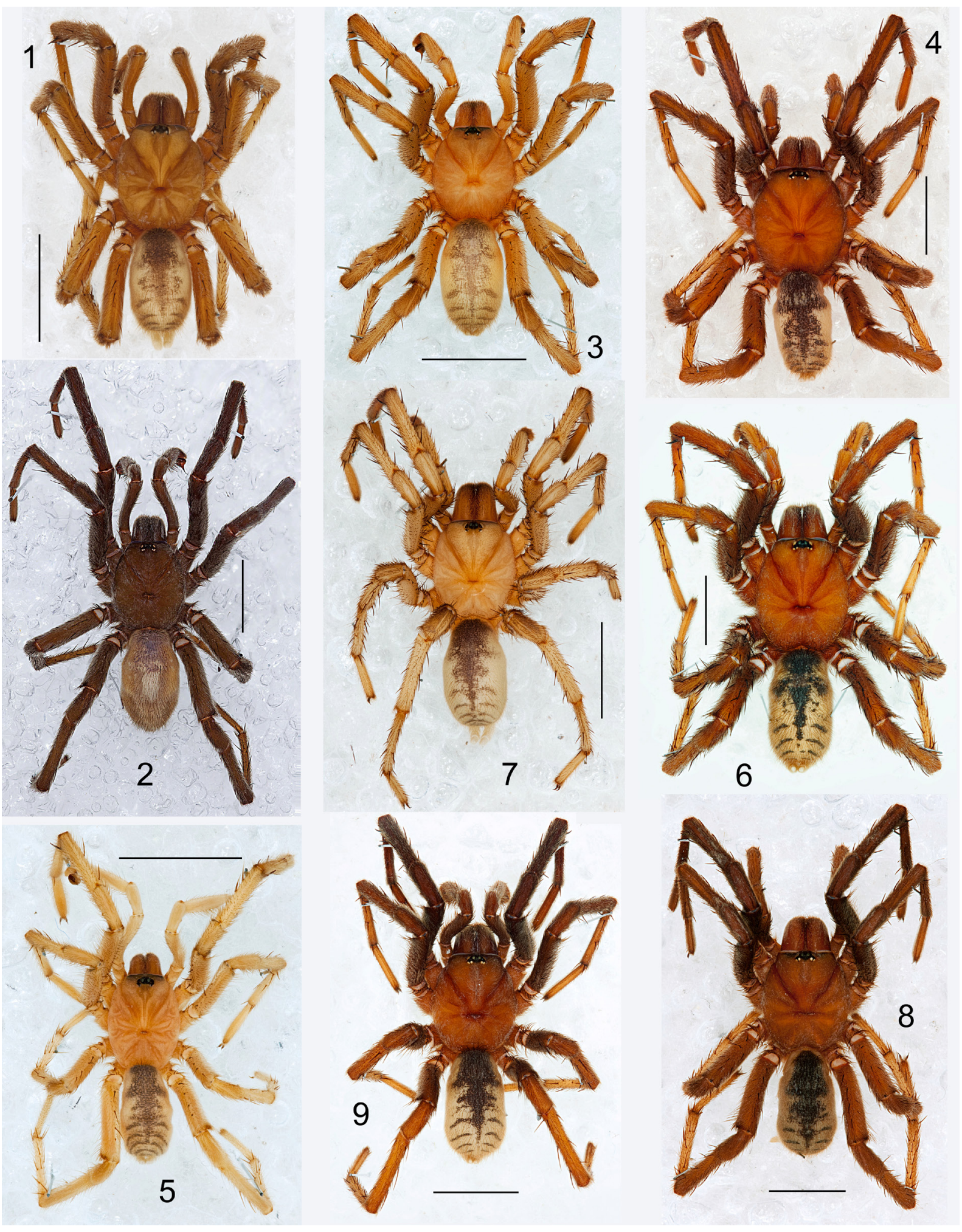

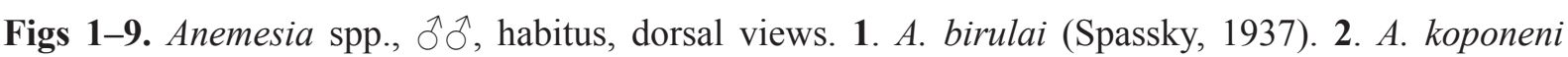
Marusik, Zamani \& Mirshamsi, 2014. 3. A. pococki sp. nov. 4. A. tubifex (Pocock, 1889). 5. A. andreevae sp. nov. 6. A. oxiana sp. nov. 7. A. sogdiana sp. nov. 8. A. castanea sp. nov. 9. A. karatauvi (Andreeva, 1968). Scale bars: $5.0 \mathrm{~mm}$. 


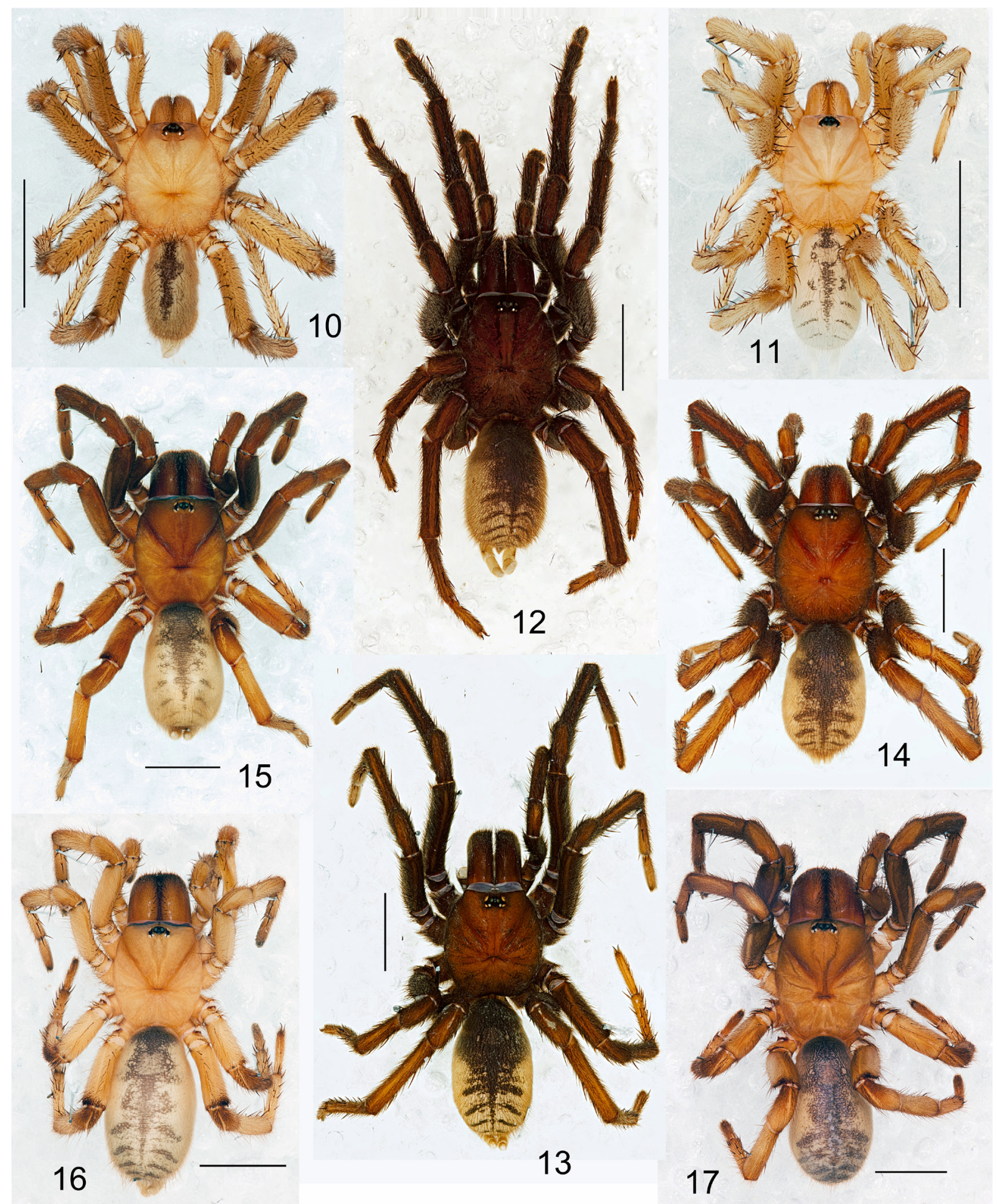

Figs 10-17. Anemesia spp., $\widehat{\partial} \widehat{\partial}(10-14)$ and $q$ + $(15-17)$, habitus, dorsal views. 10. A. pallida sp. nov. 11. A. parvula sp. nov. 12. A. incana Zonstein, 2001. 13. A. infumata sp. nov. 14. A. infuscata sp. nov. 15. A. birulai (Spassky, 1937). 16. A. pococki sp. nov. 17. A. tubifex (Pocock, 1889). Scale bars: $5.0 \mathrm{~mm}$. 


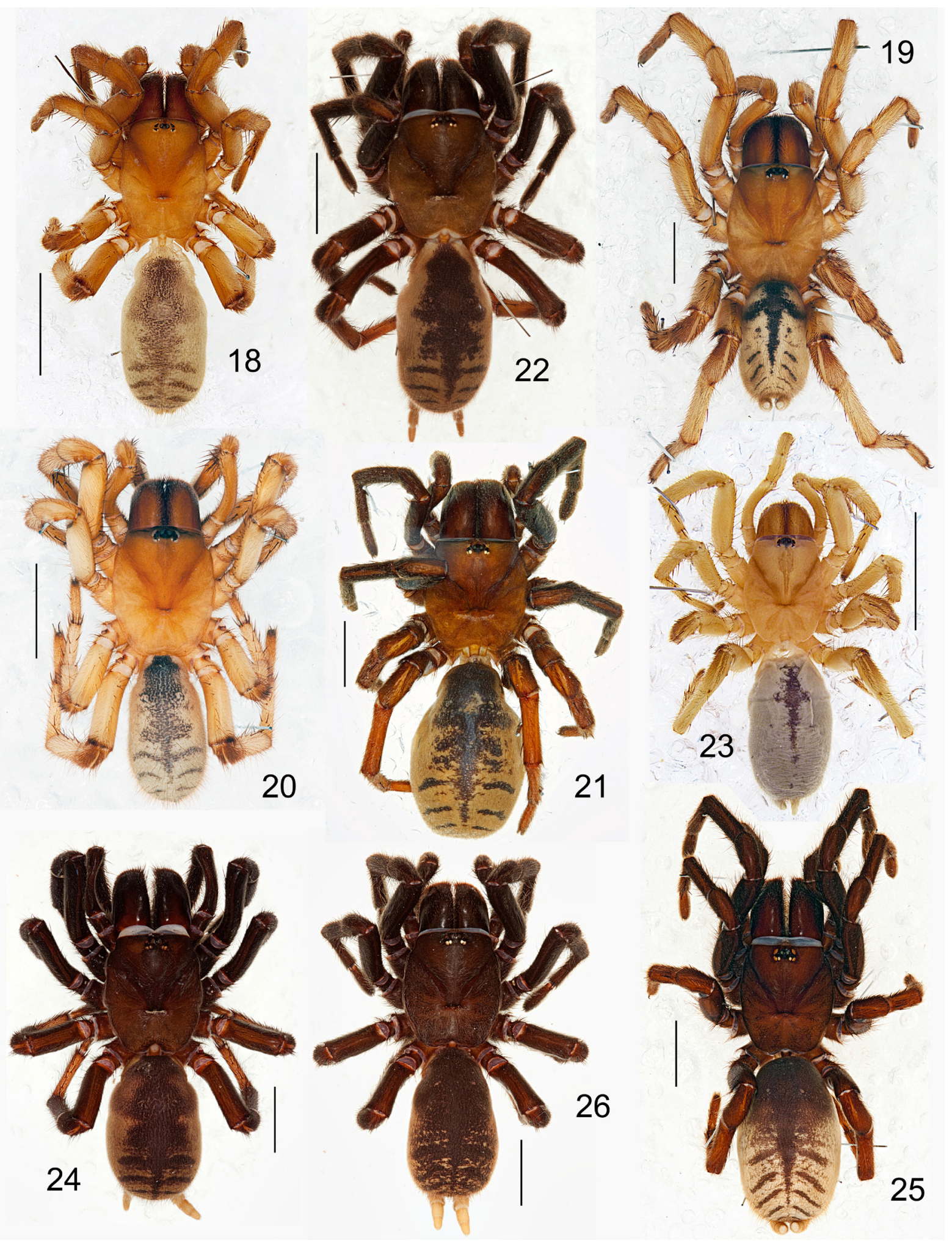

Figs 18-26. Anemesia spp., ${ }_{+}$, , habitus, dorsal views. 18. A. andreevae sp. nov. 19. A. oxiana sp. nov. 20. A. sogdiana sp. nov. 21. A. castanea sp. nov. 22. A. karatauvi (Andreeva, 1968). 23. A pallida sp. nov. 24. A. incana Zonstein, 2001. 25. A. infumata sp. nov. 26. A. infuscata sp. nov. Scale bars: $5.0 \mathrm{~mm}$. 

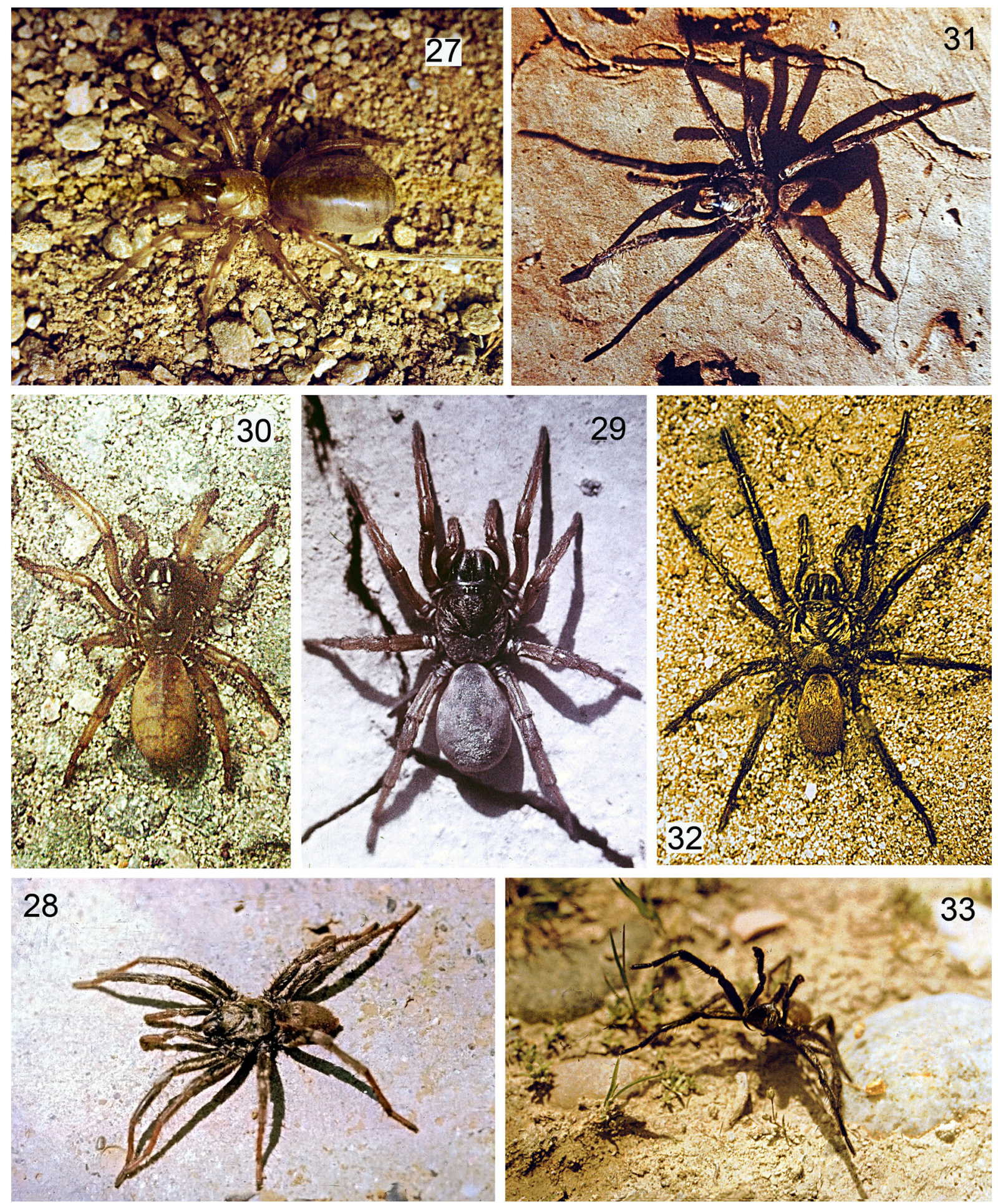

Figs 27-33. Anemesia spp., 우 $(27,29-30)$ and $\hat{\partial} \hat{\partial}(28,31-33)$, live spiders (scanned positive slides of 1986-1993); dorsolateral (27-28, 31), dorsal (29-30, 32) and frontal (33) views. 27. A. pococki sp. nov. 28-29. A. oxiana sp. nov. 30. A. sogdiana sp. nov. 31. A. karatauvi (Andreeva, 1968). 32-33. A. incana Zonstein, 2001. 

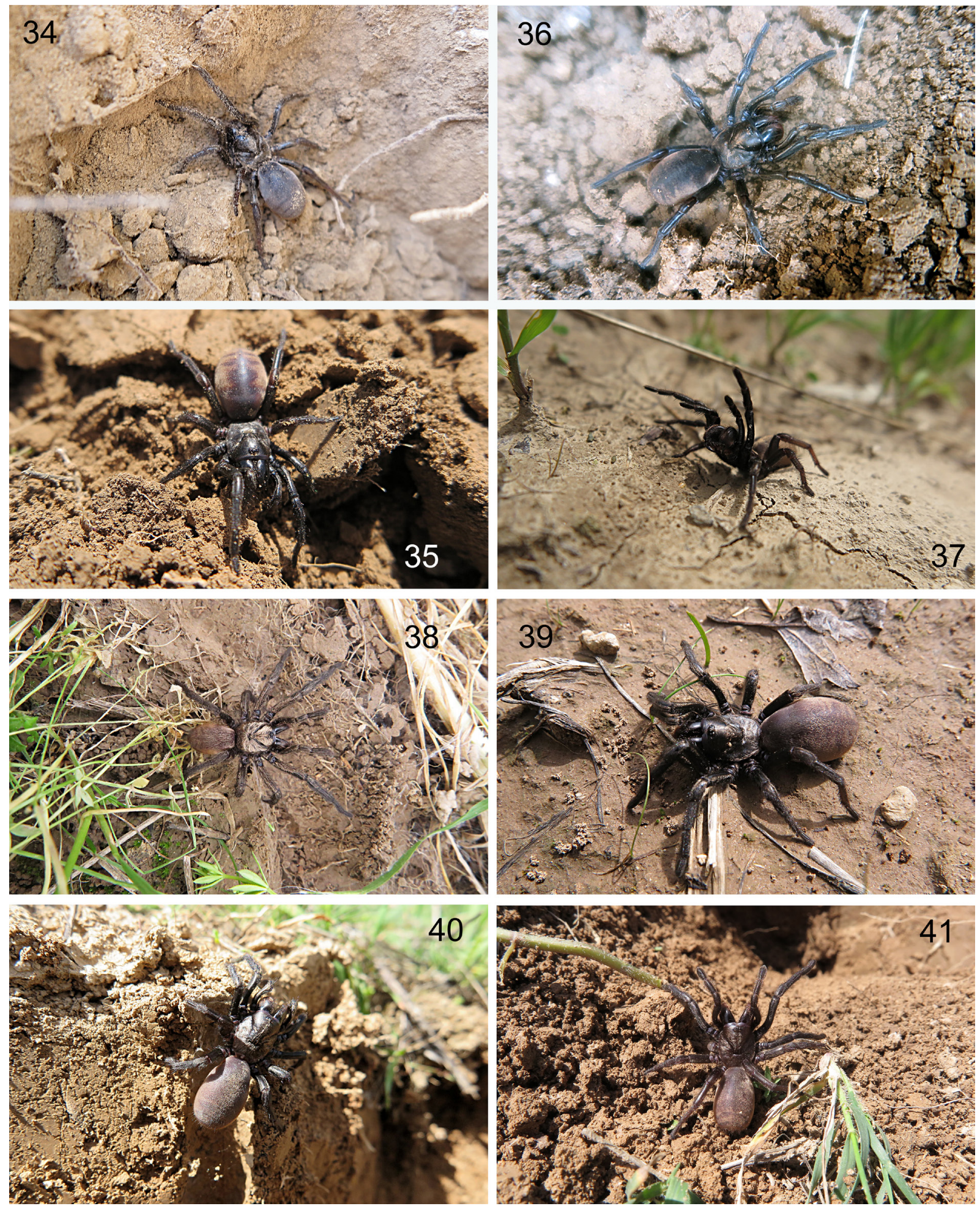

Figs 34-41. Anemesia spp., $q$ + $(34-37,39-41)$ and $\widehat{\partial}(38)$, live spiders in their natural environment; predominantly dorsal $(34-36,38-41)$ and apical (37) views. 34. A. karatauvi (Andreeva, 1968). 35. A. incana Zonstein, 2001. 36-37. A. infumata sp. nov. 38-41. A. infuscata sp. nov. 


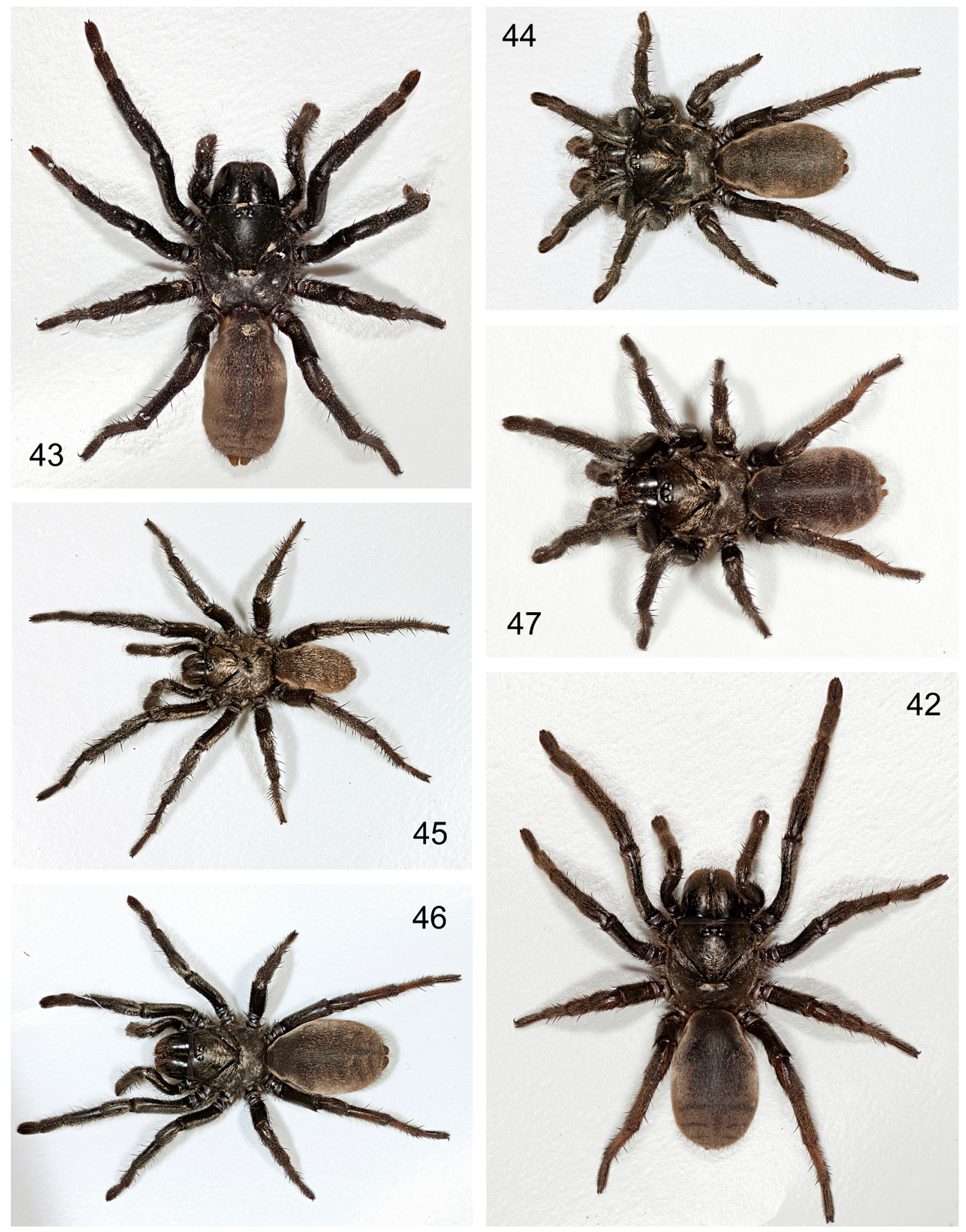

Figs 42-47. Anemesia spp., $q$ + $(42-44,46-47)$ and $\widehat{\partial}(45)$, captured live spiders; dorsal $(42-44,47)$ and dorsolateral (45-46) views. 42. A. karatauvi (Andreeva, 1968). 43-44. A. incana Zonstein, 2001, from Ganjina (43) and Vahsh Karatau Mts (44). 45-47. A. infuscata sp. nov. from Sanglok (45-46) and Kuhitek Mts (47), respectively. 

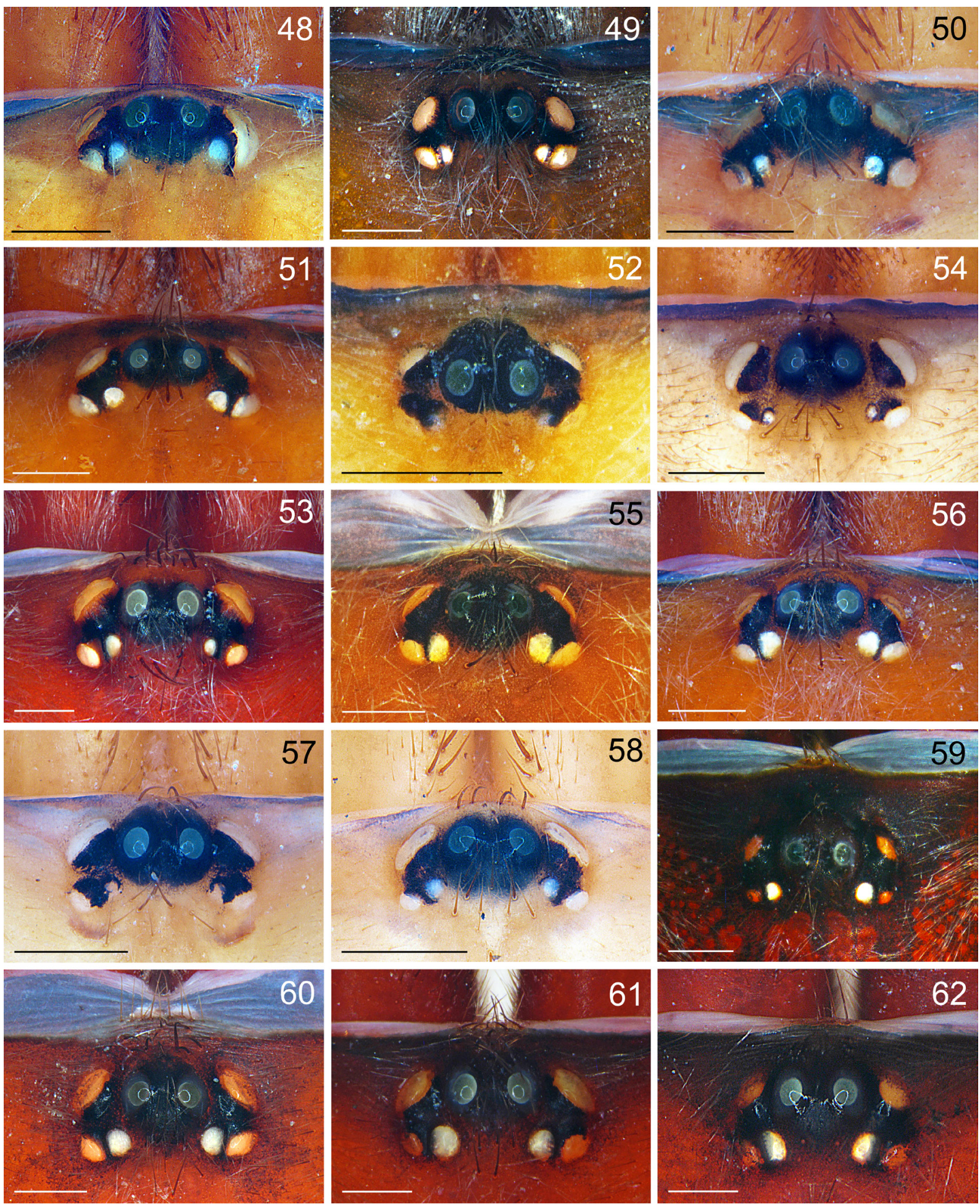

Figs 48-62. Anemesia spp., $\widehat{\jmath}$, clypeus and eye tubercle, dorsal views. 48. A. birulai (Spassky, 1937) (holotype). 49. A. koponeni Marusik, Zamani \& Mirshamsi, 2014 (holotype). 50. A. pococki sp. nov. (holotype). 51. A. tubifex (Pocock, 1889) (Kalaimor). 52. A. andreevae sp. nov. (holotype). 53. A. oxiana sp. nov. (holotype). 54. A. sogdiana sp. nov. (holotype). 55. A. castanea sp. nov. (holotype). 56. A. karatauvi (Andreeva, 1968) (Hojamaston). 57. A. pallida sp. nov. (holotype). 58. A. parvula sp. nov. (holotype). 59. A. incana Zonstein, 2001 (paratype). 60. A. infumata sp. nov. (holotype). 6162. A. infuscata sp. nov. (holotype and paratype from Sanglok Mts, respectively). Scale bars: $0.5 \mathrm{~mm}$. 

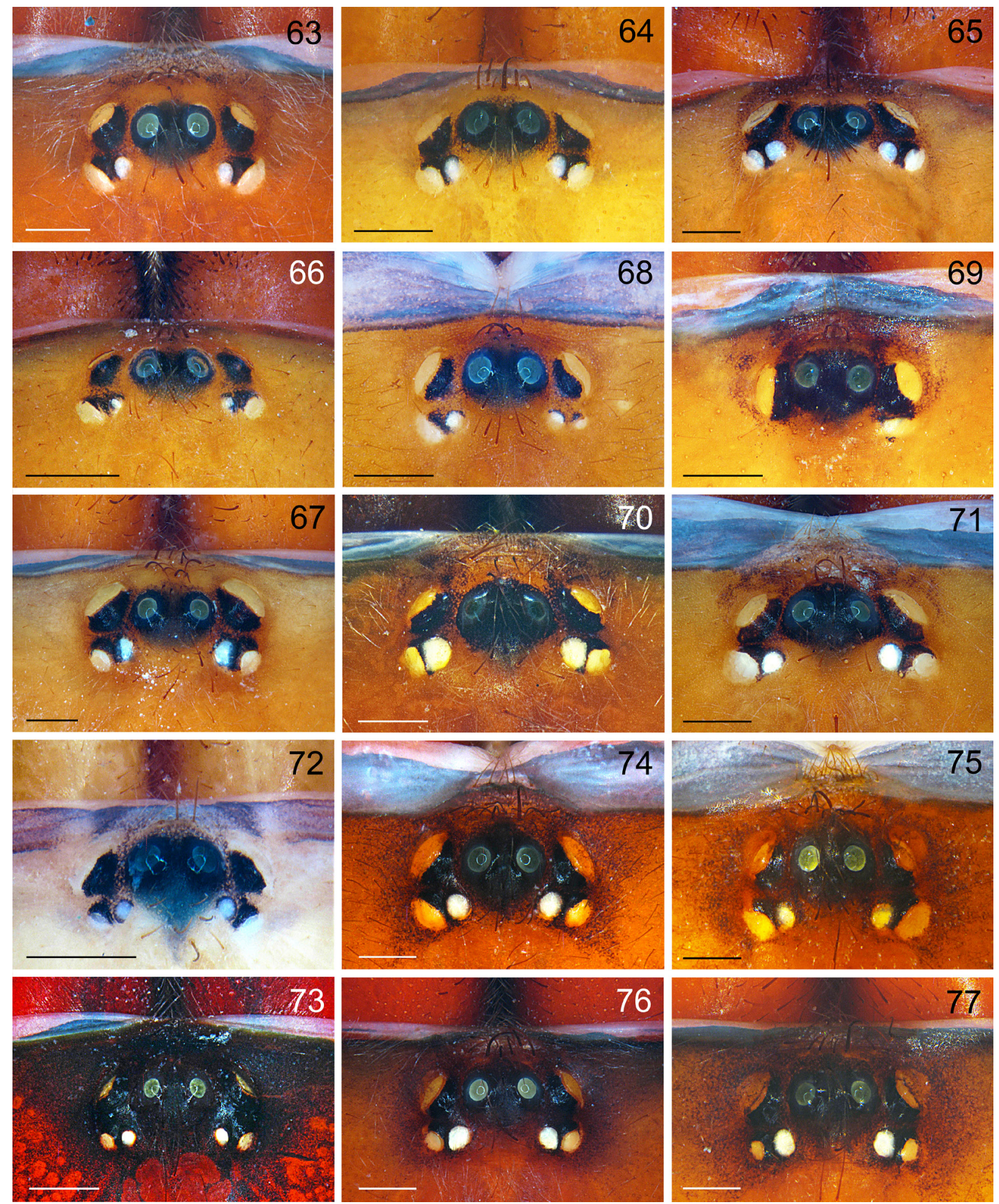

Figs 63-77. Anemesia spp., $\circ$, , clypeus and eye tubercle, dorsal views. 63. A. birulai (Spassky, 1937) (Kepele). 64. A. pococki sp. nov. (paratype). 65. A. tubifex (Pocock, 1889) (Kalaimor). 66. A. andreevae sp. nov. (paratype, Babatag Mts). 67. A. oxiana sp. nov. (paratype, Hojamaston). 68. A. sogdiana sp. nov. (paratype, Amankutan Pass). 69. Same (Baglydara). 70. A. castanea sp. nov. (Ganjina). 71. A. karatauvi (Andreeva, 1968) (paratype, Hojamaston). 72. A. pallida sp. nov. (paratype, Ganjina). 73. A. incana Zonstein, 2001. 74-75. A. infumata sp. nov. (paratypes). 76-77. A. infuscata sp. nov. (paratypes, Varzob and Sanglok Mts, respectively). Scale bars: $0.5 \mathrm{~mm}$. 

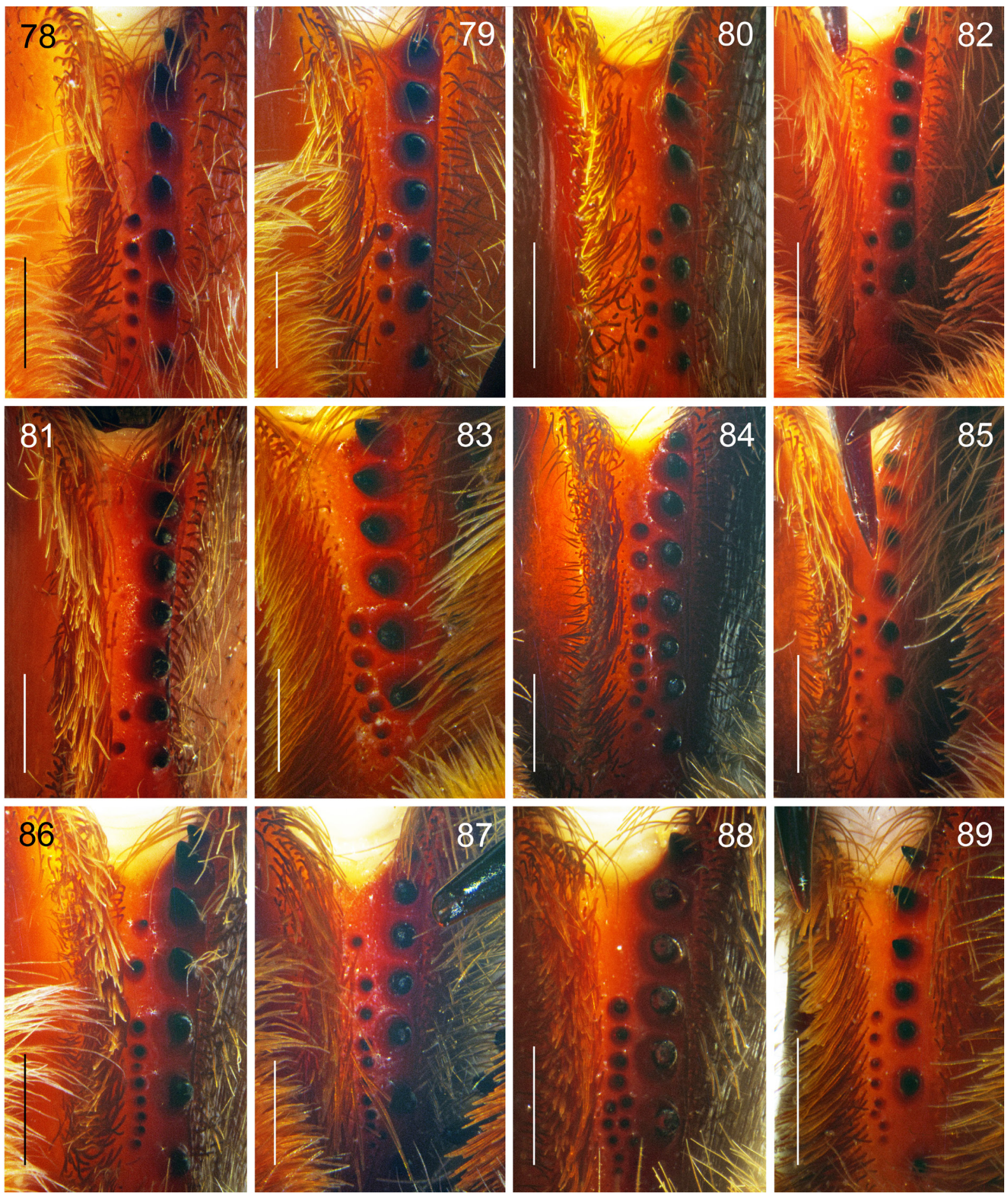

Figs 78-89. Anemesia spp., 우 $ᄋ(78-84,86-88)$ and $\widehat{\partial}(85,89)$, cheliceral furrow, ventral views. 78. A. pococki sp. nov. (paratype). 79. A. tubifex (Pocock, 1889) (Kalaimor). 80. A. andreevae sp. nov. (paratype, Babatag Mts). 81. A. oxiana sp. nov. (paratype, Ganjina). 82. A. sogdiana sp. nov. (paratype, Amankutan Pass). 83. A. karatauvi (Andreeva, 1968) (Mt Hojamaston). 84-85. A. incana Zonstein, 2001 (paratypes). 86. A. infumata sp. nov. (paratype). 87-89. A. infuscata sp. nov. (paratypes, Sanglok Mts). Scale bars: $0.5 \mathrm{~mm}$. 

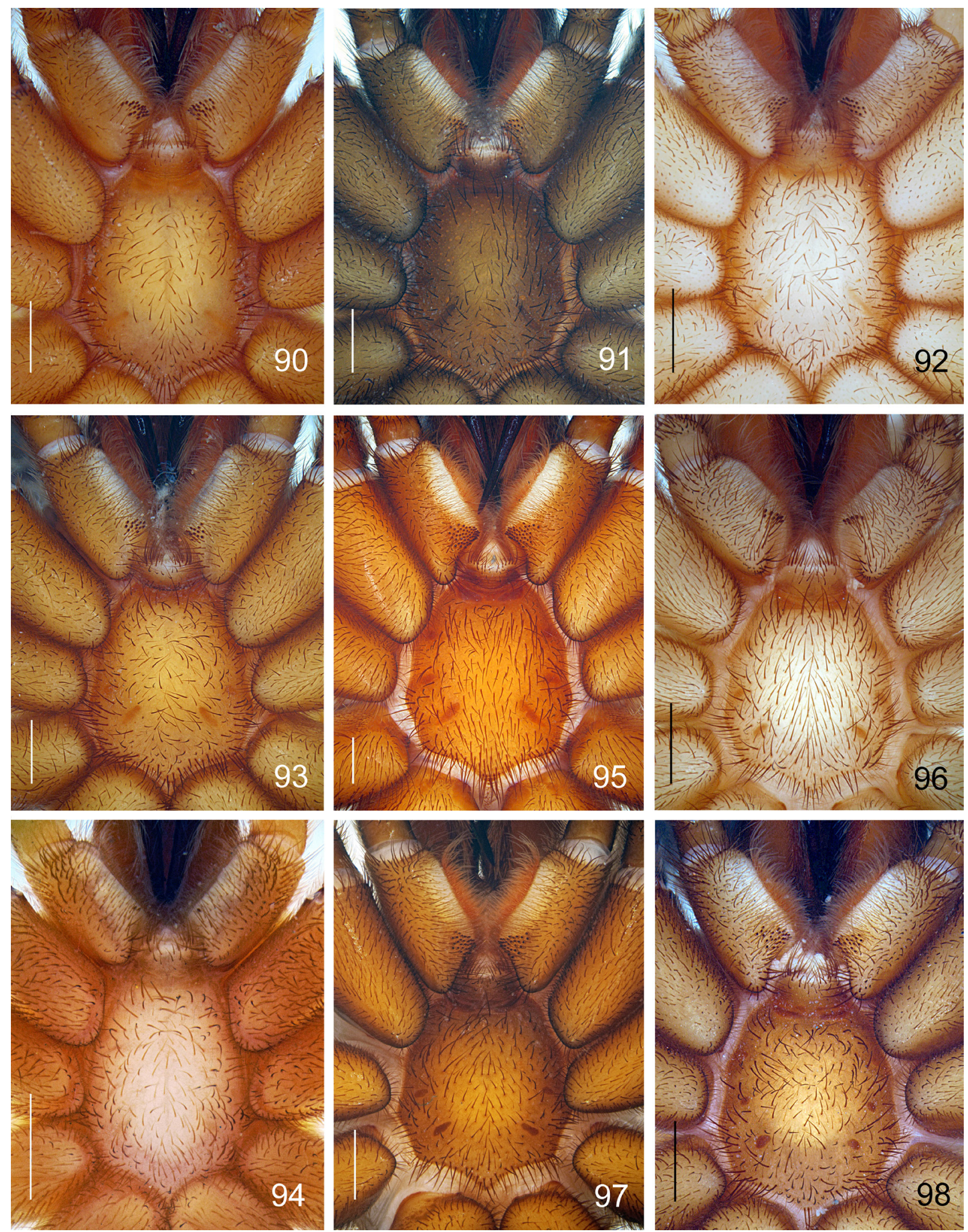

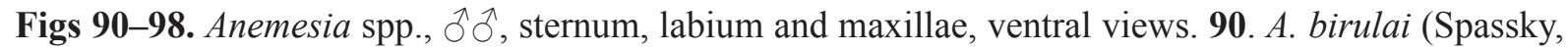
1937) (holotype). 91. A. koponeni Marusik, Zamani \& Mirshamsi, 2014 (holotype). 92. A. pococki sp. nov. (holotype). 93. A. tubifex (Pocock, 1889) (Kalaimor). 94. A. andreevae sp. nov. (holotype). 95. A. oxiana sp. nov. (holotype). 96. A. sogdiana sp. nov. (holotype). 97. A. castanea sp. nov. (holotype). 98. A. karatauvi (Andreeva, 1968) (Hojamaston). Scale bars: $1.0 \mathrm{~mm}$. 

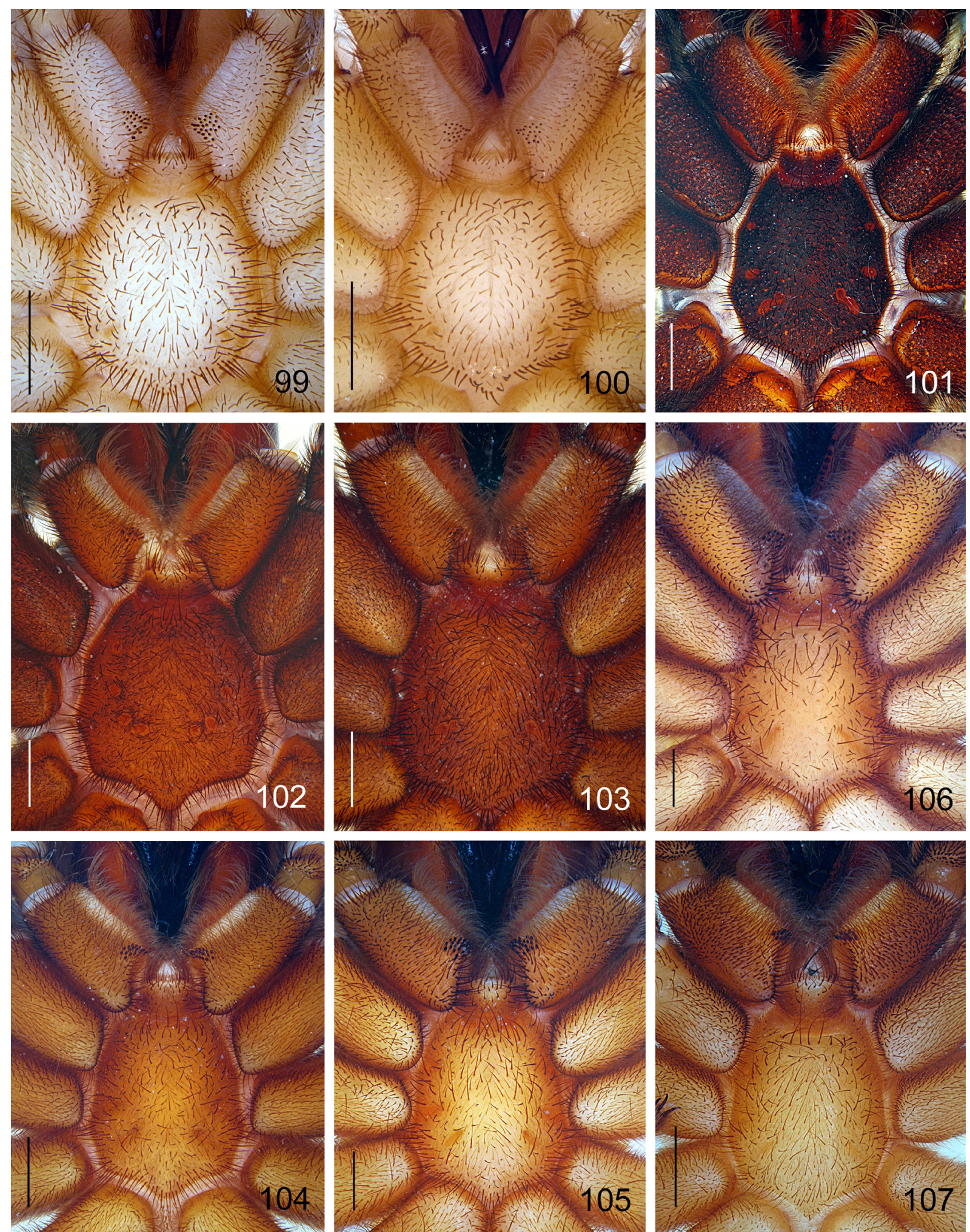

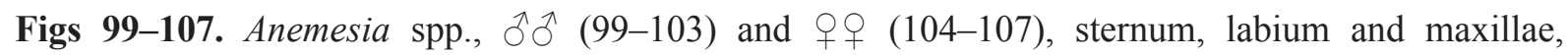
ventral views. 99. A. pallida sp. nov. (holotype). 100. A. parvula sp. nov. (holotype). 101. A. incana Zonstein, 2001 (holotype). 102. A. infumata sp. nov. (holotype). 103. A. infuscata sp. nov. (holotype). 104. A. birulai (Spassky, 1937) (Kepele). 105. A. pococki sp. nov. (paratype). 106. A. tubifex (Pocock, 1889) (Kalaimor). 107. A. andreevae sp. nov. (paratype, Babatag Mts). Scale bars: $1.0 \mathrm{~mm}$. 

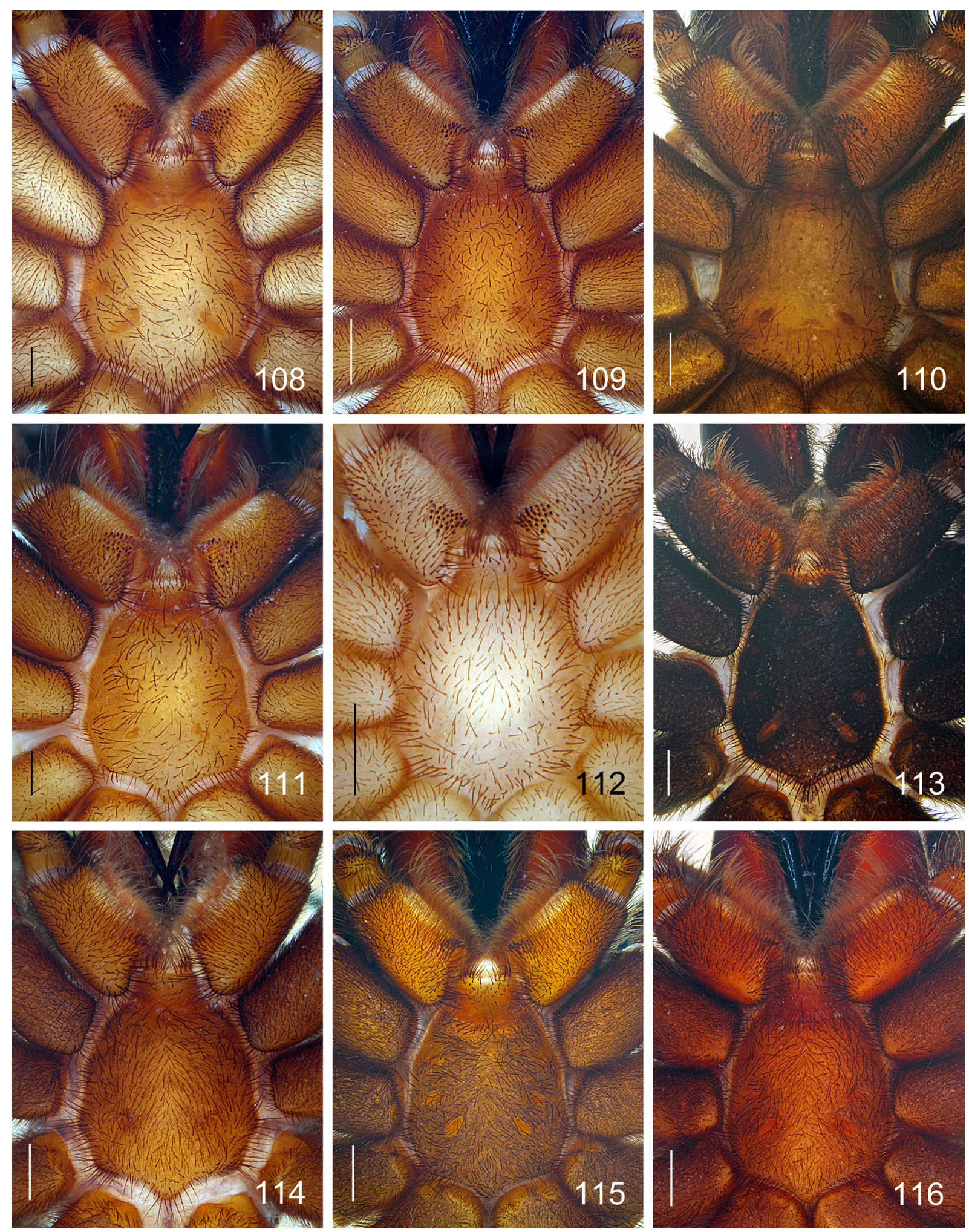

Figs 108-116. Anemesia spp., +9 , sternum, labium and maxillae, ventral views. 108. A. oxiana sp. nov. (paratype, Hojamaston). 109. A. sogdiana sp. nov. (paratype, Amankutan Pass). 110. A. castanea sp. nov. (Ganjina). 111. A. karatauvi (Andreeva, 1968) (paratype, Hojamaston). 112. A. pallida sp. nov. (paratype, Ganjina). 113. A. incana Zonstein, 2001 (paratype). 114. A. infumata sp. nov. (paratype). 115-116. A. infuscata sp. nov. (paratypes, Varzob and Sanglok Mts, respectively). Scale bars: $1.0 \mathrm{~mm}$. 

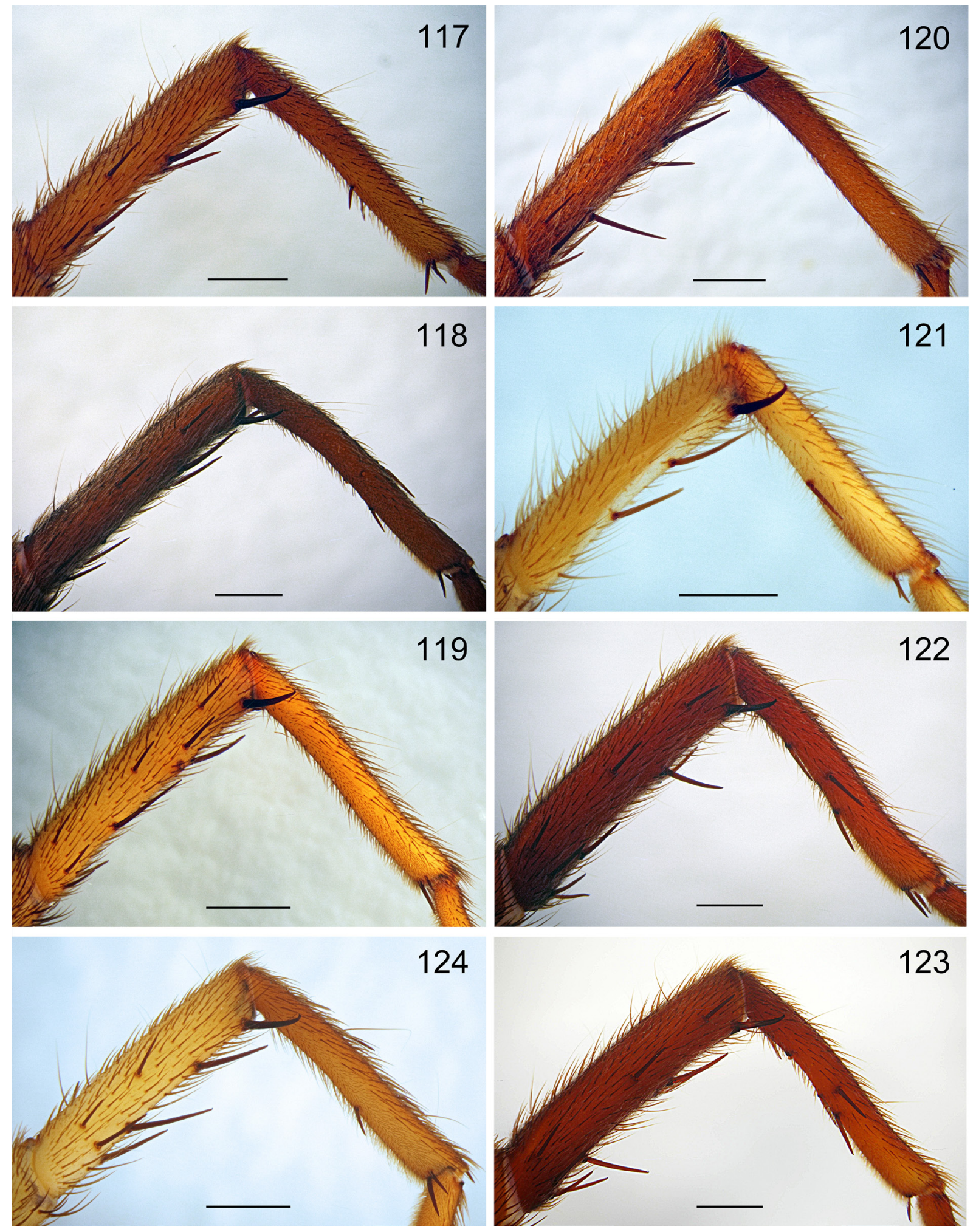

Figs 117-124. Anemesia spp., $ぇ ð$, tibia and metatarsus I, retrolateral views. 117. A. birulai (Spassky, 1937) (holotype). 118. A. koponeni Marusik, Zamani \& Mirshamsi, 2014 (holotype). 119. A. pococki sp. nov. (holotype). 120. A. tubifex (Pocock, 1889) (Kalaimor). 121. A. andreevae sp. nov. (holotype). 122-123. A. oxiana sp. nov. (holotype and paratype from Sanglok Mts, respectively). 124. A. sogdiana sp. nov. (holotype). Scale bars: $1.0 \mathrm{~mm}$. 

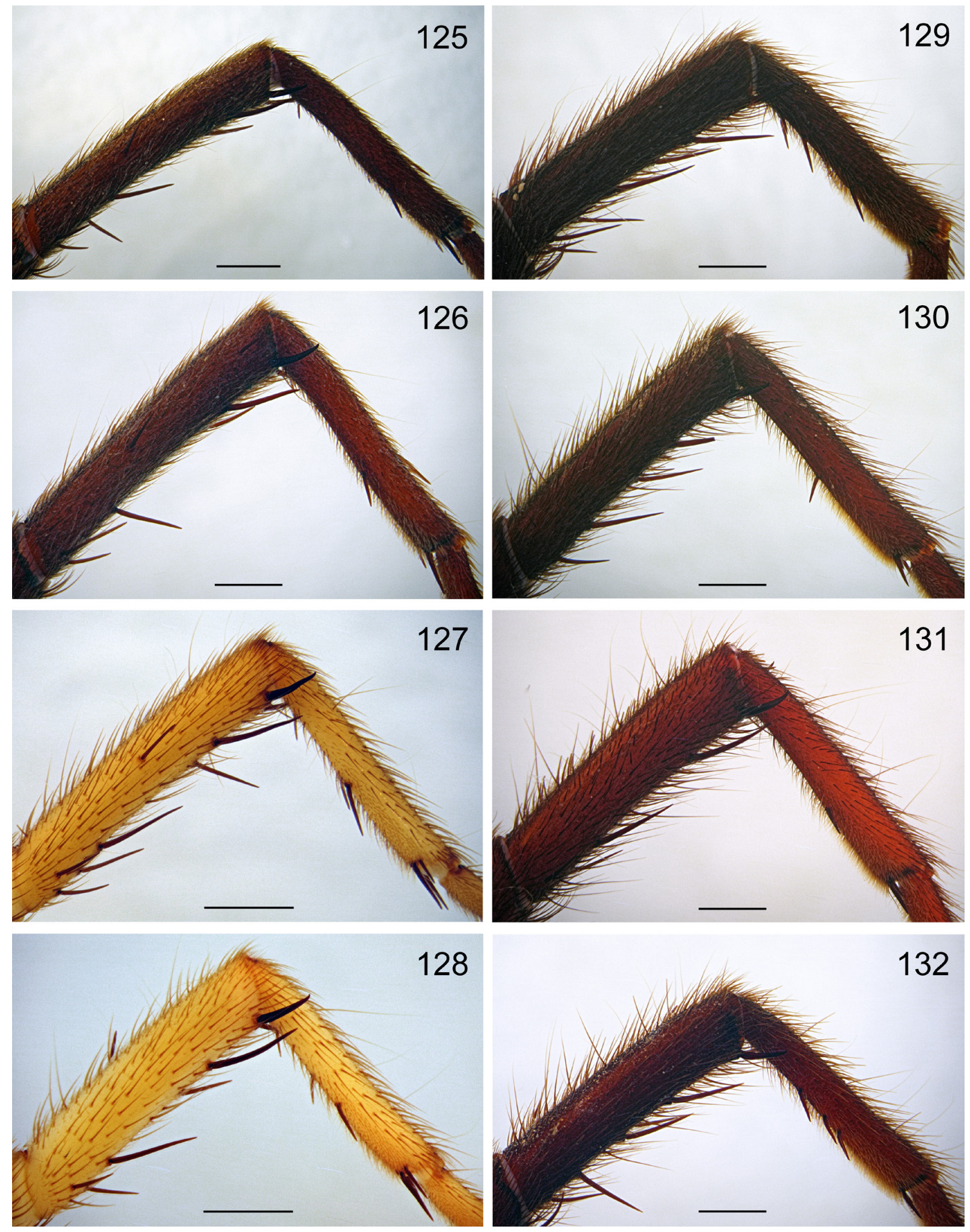

Figs 125-132. Anemesia spp., $\widehat{\partial}$, tibia and metatarsus I, retrolateral views. 125. A. castanea sp. nov. (holotype). 126. A. karatauvi (Andreeva, 1968) (Hojamaston). 127. A. pallida sp. nov. (holotype). 128. A. parvula sp. nov. (holotype). 129. A. incana Zonstein, 2001 (holotype). 130. A. infumata sp. nov. (holotype). 131-132. A. infuscata sp. nov. (paratype from Sanglok Mts and holotype, respectively). Scale bars: $1.0 \mathrm{~mm}$. 


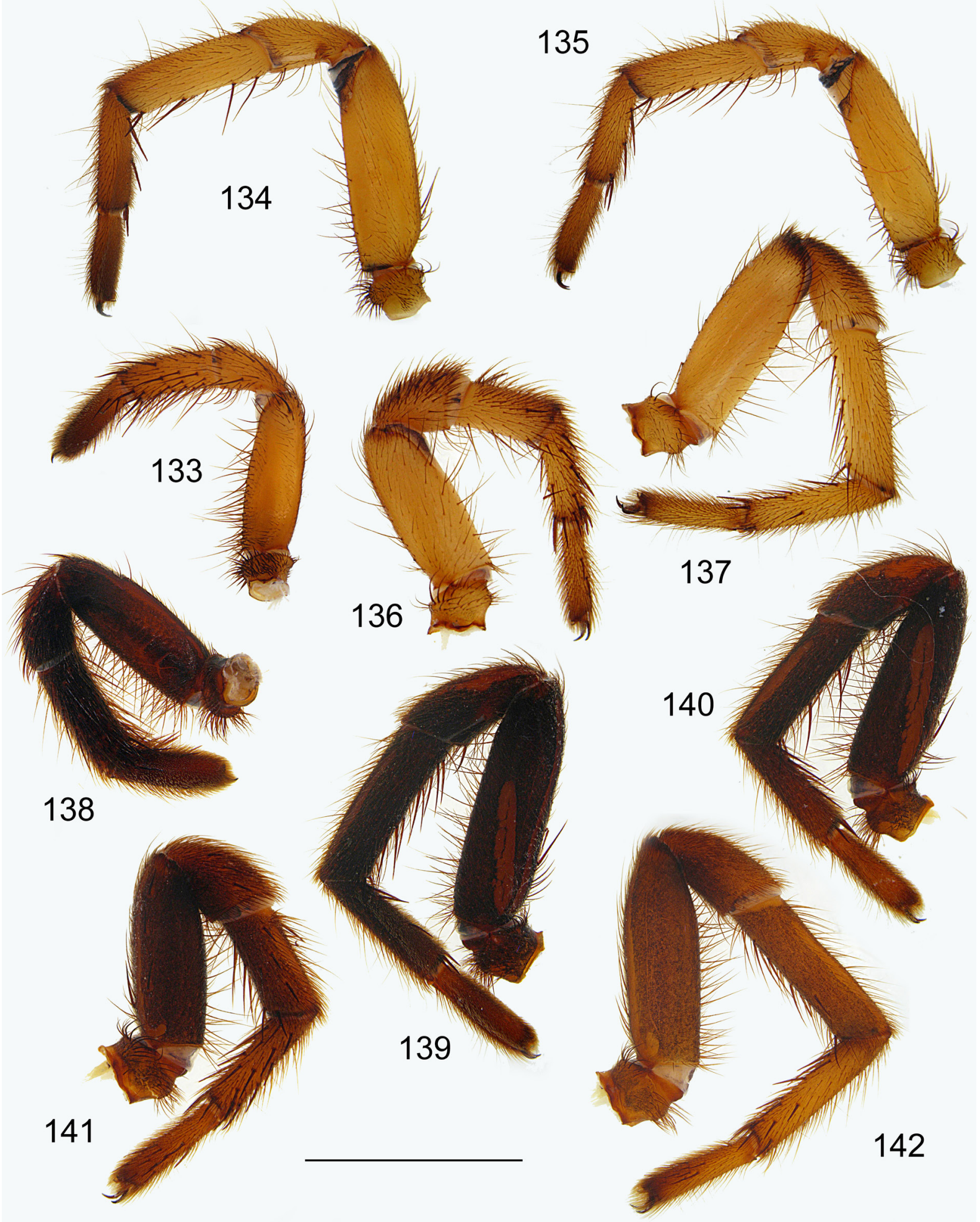

Figs 133-142. Anemesia sogdiana sp. nov. (133-137) and A. incana Zonstein, 2001 (138-142), palps and legs I-IV, retrolateral views. 133, 138. Palp. 134, 139. Leg I. 135, 140. Leg II. 136, 141. Leg III. 137, 142. Leg IV. Scale bar: $5.0 \mathrm{~mm}$. 

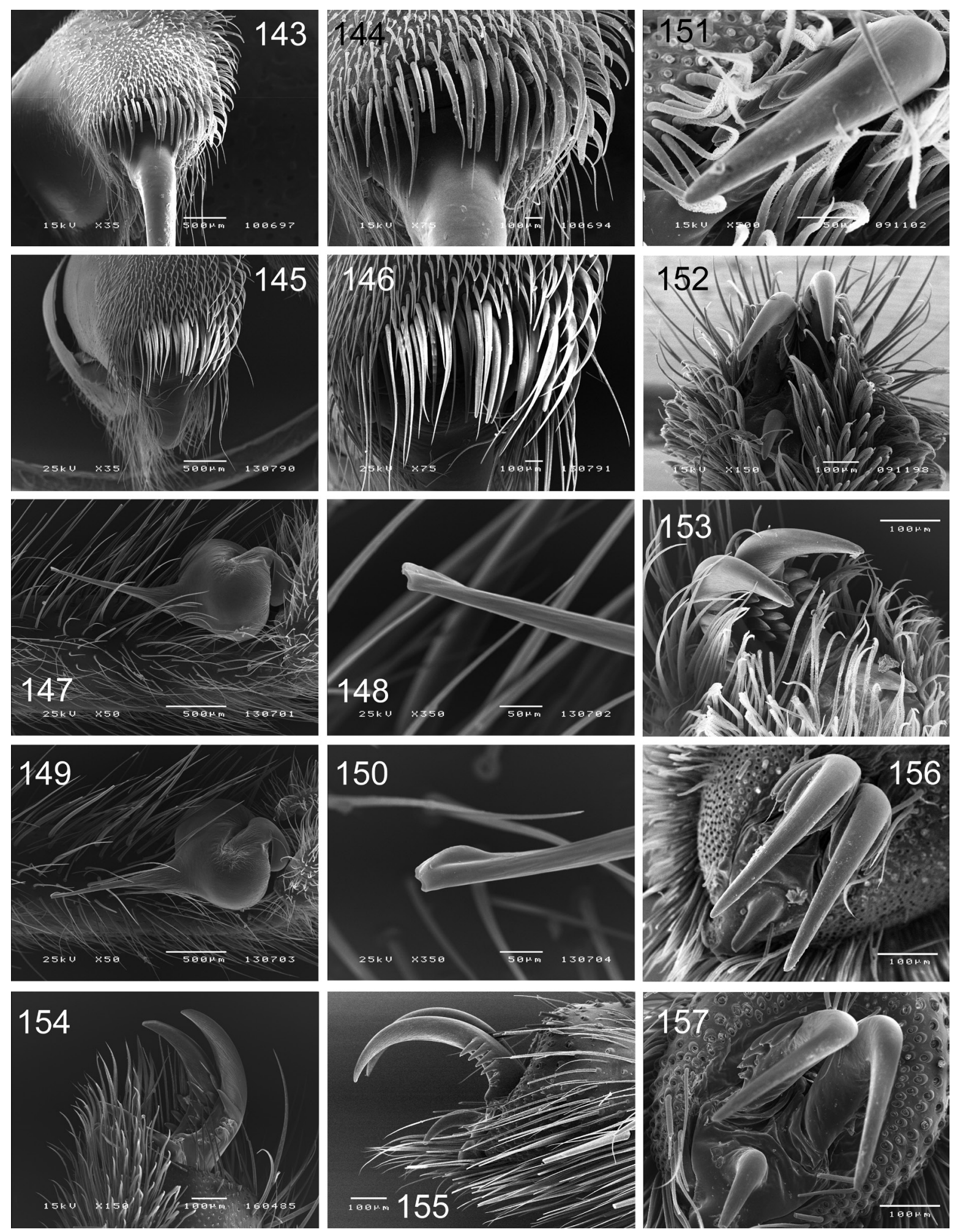

Figs 143-157. Anemesia spp., 우 (143-146, 151-157) and $\widehat{\partial} \widehat{\partial}(147-150)$, distal edge of chelicerae (143-146), palpal organ $(147,149)$, tip of embolus $(148,150)$, palpal claw (151), tarsal claws of leg I $(152-154,156)$ and leg IV $(155,157)$; apical $(143-146,151,156-157)$, retrolateral $(147-148$, 154-155), ventral (149-150) and ventroapical (152-153) views. 143-144. A. pococki sp. nov. 145146. A. karatauvi (Andreeva, 1966). 147-150, 156-157. A. incana Zonstein, 2001. 151-153. A. oxiana sp. nov. 154-155. A. sogdiana sp. nov. 

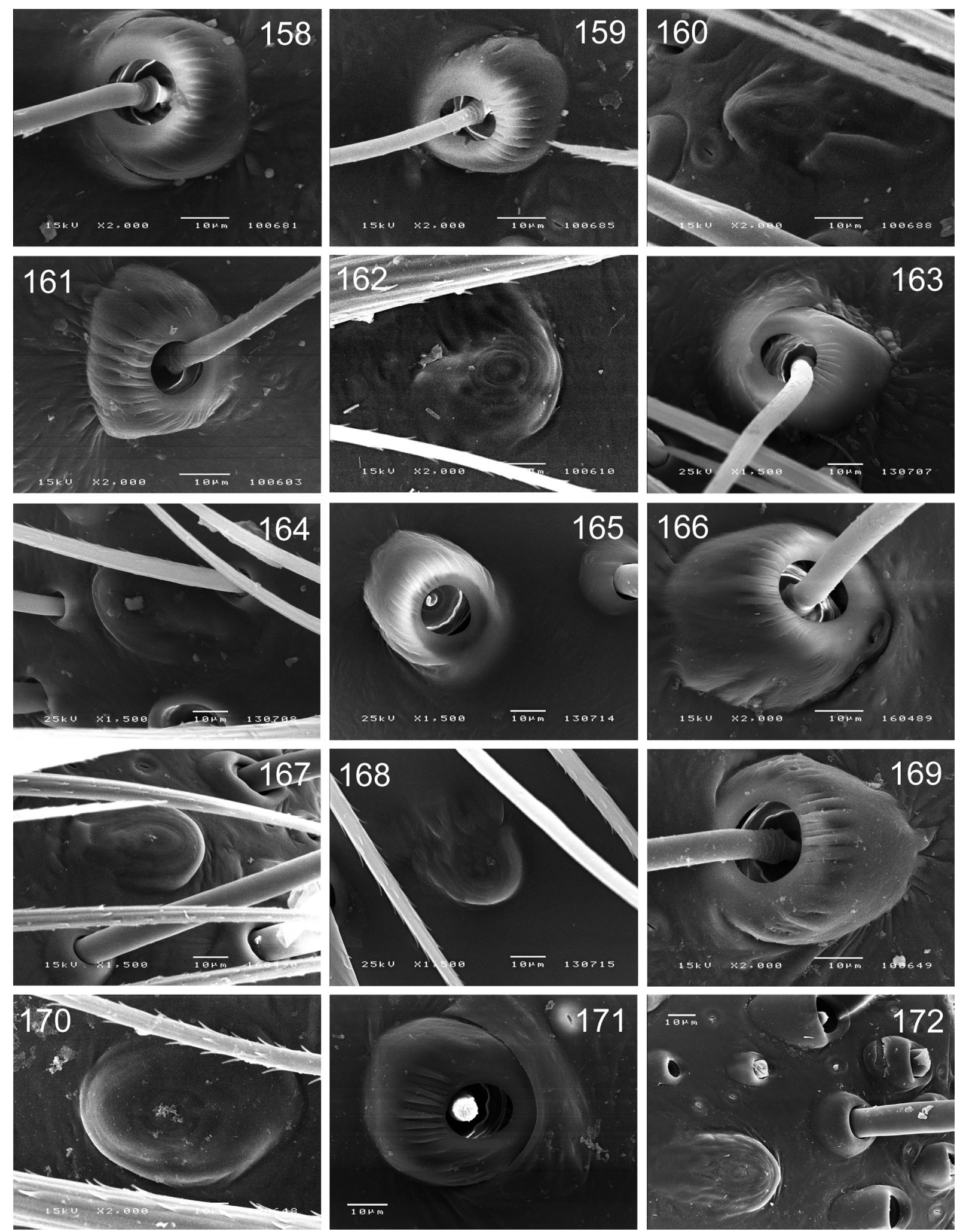

Figs 158-172. Anemesia spp., 우 $(158-160,163-172)$ and $\widehat{\partial} \hat{o}(161-162)$, bases of trichobothria $(158-159,161,163,165-166,169,171)$ and tarsal organ $(160,162,164,167-168,170,172)$ of leg I (158-167, 169-172) and leg IV (168); dorsal views. 158-160. A. pococki sp. nov. 161-162. A. tubifex (Pocock, 1889). 163-164. A. andreevae sp. nov. 165-168. A. sogdiana sp. nov. 169-170. A. karatauvi (Andreeva, 1968). 171-172. A. incana Zonstein, 2001. 

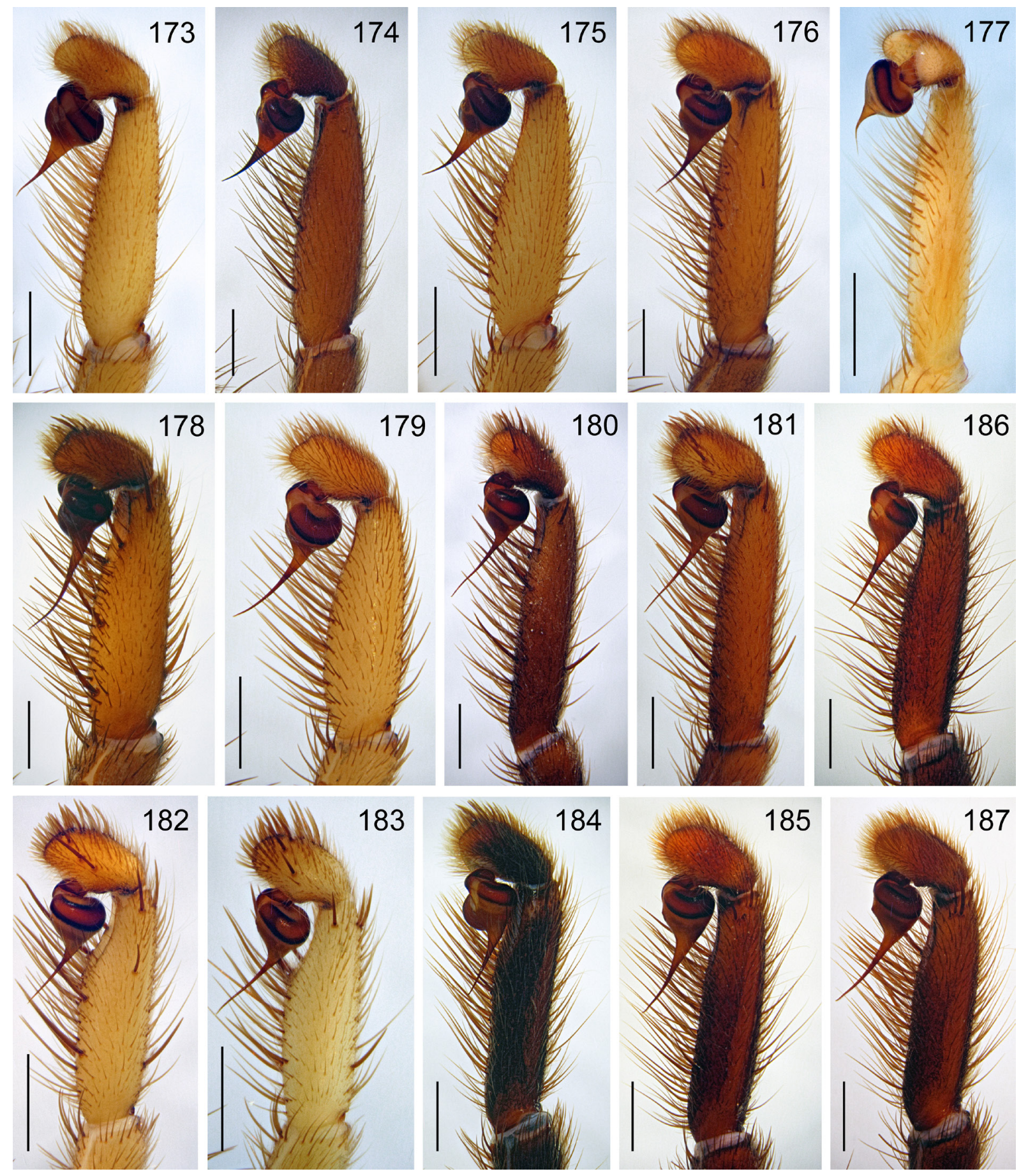

Figs 173-187. Anemesia spp., $\widehat{\partial}$, palpal tibia, cymbium and palpal organ, retrolateral views. 173. A. birulai (Spassky, 1937) (holotype). 174. A. koponeni Marusik, Zamani \& Mirshamsi, 2014 (holotype). 175. A. pococki sp. nov. (holotype). 176. A. tubifex (Pocock, 1889) (Kalaimor). 177. A. andreevae sp. nov. (holotype). 178. A. oxiana sp. nov. (holotype). 179. A. sogdiana sp. nov. (holotype). 180. A. castanea sp. nov. (holotype). 181. A. karatauvi (Andreeva, 1968) (Hojamaston). 182. A. pallida sp. nov. (holotype). 183. A. parvula sp. nov. (holotype). 184. A. incana Zonstein, 2001 (holotype). 185. A. infumata sp. nov. (holotype). 186-187. A. infuscata sp. nov. (paratype from Sanglok Mts and holotype, respectively). Scale bars: $1.0 \mathrm{~mm}$. 

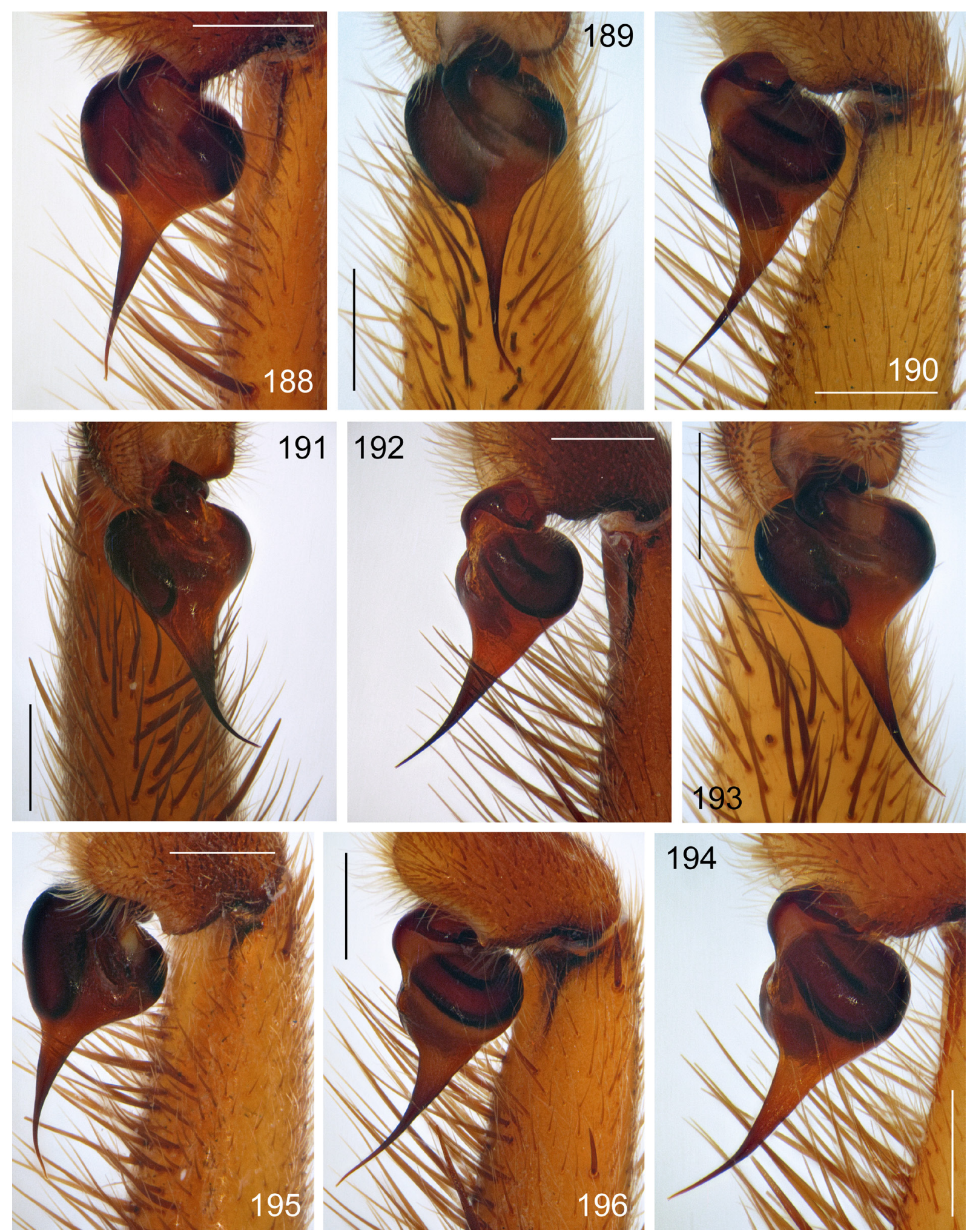

Figs 188-196. Anemesia spp., $\widehat{\jmath} \hat{\jmath}$, details of palpal organ; ventral $(188-189,191,193-194)$ and retrolateral (191, 192, 195-196) views. 188-190. A. birulai (Spassky, 1937) (holotype and conspecific $\widehat{\sigma}$ from Zulfagar Mts, respectively). 191-192. A. koponeni Marusik, Zamani \& Mirshamsi, 2014 (holotype). 193-194. A. pococki sp. nov. (holotype). 195-196. A. tubifex (Pocock, 1889) (Kalaimor). Scale bars: $0.5 \mathrm{~mm}$. 

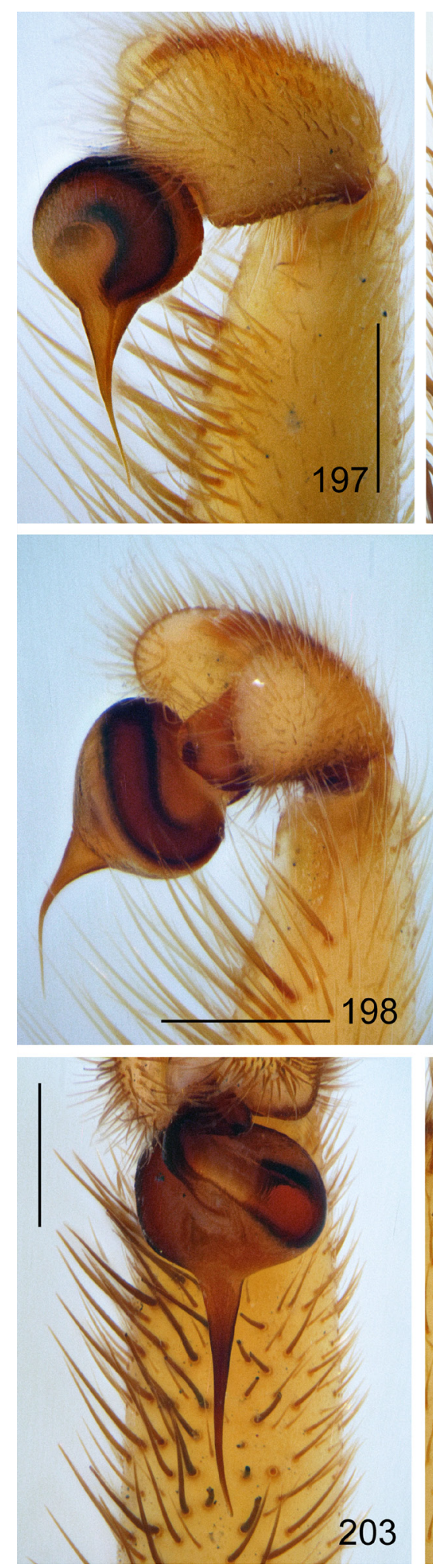
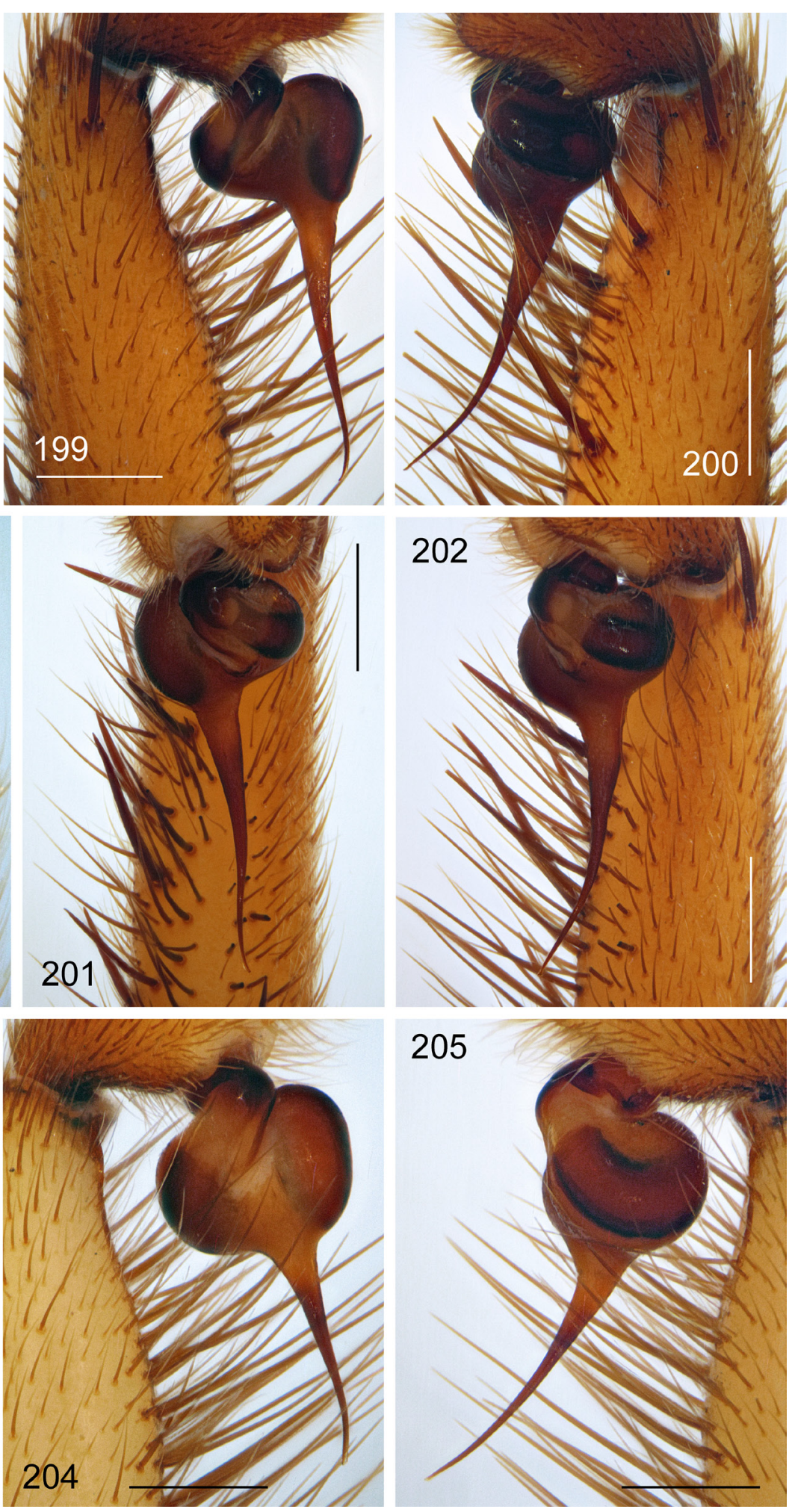

Figs 197-205. Anemesia spp., $\widehat{\partial} \hat{\partial}$, details of palpal organ; proventral (197), retroventral (198, 202), ventral $(199,201,203-204)$ and retrolateral $(200,205)$ views. 197-198. A. andreevae sp. nov. (holotype). 199-202. A. oxiana sp. nov. (holotype and paratype from Sanglok Mts, respectively). 203205. A. sogdiana sp. nov. (conspecific $\hat{\sigma}$ from Zaamin and holotype, respectively). Scale bars: $0.5 \mathrm{~mm}$. 

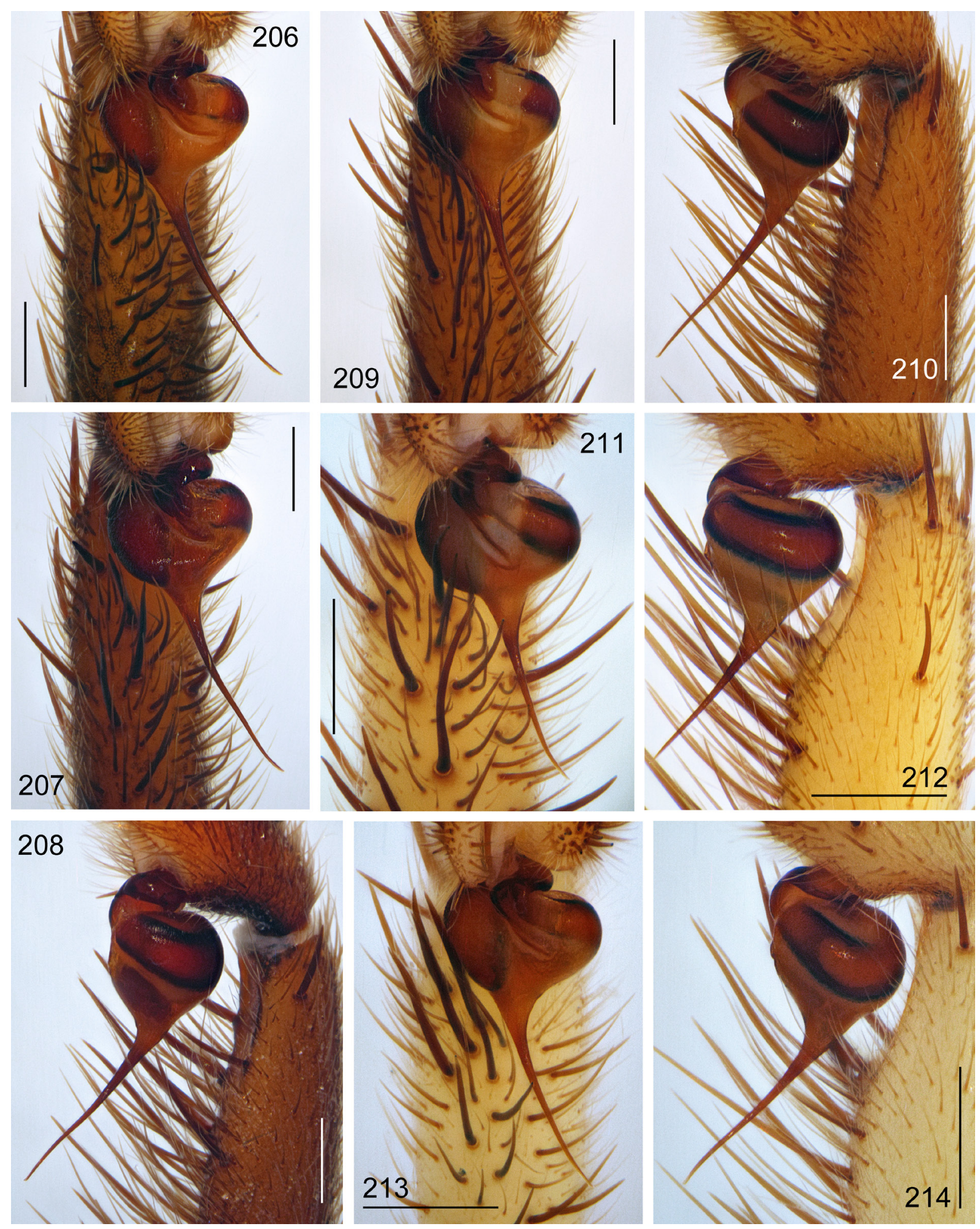

Figs 206-214. Anemesia spp., $\widehat{\partial} \widehat{\jmath}$, details of palpal organ; ventral $(206-207,209,211,213)$ and retrolateral $(208,210,212,214)$ views. 206-208. A castanea sp. nov. (paratype and holotype, respectively). 209-210. A. karatauvi (Andreeva, 1968) (Hojamaston). 211-212. A. pallida sp. nov. (holotype). 213-214. A. parvula sp. nov. (holotype). Scale bars: $0.5 \mathrm{~mm}$. 

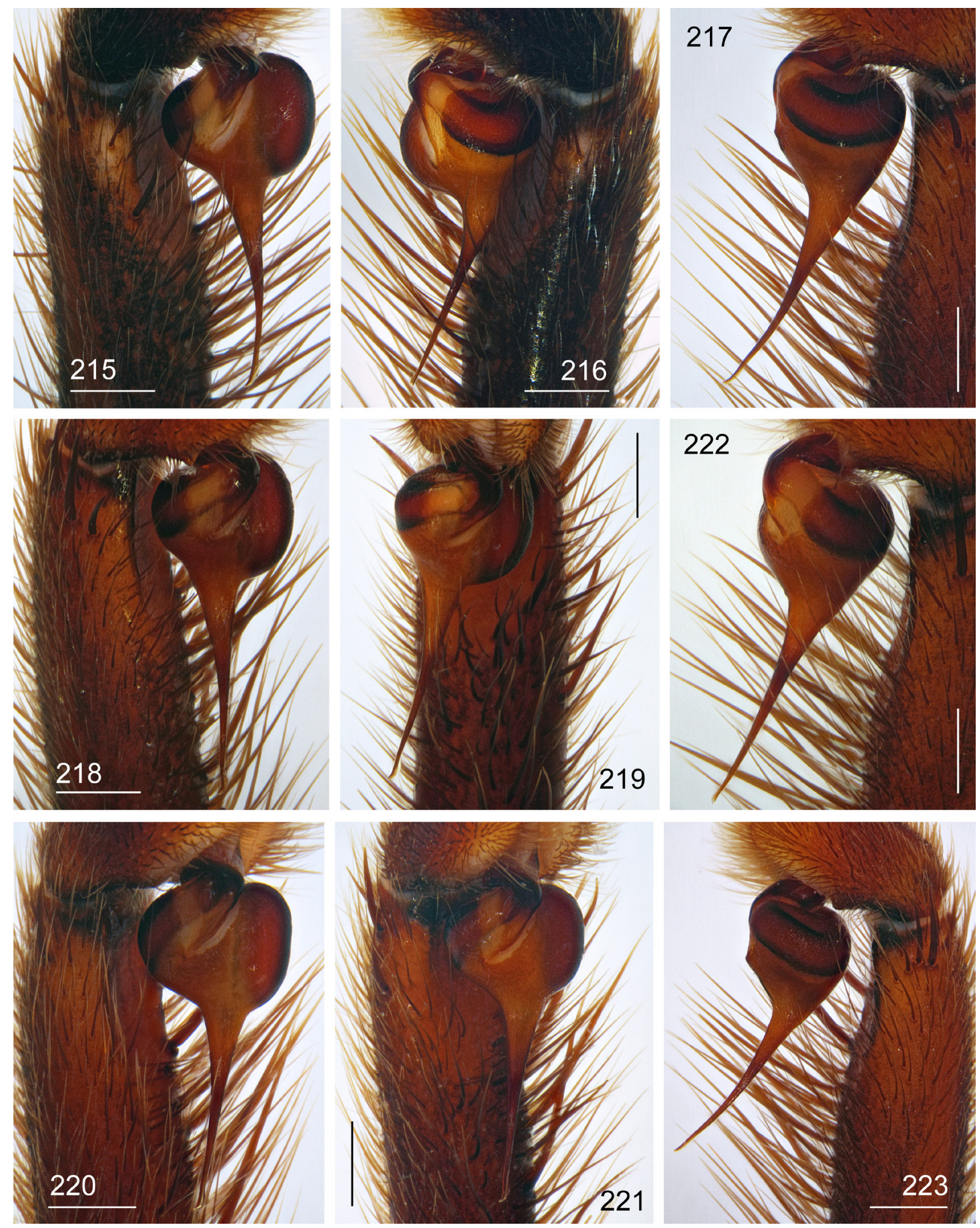

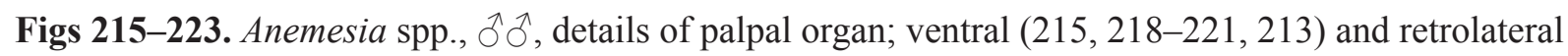
(216-217, 222-223) views. 215-216. A. incana Zonstein, 2001 (holotype). 217-219. A. infumata sp. nov. (holotype). 220-221, 223. A. infuscata sp. nov. (holotype). 222. Same (paratype from Sanglok Mts). Scale bars: $0.5 \mathrm{~mm}$. 



Figs 224-244. Anemesia spp., ${ } \bigcirc$, spermathecae, dorsal views. 224. A. birulai (Spassky, 1937) (Kepele). 225. Same (Zulfagar Mts). 226-227. Same (Kushka). 228-229. A. pococki sp. nov. (paratypes). 230. A. tubifex (Pocock, 1889) (Kalaimor). 231. Same (Zulfagar Mts). 232. Same (Gyangaly). 233234. A. andreevae sp. nov. (paratypes from Babatag Mts and Varzob, respectively). 235. A. sogdiana sp. nov. (Varzob). 236. Same (paratype, Amankutan). 237-238. Same (Akrabat). 239-240. Same (Kugitang Mts: Badlydara and Vandob, respectively). 241-242. A. oxiana sp. nov. (paratypes, Ganjina). 243-244. Same (paratypes, Sanglok Mts and Mt Astana, respectively). Scale bars: $0.5 \mathrm{~mm}$. 

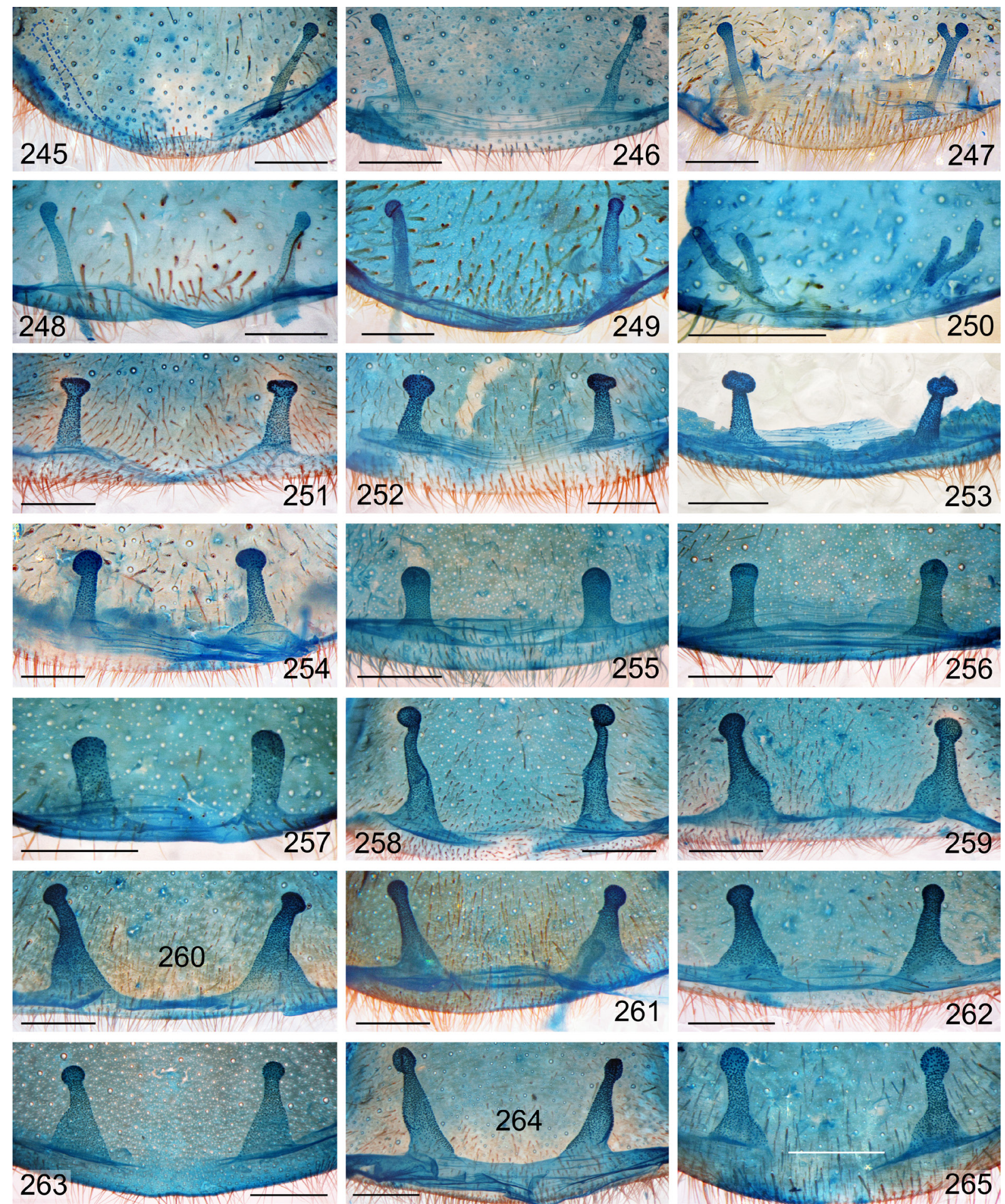

Figs 245-265. Anemesia spp.,,$\bigcirc$, spermathecae, dorsal views. 245. A. castanea sp. nov. (Ganjina). 246249. A. karatauvi (Andreeva, 1968) (Mt Hojamaston). 250. A. pallida sp. nov. (paratype, Ganjina). 251253. A. incana Zonstein, 2001 (paratypes, Ganjina). 254. Same (Mt Hojamaston). 255-257. A. infumata sp. nov. (paratypes). 258-259. A. infuscata sp. nov. (paratypes, Varzob). 260-262. Same (paratypes, Sanglok Mts). 263-265. Same (paratypes from Kuhitek Mts, Sultanmazar and Sangdara, respectively). Scale bars: $0.5 \mathrm{~mm}$. 

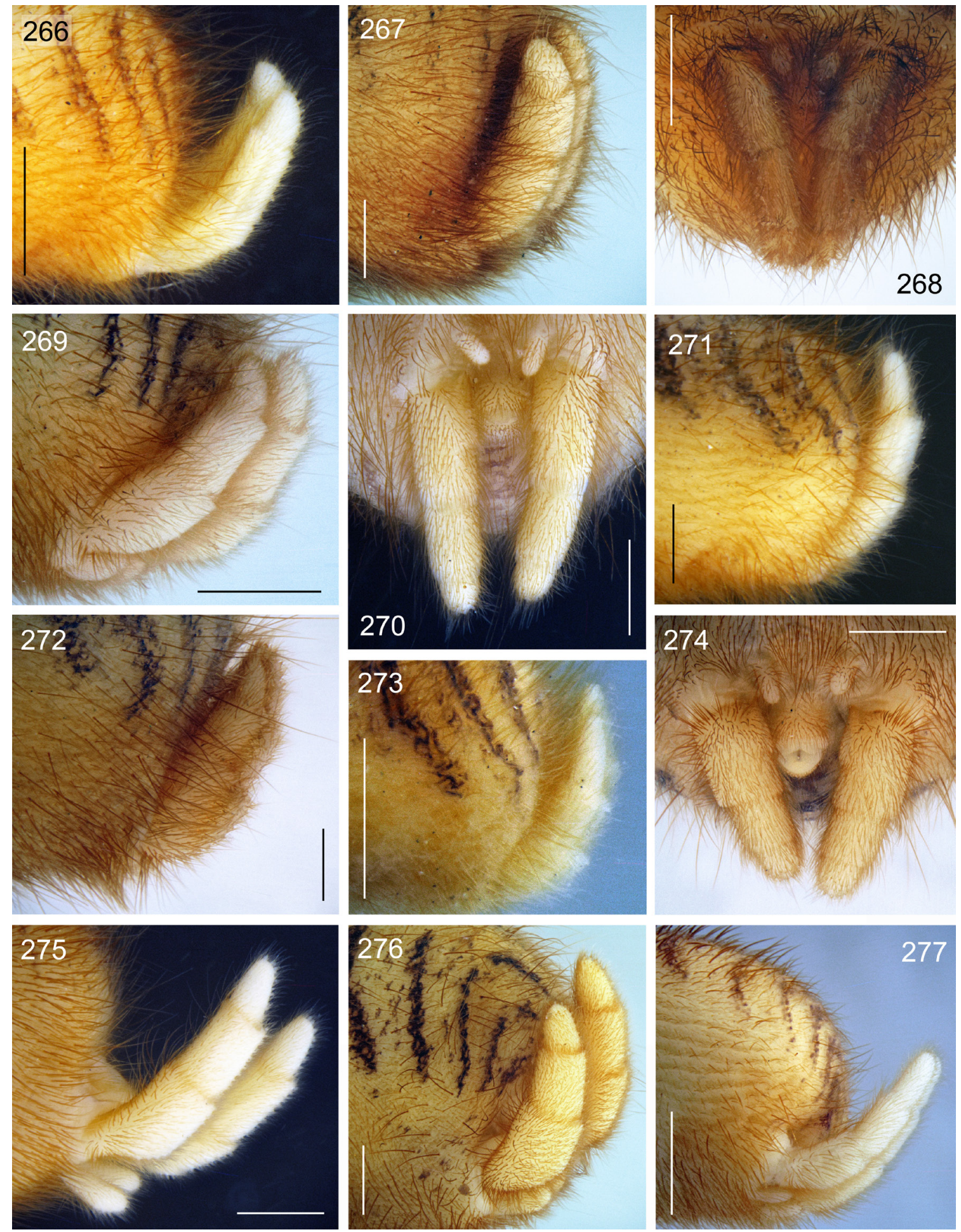

Figs 266-277. Anemesia spp., $\widehat{\partial} \widehat{\partial}(266,268-269,271,273,275,277)$ and + q $q(267,270,272,274$, 276), spinnerets; lateral $(266-267,269,271-273,275-277)$ and ventral $(268,270,274)$ views. 266267. A. birulai (Spassky, 1937) (Zulfagar Mts). 268. A. koponeni Marusik, Zamani \& Mirshamsi, 2014 (holotype). 269-270. A. pococki sp. nov. (holotype and paratype). 271-272. A. tubifex (Pocock, 1889) (Kalaimor). 273-274. A. andreevae sp. nov. (holotype and paratype from Babatag Mts). 275276. A. oxiana sp. nov. (holotype and paratype from Ganjina). 277. A. sogdiana sp. nov. (holotype). Scale bars: $1.0 \mathrm{~mm}$. 

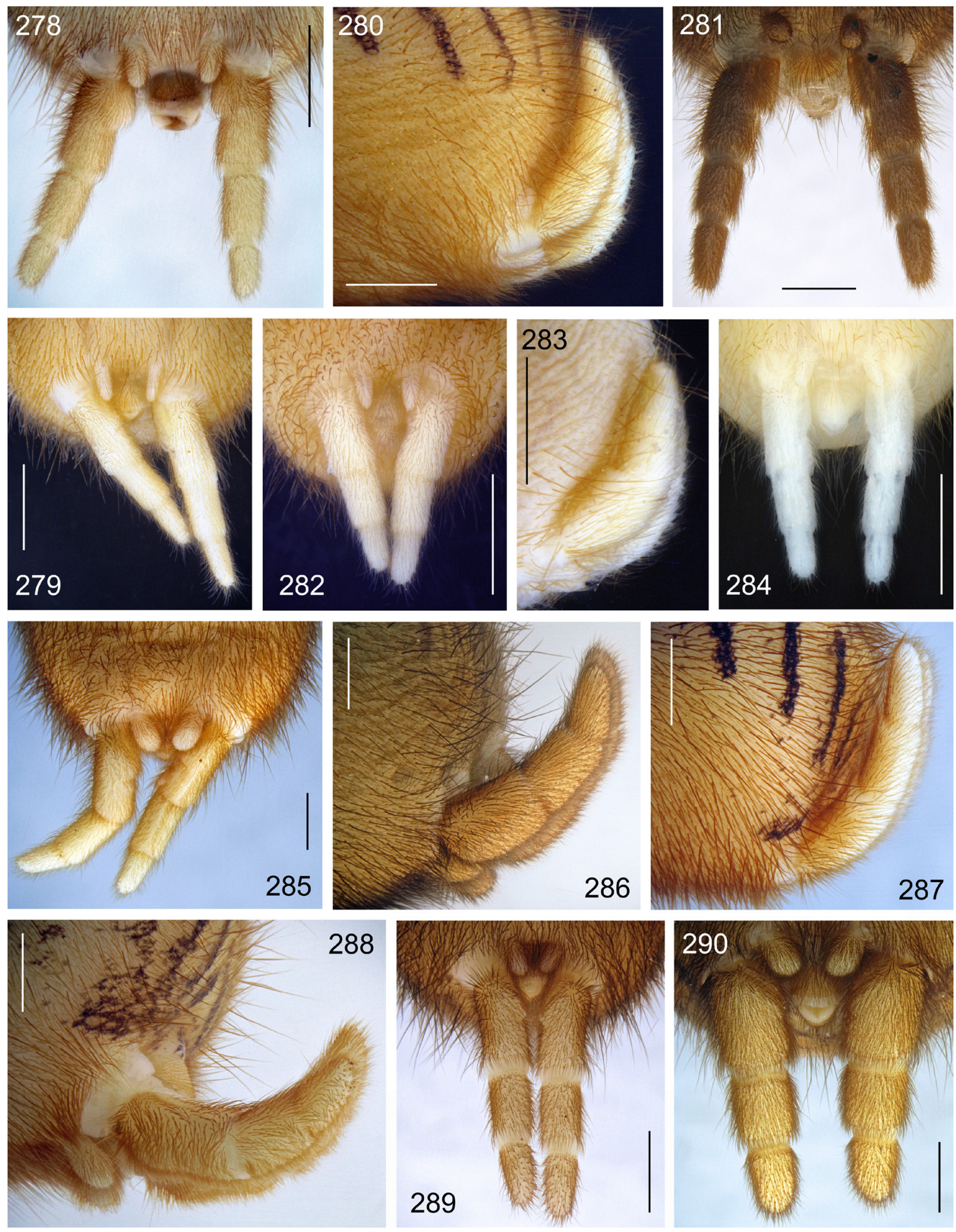

Figs 278-290. Anemesia spp., 우 $(278,281,283,285,286,288,290)$ and $\hat{\partial} \widehat{\partial}(279-280,282,284-285$, 287, 289), spinnerets; ventral (278-279, 281-282, 284-285, 289-290) and lateral (280, 283, 286-288) views. 278. A. sogdiana sp. nov. (paratype, Amankutan). 279. A. castanea sp. nov. (holotype). 280 281. A. karatauvi (Andreeva, 1968) (Hojamaston). 282-283. A. pallida sp. nov. (holotype and paratype from Ganjina). 284. A. parvula sp. nov. (holotype). 285-286. A. incana Zonstein, 2001 (holotype and paratype). 287-288. A. infumata sp. nov. (holotype and paratype). 289-290. A. infuscata sp. nov. (holotype and paratype from Varzob). Scale bars: $1.0 \mathrm{~mm}$. 

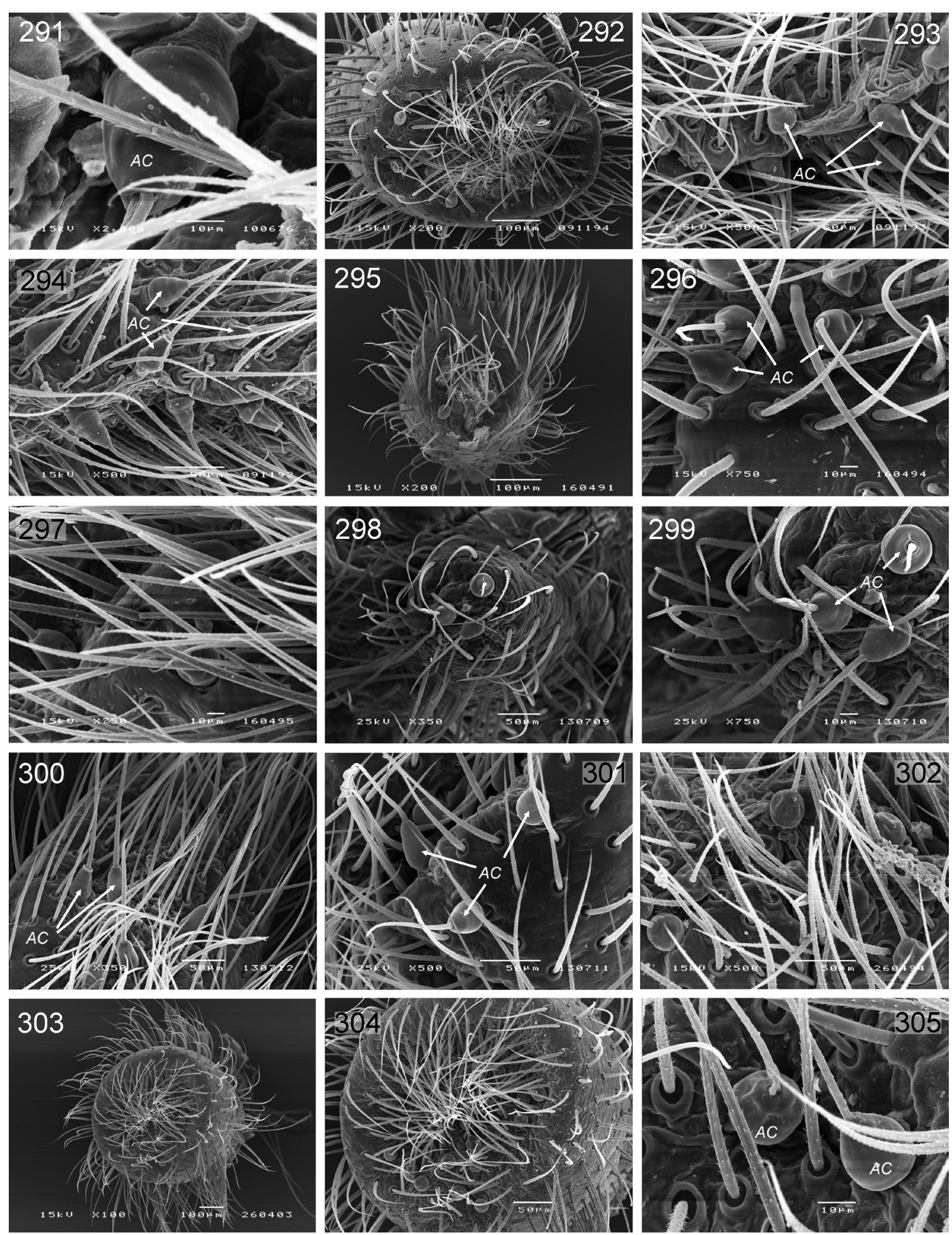

Figs 291-305. Anemesia spp., conspecific $\bigcirc \uparrow$, details of spinnerets and spigots; ventral (291, 293294, 296-297, 300-302) and apical (292, 295, 298-299, 303-305) views. 291. A. pococki sp. nov. (apical spigot on PMS). 292-294. A. oxiana sp. nov. (PMS, median and apical segments of PLS, respectively). 295-297. A. sogdiana sp. nov. (PMS, median and apical segments of PLS, respectively). 298-301. A. karatauvi (Andreeva, 1968) (PMS, apical spigots on PLS, median and apical segments of PLS, respectively). 302-305. A. incana Zonstein, 2001 (apical segment of PLS; PMS with apical spigots at larger magnification, respectively). Abbreviations: see Material and methods. 

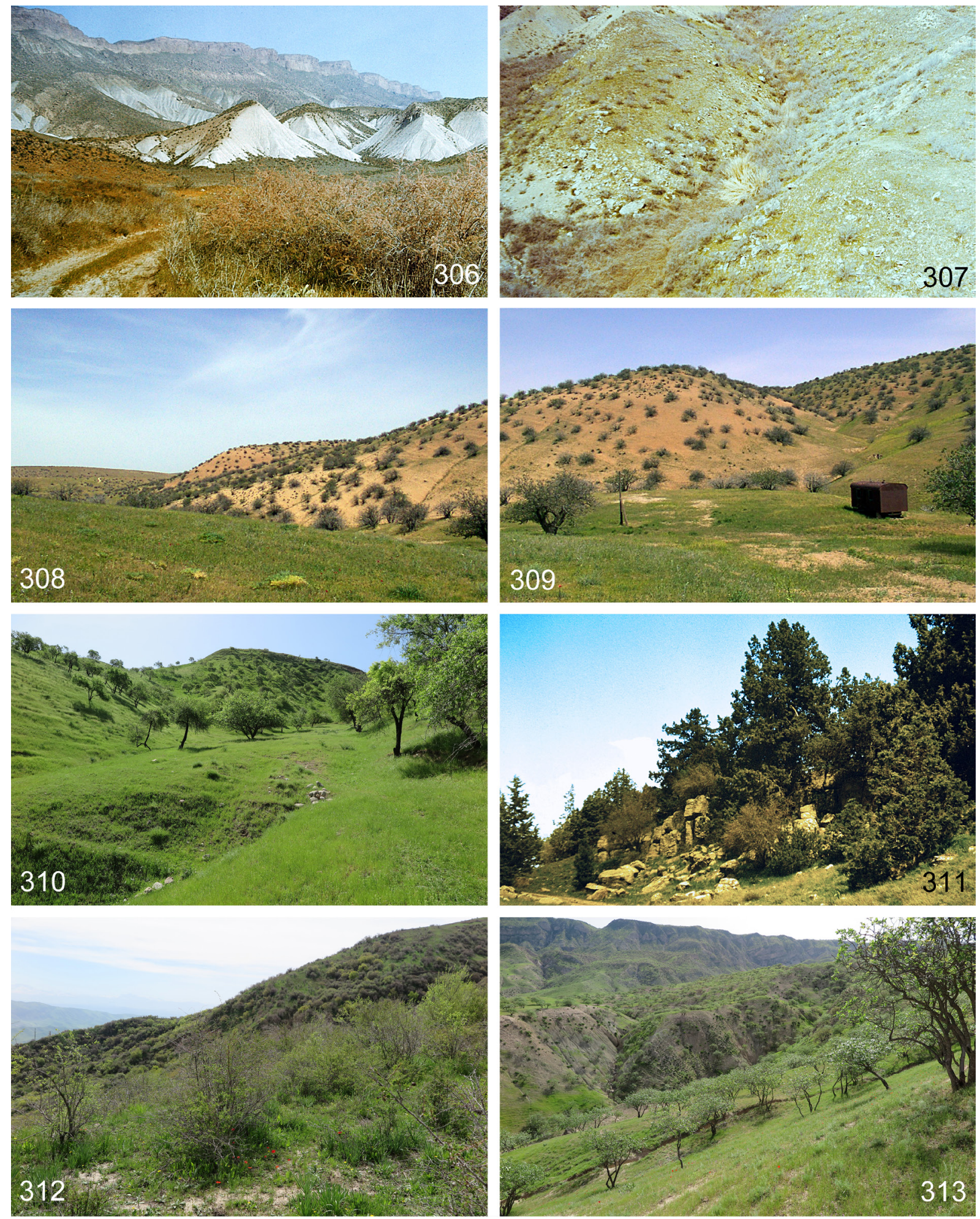

Figs 306-313. Anemesia spp., habitats of A. birulai (Spassky, 1937) (306-309), A. pococki sp. nov. (306-307), A. tubifex (Pocock, 1889) (306-307), A. andreevae sp. nov. (310-311), A. oxiana sp. nov. (312-313), A. karatauvi (Andreeva, 1968) (313) and A. pallida sp. nov. (313); Turkmenistan (306309), Tajikistan (310, 312-313) and Uzbekistan (311). 306-307. Zulfagar Mts. 308-309. Badhyz Plateau, surroundings of Kepele Well (images courtesy of Victor Fet). 310. Hissar Mts, Varzob Canyon. 311. Flattened summit part of Babatag Mts. 312-313. Sanglok Mts and Vahsh Karatau Mts, respectively. 

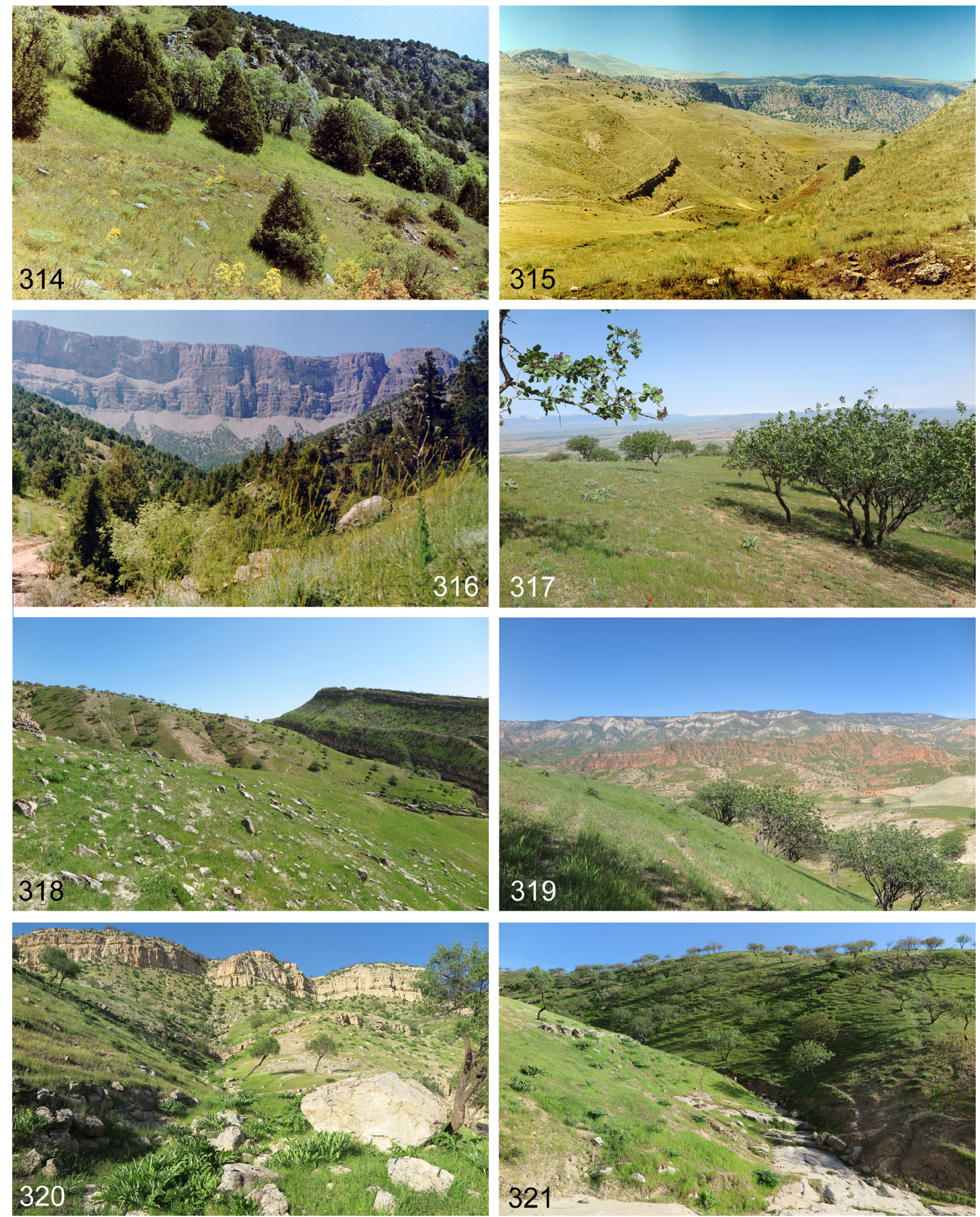

Figs 314-321. Anemesia spp., habitats of A. sogdiana sp. nov. (314-316), A. karatauvi (Andreeva, 1968) (317), A. oxiana sp. nov., A. castanea sp. nov., A. pallida sp. nov. and A. incana Zonstein, 2001 (318-321); Uzbekistan (334-336) and Tajikistan (317-321). 314-316. Zeravshan Mts (Amankutan Pass), south-western Hissar Mts (near Akrabat Pass) and Kugitang Mts (Kampyrtepa), respectively. 317. Foothills of Vahsh Karatau Mts. 318-321. Surroundings of Ganjina. 

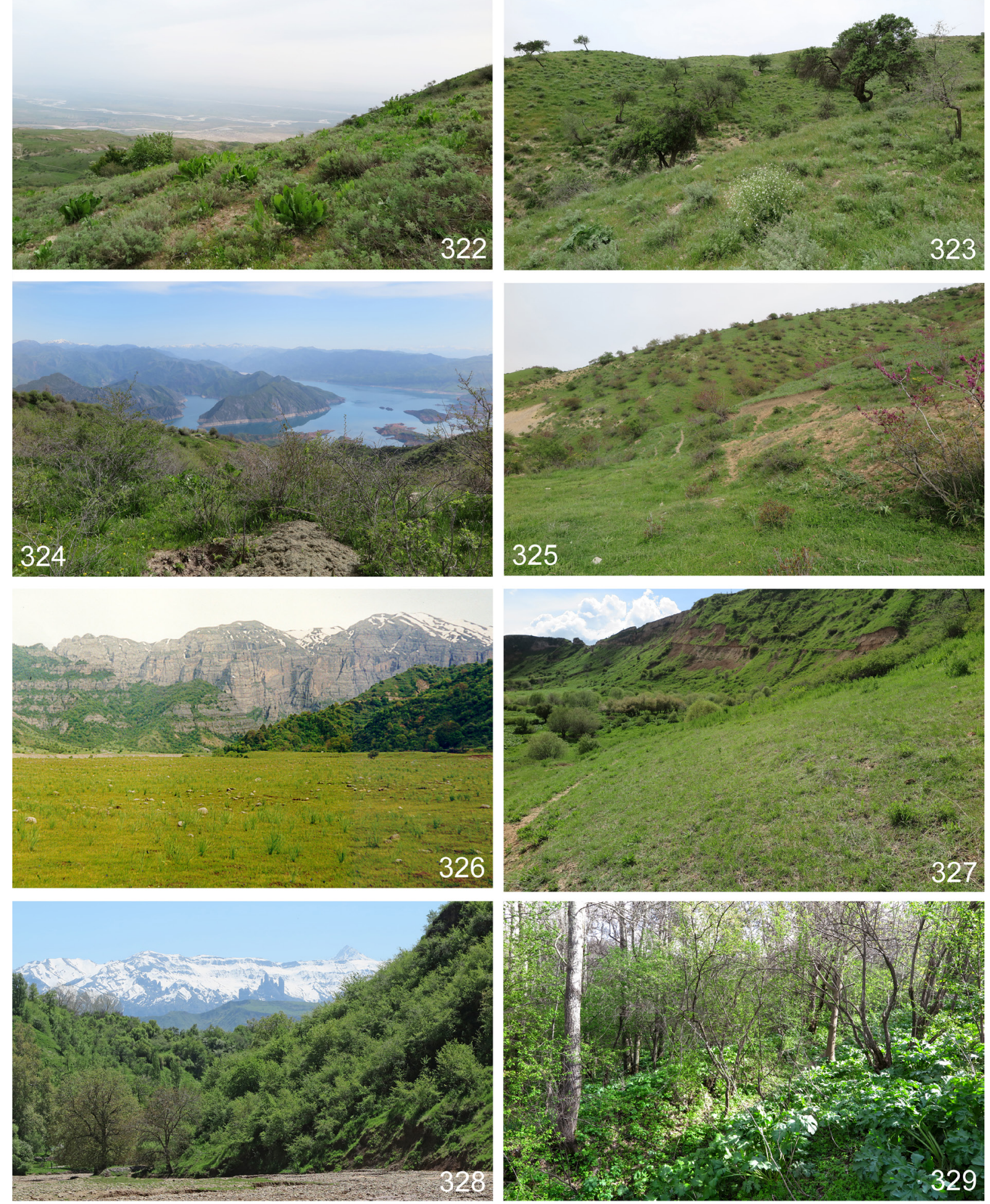

Figs 322-329. Anemesia spp., habitats of A. infumata sp. nov. (322-323), A. parvula sp. nov. (324) and A. infuscata sp. nov. (324-329); Tajikistan. 322-323. Summit part of Panj Karatau Mts north of the Panj River bordering Tajikistan and Afghanistan. 324-325. Summit part of Sanglok Mts., south of the Nurek Reservoir. 326. Midland zone of Hazratisho Mts (Sangdara), 327. Same, Kuhitek Mts (east of Hovaling). 328-329. Same, Mazar Mts (Mazarsultan). 

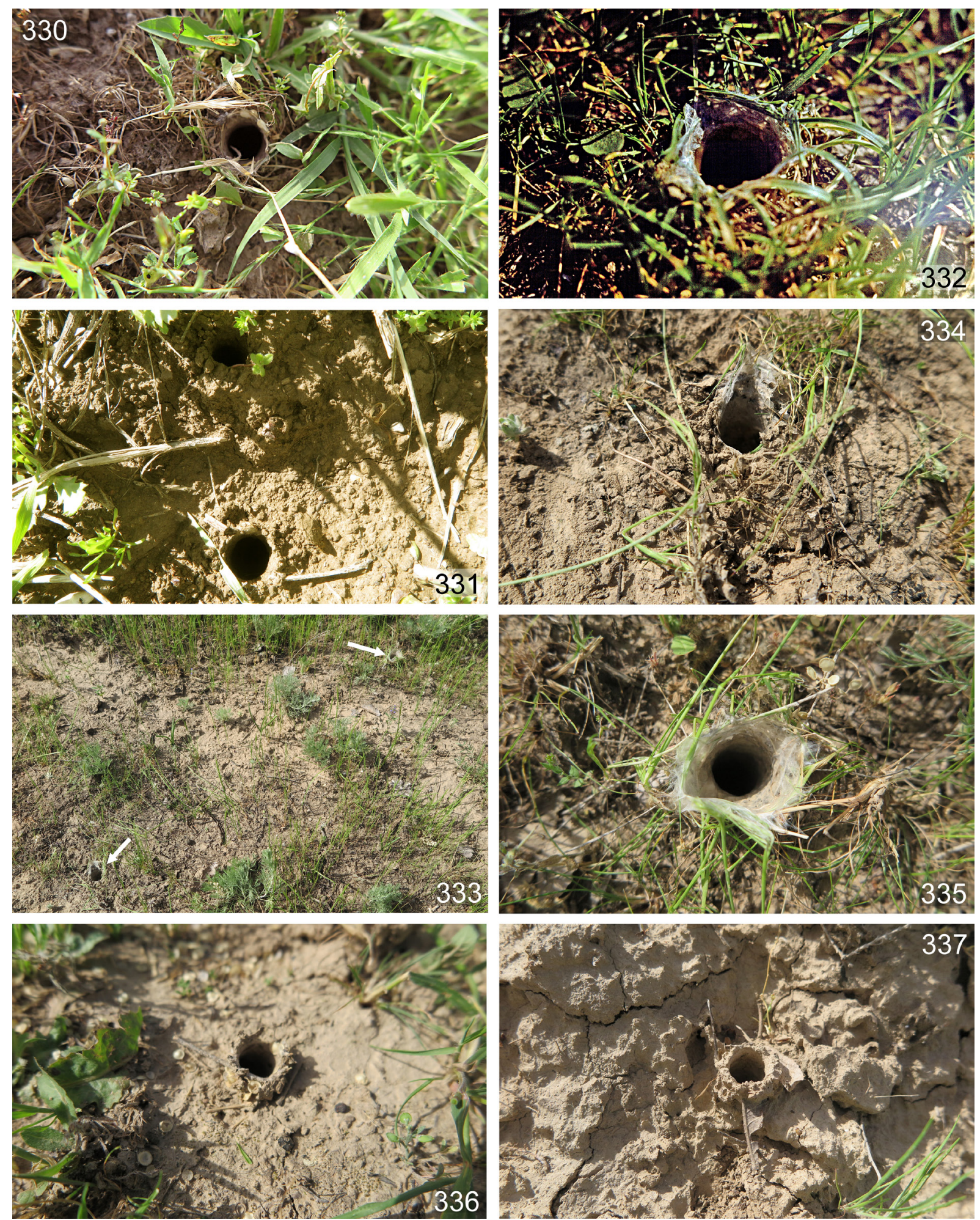

Figs 330-337. Anemesia spp., burrow entrances; Tajikistan (330-331, 333-337) and Uzbekistan (332). 330. A. andreevae sp. nov. (Varzob Canyon). 331. A. oxiana sp. nov. (Mt Hojamaston). 332. A. sogdiana sp. nov. (Amankutan Pass). 333-336. A. karatauvi (Andreeva, 1968) (Vahsh Karatau Mts). 337. A. pallida sp. nov. (Mt Hojamaston). White arrows indicate burrow entrances. 

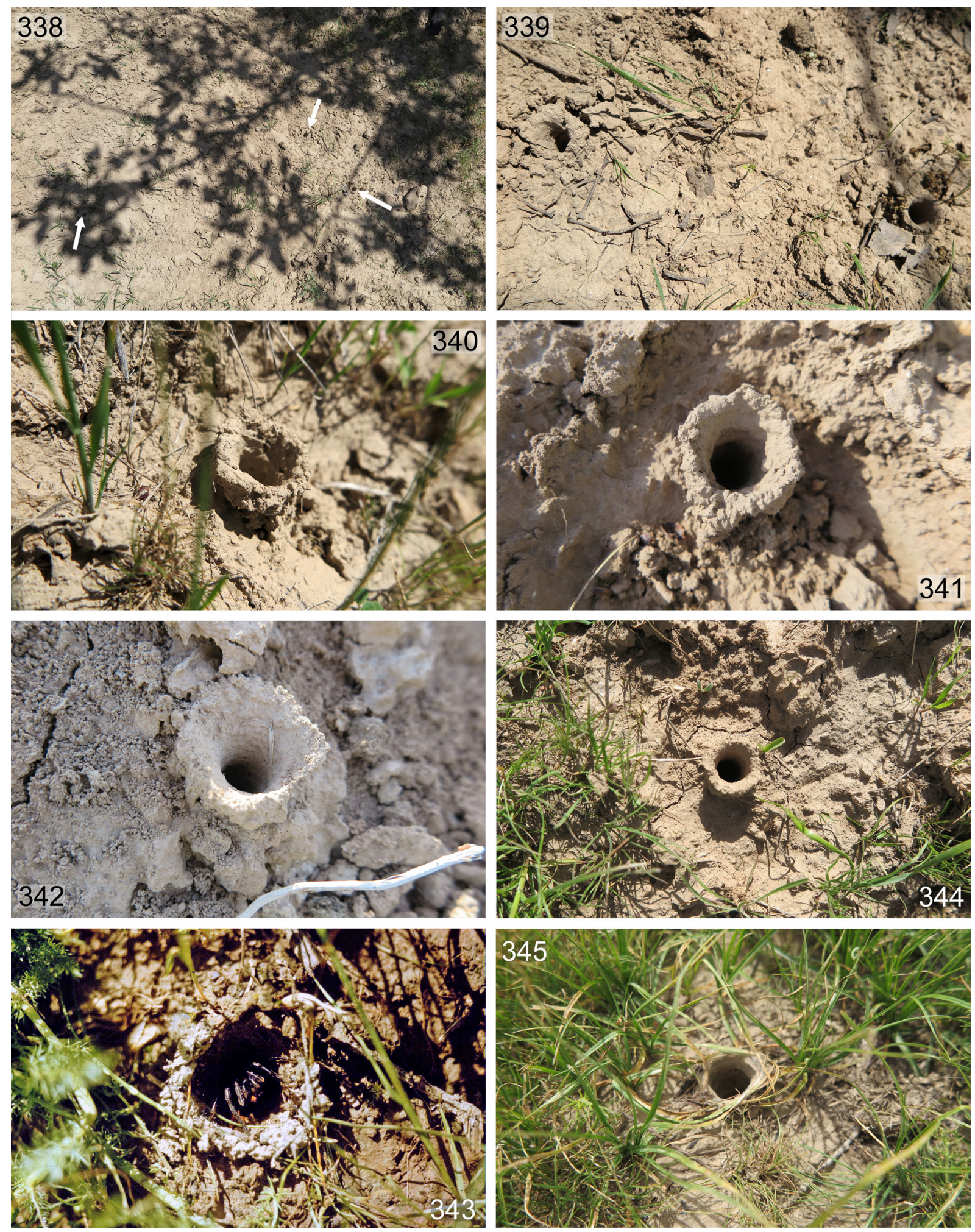

Figs 338-345. Anemesia spp., burrow entrances and their aggregations (338-339); Tajikistan. 338343. A. incana Zonstein, 2001 (Ganjina). 344. Same (Mt Hojamaston). 345. A. infumata sp. nov. (Panj Karatau Mts). White arrows indicate burrow entrances. 

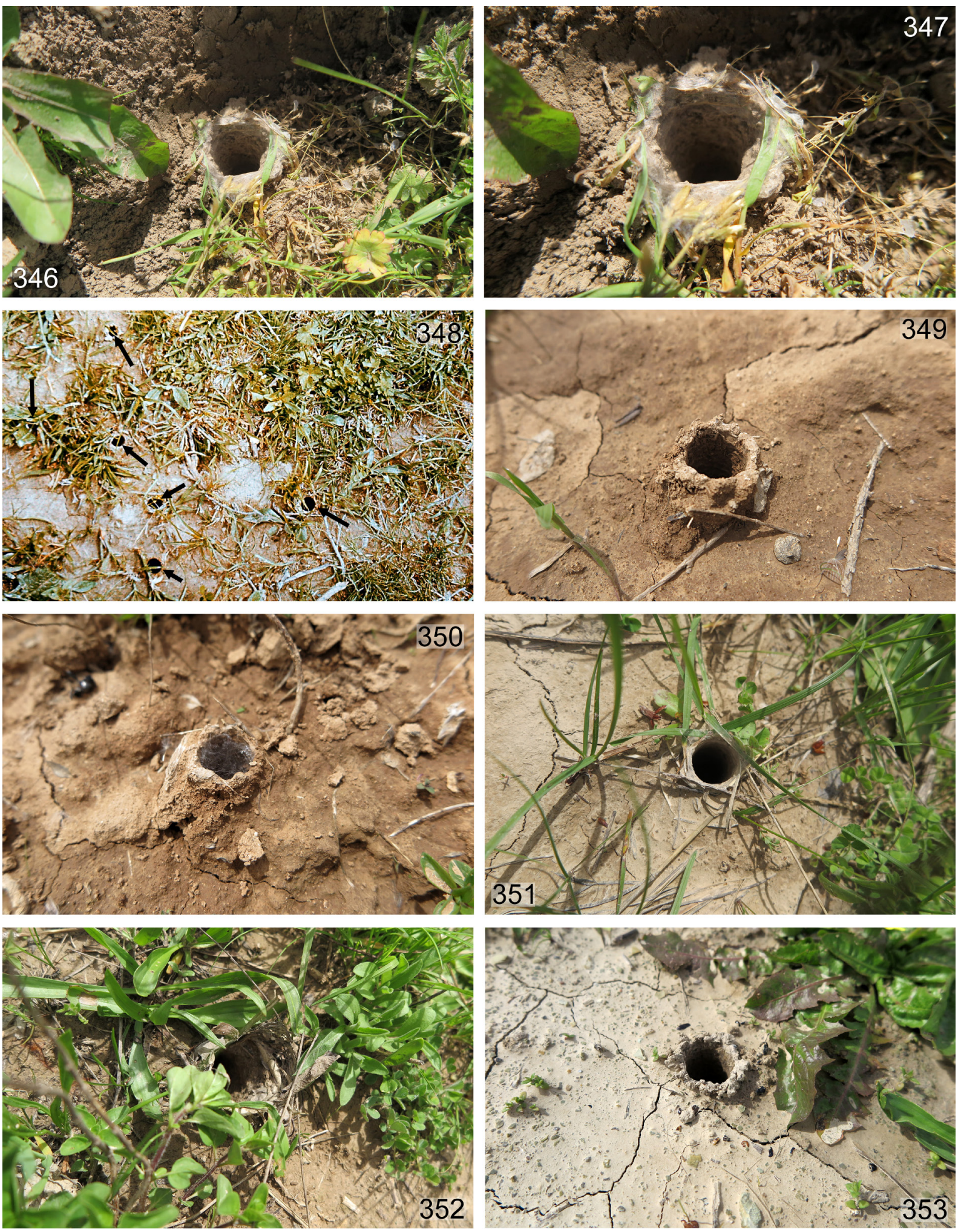

Figs 346-353. Anemesia infuscata sp. nov., burrow entrances: opened (346-349, 351-353), aggregated (348), curtained with web (350), located on escarp (352) and different substrates; Tajikistan. 346347. Varzob Canyon. 348-353. Sanglok Mts. Black arrows indicate burrow entrances. 

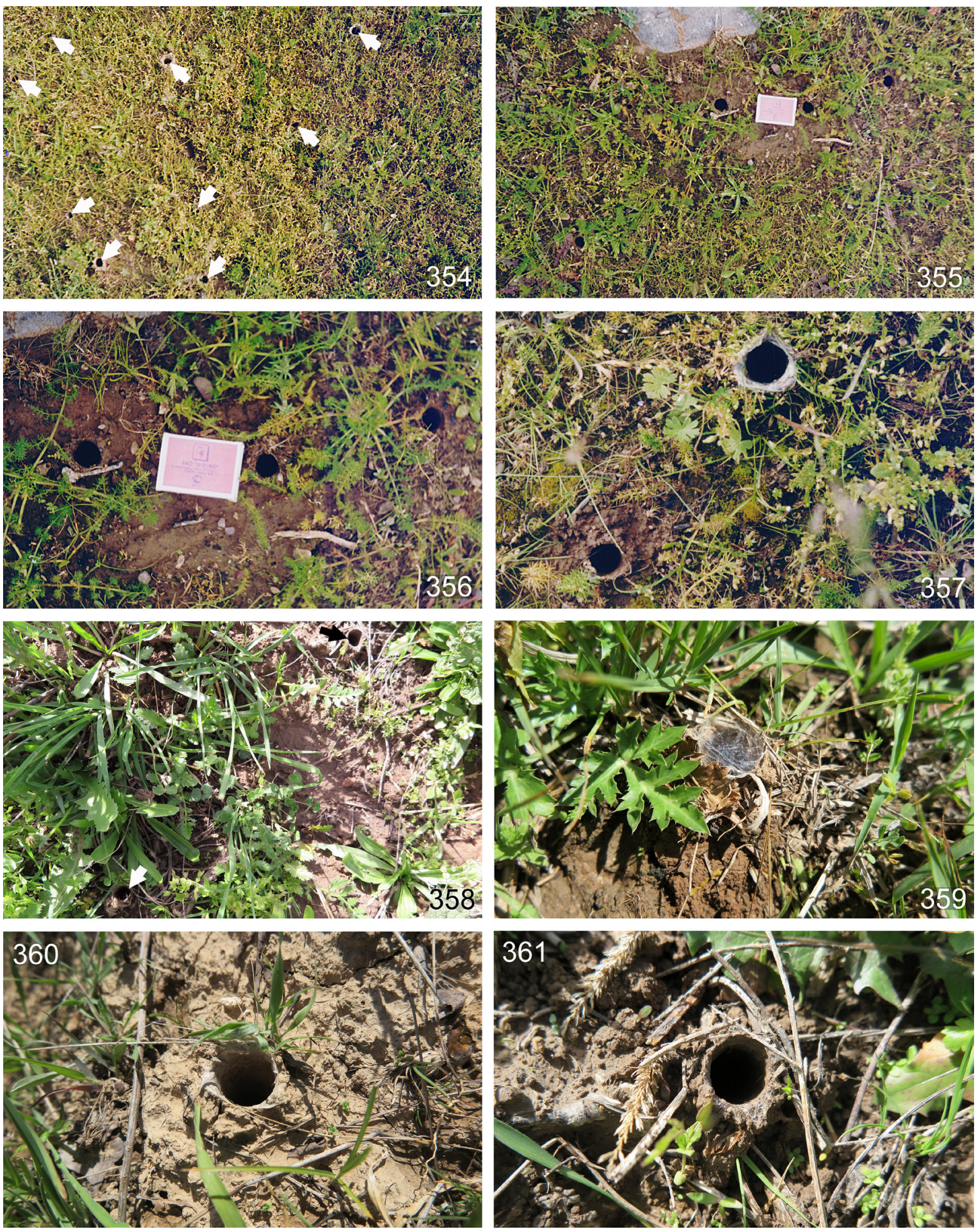

Figs 354-361. Anemesia spp., burrow entrances of A. infuscata sp. nov. (354-356, 358-361 and 357, bottom left) and $A$. oxiana sp. nov. (357, above centre): opened (354-358, 360-361), aggregated (354358 ) and curtained with web (359); located on the open ground (354-357) and on the forest floor (358361); Tajikistan. 354-357. Sangdara. 358-361. Sultanmazar. White and black arrows indicate burrow entrances. A matchbox $5 \mathrm{~cm}$ long intended to capture a live spider is used to indicate measurements. 

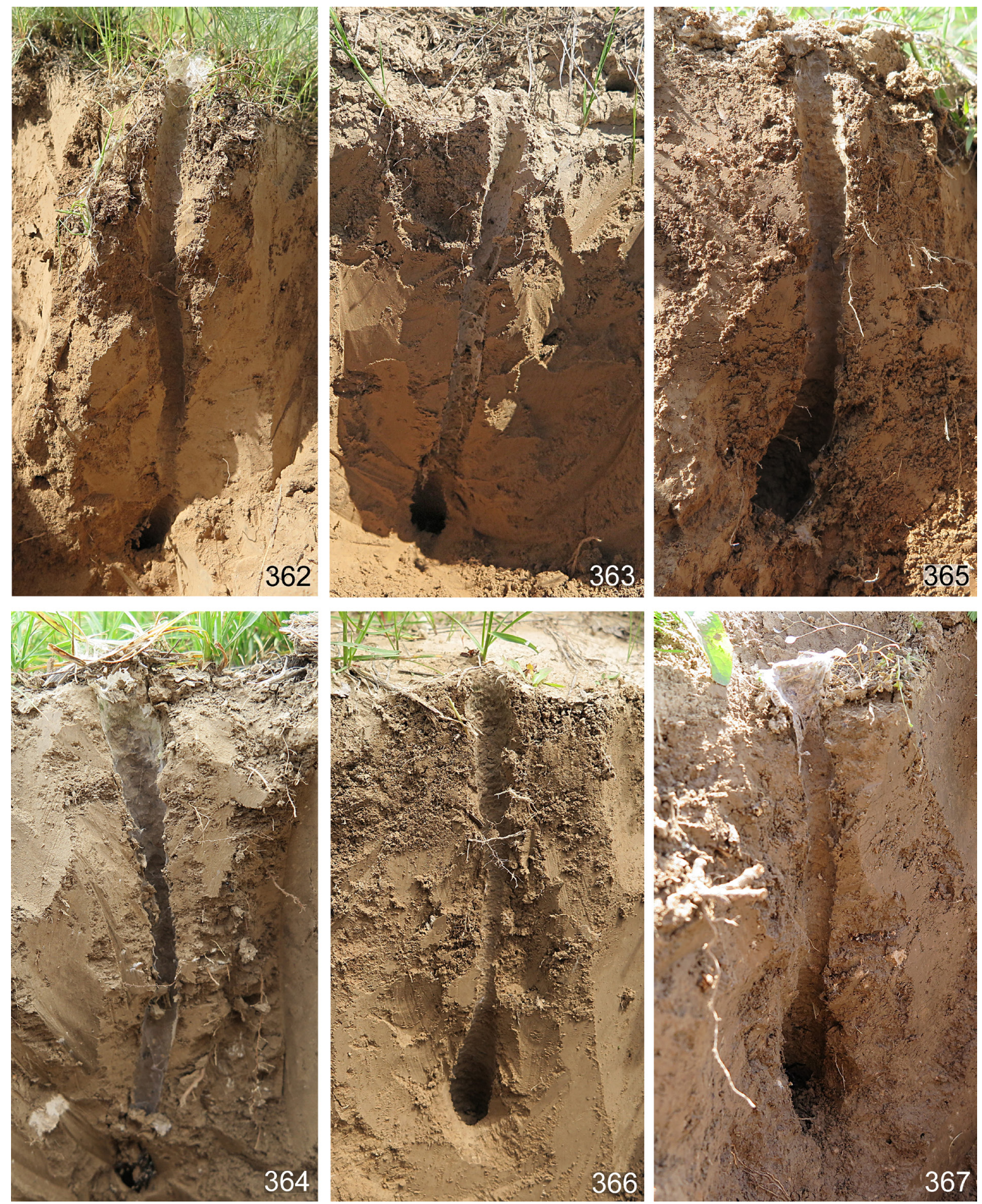

Figs 362-367. Anemesia spp., burrows in cross section, dug and exposed laterally; Tajikistan. 362. A. karatauvi (Andreeva, 1968) (Mt Hojamaston). 363. A. incana Zonstein, 2001 (Ganjina), 364. A. infumata sp. nov. (Panj Karatau Mts). 365-367. A. infuscata sp. nov. (Kuhitek Mts, Sanglok Mts and Varzob Canyon, respectively). 


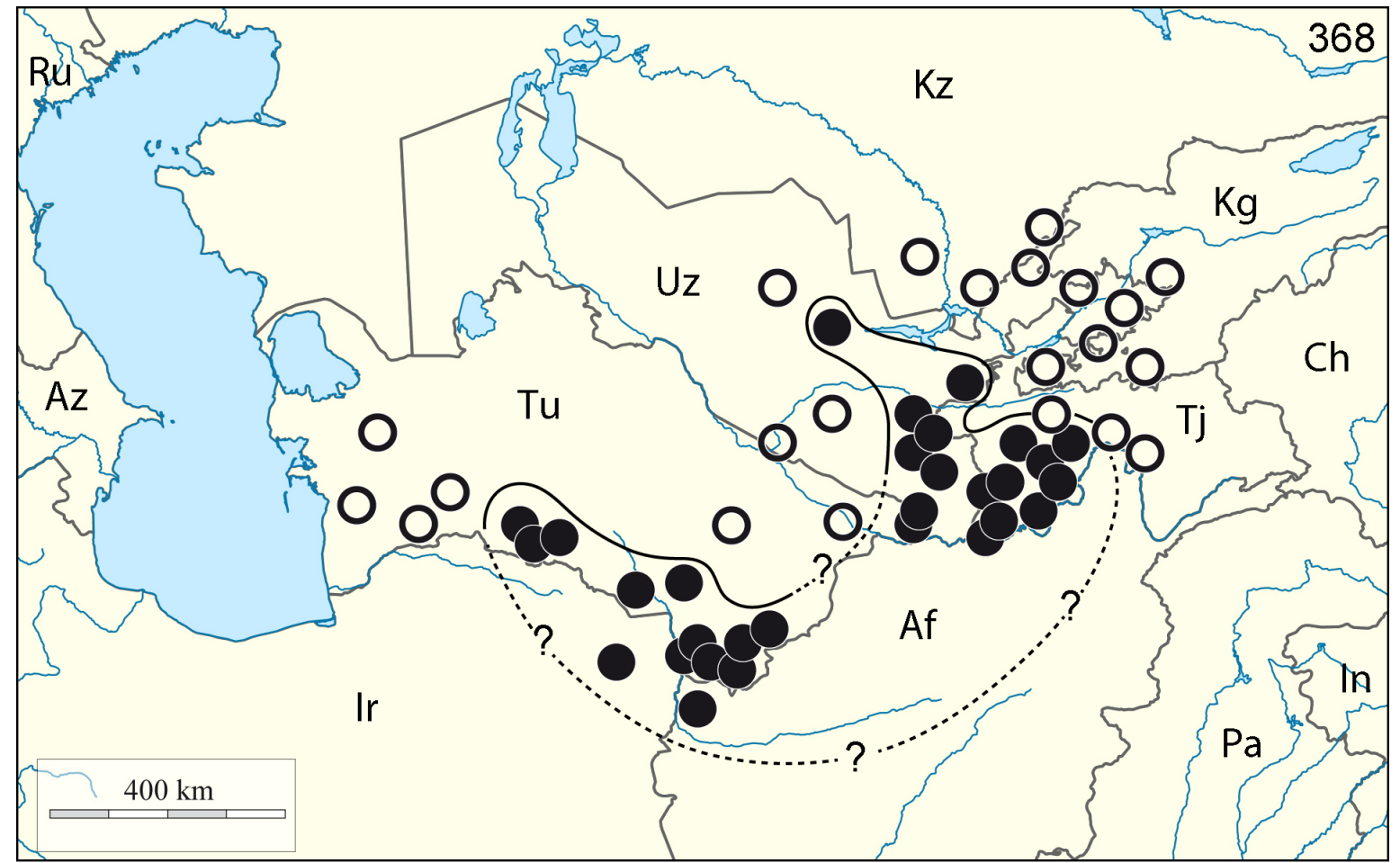

Fig. 368. Suggested range of Anemesia. Records of Anemesia spp. () and intensively sampled localities without those records (O). Range boundaries: relatively veracious (-) and assumed (--?--). Country abbreviations: Af = Afghanistan; Az = Azerbaijan; Ch = China; In = India; Ir = Iran; Kg = Kyrgyzstan; $\mathrm{Kz}=$ Kazakhstan; $\mathrm{Pa}=$ Pakistan; $\mathrm{Ru}=$ Russia; $\mathrm{Tj}=$ Tajikistan; $\mathrm{Tu}=$ Turkmenistan; $\mathrm{Uz}=$ Uzbekistan .

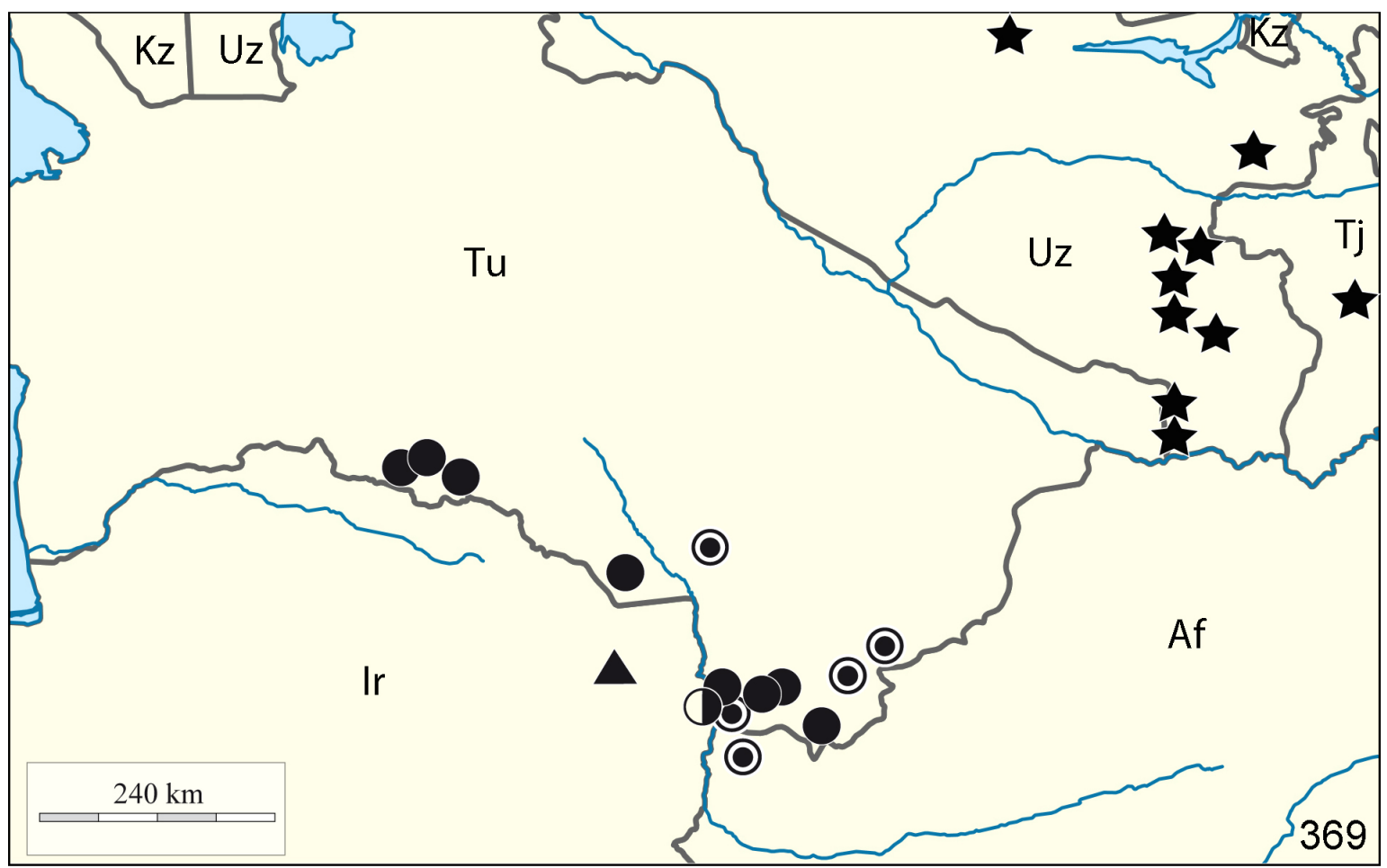

Fig. 369. Distribution of Anemesia spp. Records of A. birulai (Spassky, 1937) (-), A. koponeni Marusik, Zamani \& Mirshamsi, 2014 (公), A. pococki sp. nov. (O), A. tubifex (Pocock, 1889) (О) and A. sogdiana sp. nov. (穴). Country abbreviations as in Fig. 368. 


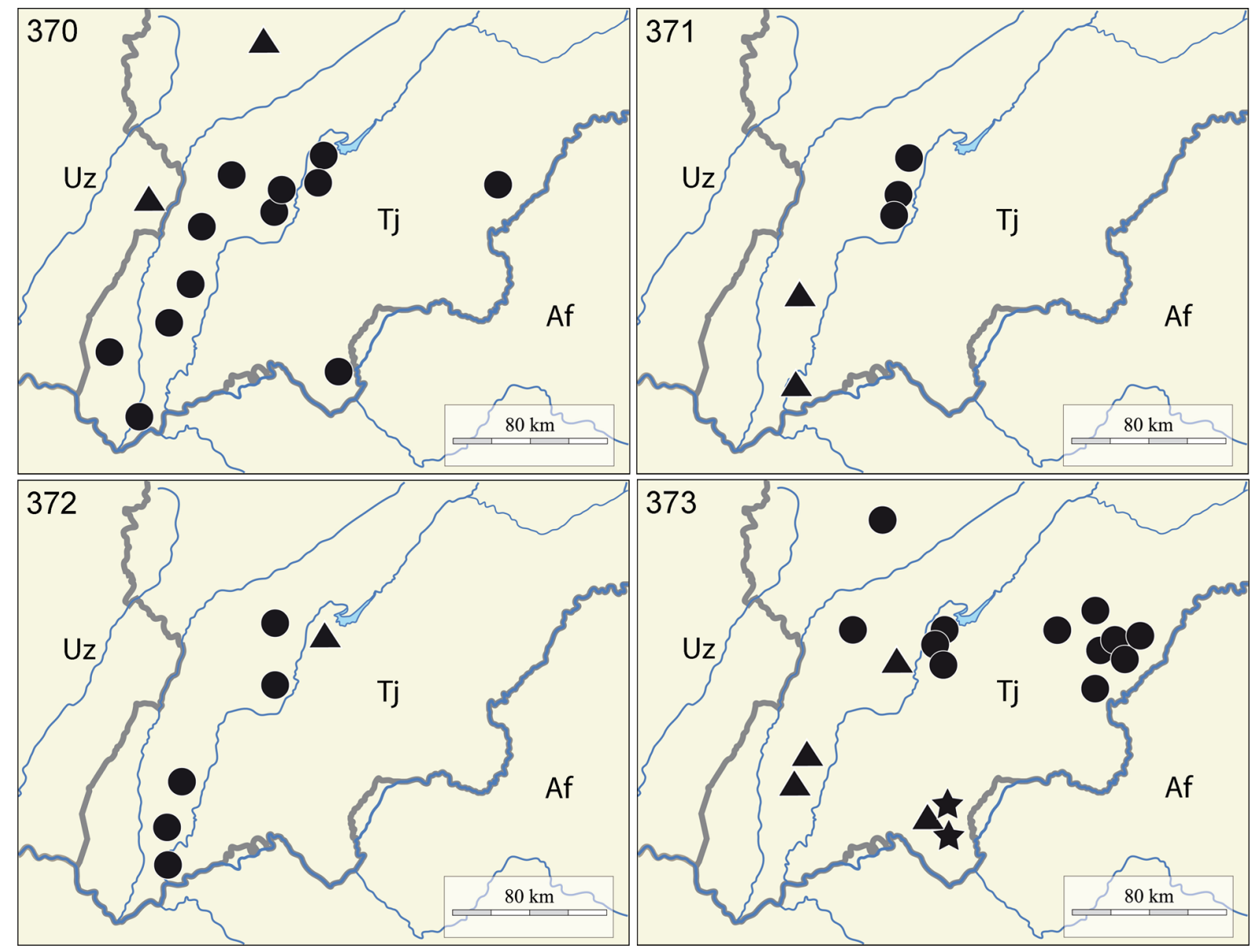

Fig. 370-373. Distribution of Anemesia spp. 370. Records of $A$. andreevae sp. nov. ( $\mathbf{\Delta})$ and $A$. oxiana sp. nov. (O). Country abbreviations: Af = Afghanistan; $\mathrm{Tj}=$ Tajikistan; $\mathrm{Uz}=$ Uzbekistan. Fig. 371. Distribution of Anemesia spp. Records of A. castanea sp. nov. ( $\mathbf{A})$ and A. karatauvi (Andreeva, 1968) (O). Country abbreviations as in Fig. 370. Fig. 372. Distribution of Anemesia spp. Records of A. pallida sp. nov. (O) and A. parvula sp. nov. (ג). Country abbreviations as in Fig. 370. Fig. 373. Distribution of Anemesia spp. Records of A. incana Zonstein, 2001 (A), A. infumata sp. nov. () and A. infuscata sp. nov. (). Country abbreviations as in Fig. 370. 


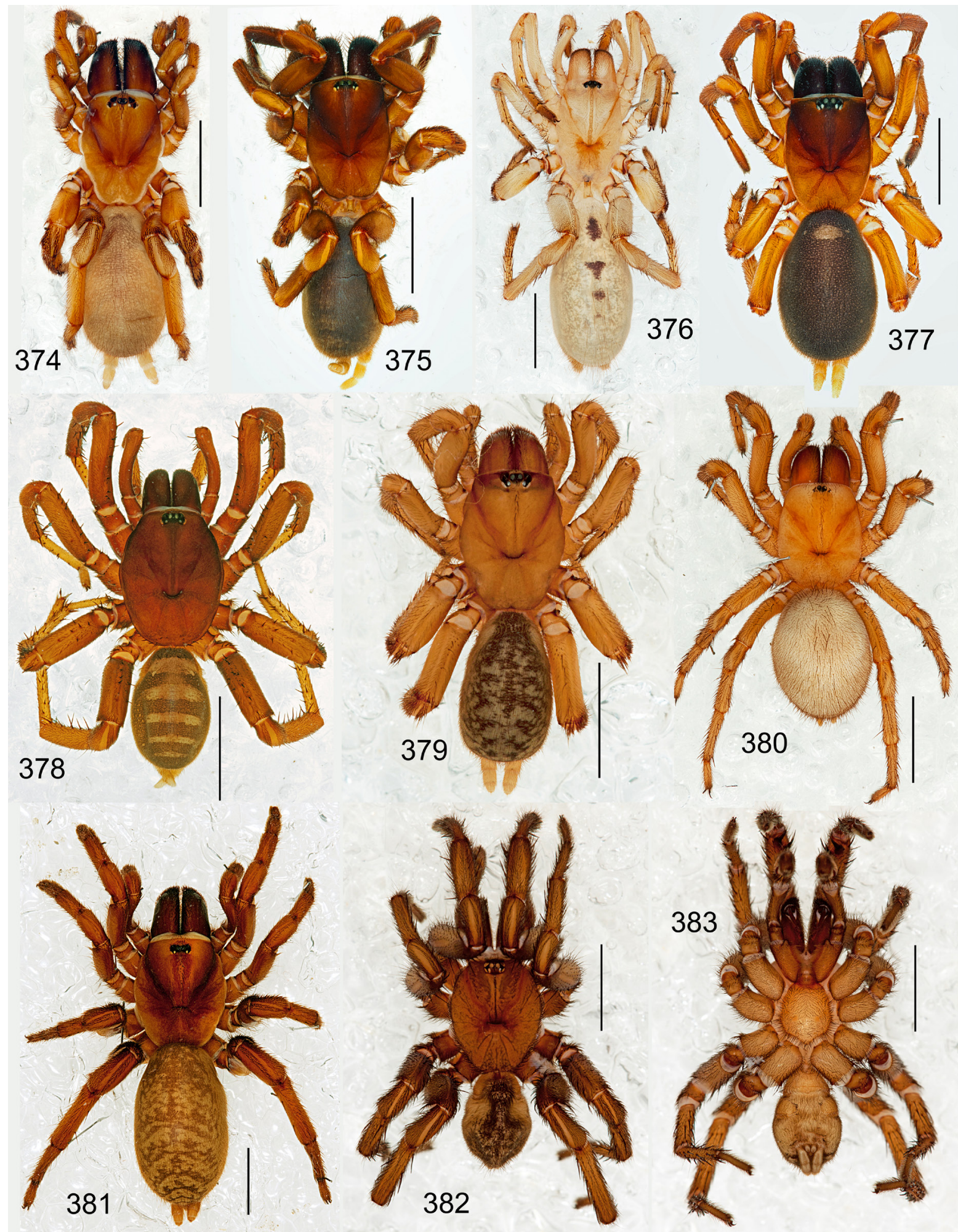

Figs 374-383. Mygalomorph spiders, members of Cyrtaucheniidae (374-380) and Nemesiidae (381-

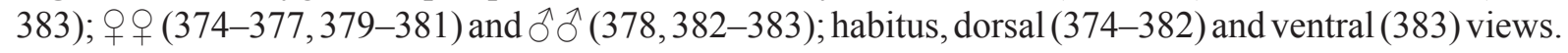
374. Cyrtauchenius terricola (Lucas, 1846). 375. Acontius nimba Zonstein, 2018. 376. Ancylotrypa elongata Purcell, 1908. 377. Acontius kiriba Zonstein, 2018. 378. Ancylotrypa sp. aff. zebra (Simon, 1892). 379. Homostola zebrina Purcell, 1902. 380. Angka hexops Raven \& Schwendinger, 1995. 381. Nemesia sp. aff. africana (C.L. Koch, 1839). 382-383. Spiroctenus sp. Scale bars: 5 mm. 

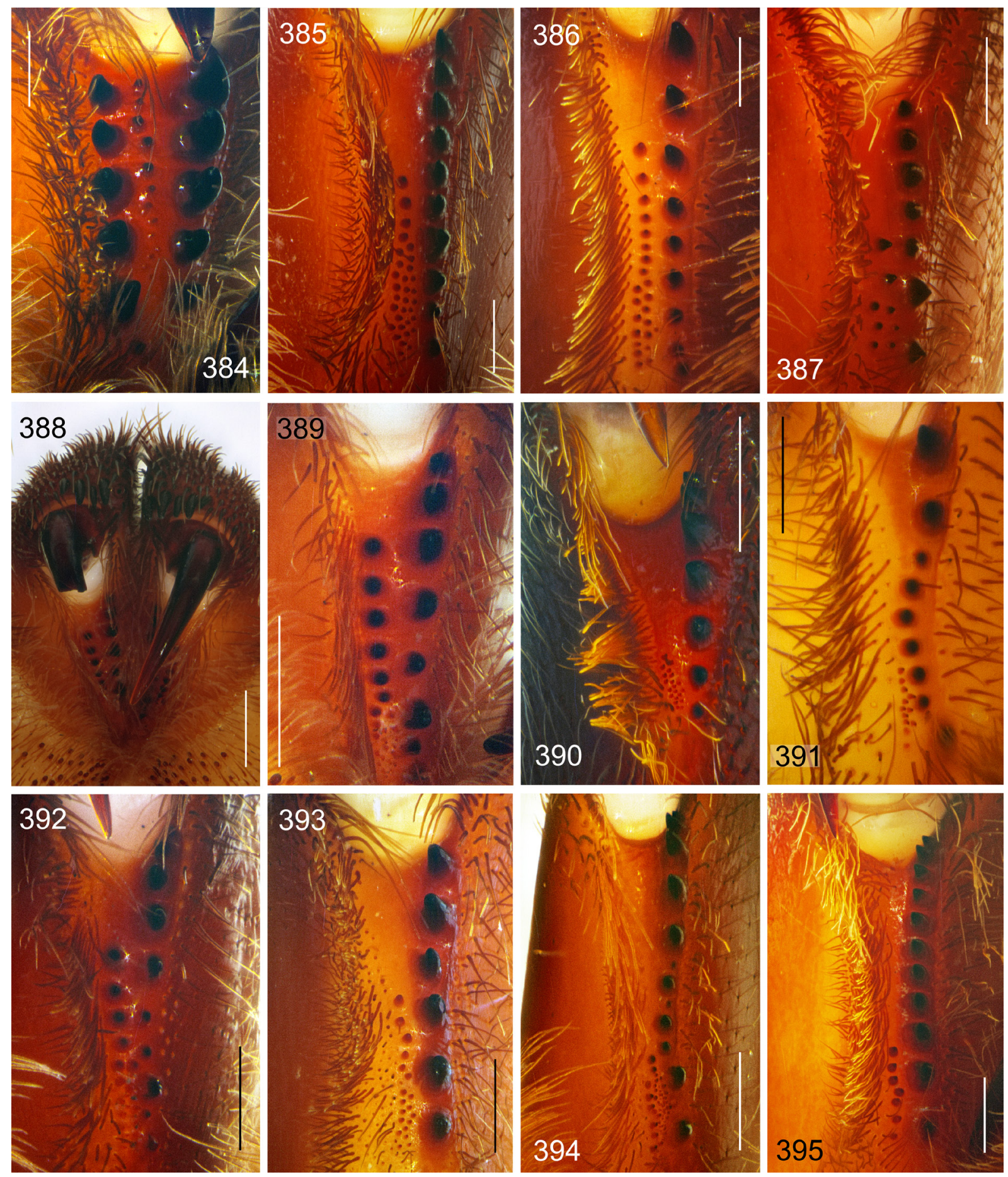

Figs 384-395. Mygalomorph spiders, members of Ctenizidae (384), Euctenizidae (385), Cyrtaucheniidae (386-391) and Nemesiidae (392-395); 우 (384-386, 388-391, 393-395) and ô $\widehat{o}$ (387, 392); cheliceral furrow, ventral views. 384. Cyrtocarenum cunicularium (Olivier, 1811). 385. Myrmekiaphila torreya Gertsch \& Wallace, 1936. 386. Cyrtauchenius maculatus (Simon, 1889). 387. Amblyocarenum walckenaeri (Lucas, 1846). 388-389. Homostola zebrina Purcell, 1902. 390. Acontius nimba Zonstein, 2018. 391. Ancylotrypa elongata Purcell, 1908. 392. Spiroctenus sp. 393. Iberesia barbara (Lucas, 1946). 394. Entypesa sp. M (undescribed species). 395. Raveniola ferghanensis (Zonstein, 1984). Scale bars: $0.5 \mathrm{~mm}$. 

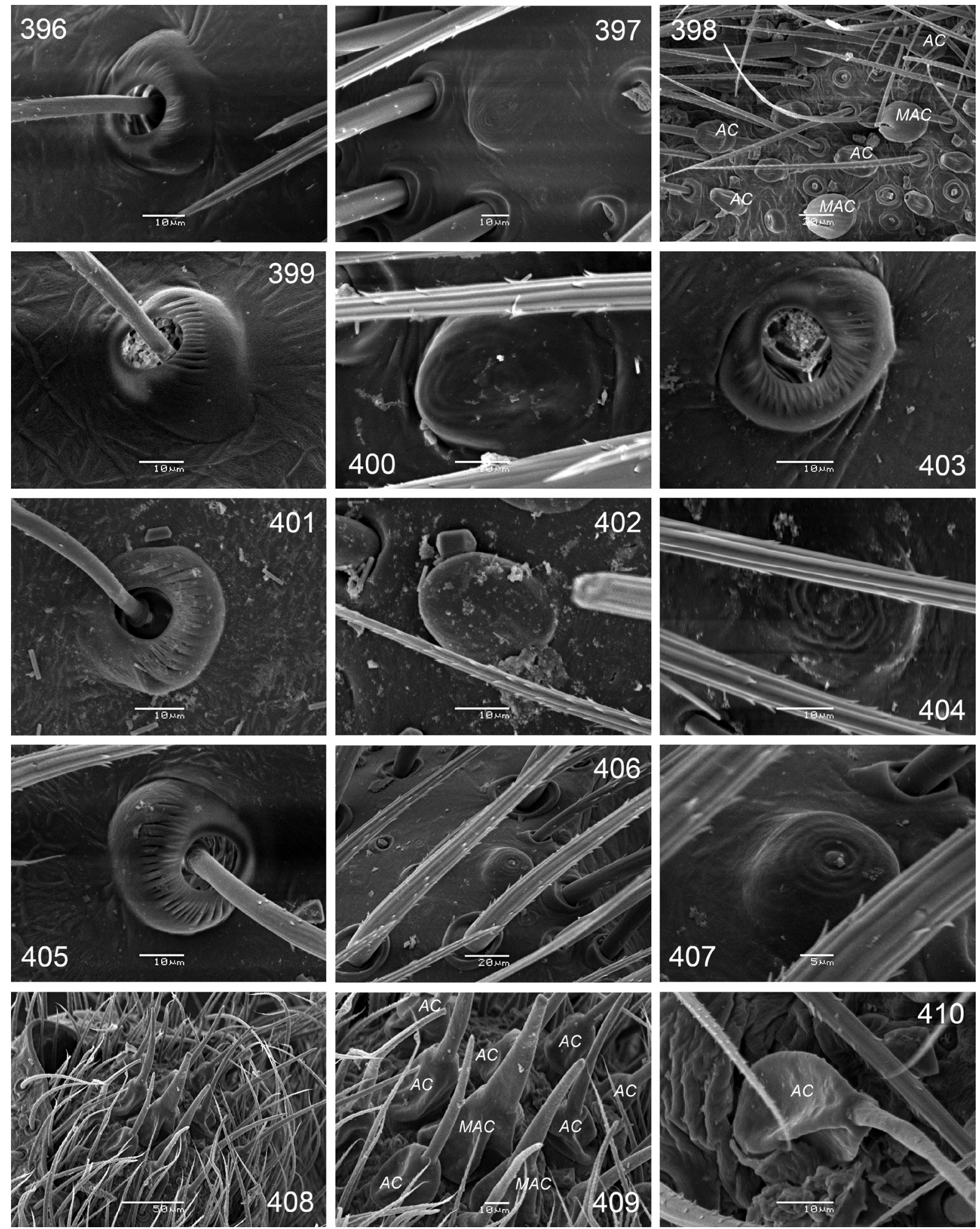

Figs 396-410. Mygalomorph spiders, members of Cyrtaucheniidae (396-402) and Nemesiidae (403410); 우우. Bases of trichobothria $(396,399,401,403,405)$ and tarsal organ $(397,400,402,404,406-407)$ of leg I, and details of PLS (398), PMS (408-409) and spigots (410); dorsal (396-397, 399-407), ventral (398), and apical (408-410) views. 396-398. Acontius nimba Zonstein, 2018. 399-400. Ancylotrypa sp. aff. zebra (Simon, 1892). 401-402. Cyrtauchenius sp. (Algeria). 403-404. Entypesa sp. (Madagascar). 405-410. Nemesia sp. aff. pannonica Herman, 1879 (Turkey). Abbreviations: see Material and methods. 